Illinois State University

ISU ReD: Research and eData

Theses and Dissertations

$4-25-2018$

\title{
Diffusion Of Innovations And Public Communication Campaigns: An Examination of The 4r Nutrient Stewardship Program
}

Henry Seeger

Illinois State University, henryseeger@gmail.com

Follow this and additional works at: https://ir.library.illinoisstate.edu/etd

Part of the Communication Commons

\section{Recommended Citation}

Seeger, Henry, "Diffusion Of Innovations And Public Communication Campaigns: An Examination Of The 4r Nutrient Stewardship Program" (2018). Theses and Dissertations. 887.

https://ir.library.illinoisstate.edu/etd/887

This Thesis is brought to you for free and open access by ISU ReD: Research and eData. It has been accepted for inclusion in Theses and Dissertations by an authorized administrator of ISU ReD: Research and eData. For more information, please contact ISUReD@ilstu.edu. 


\section{DIFFUSION OF INNOVATIONS AND PUBLIC COMMUNICATION CAMPAIGNS: AN EXAMINATION OF THE 4R NUTRIENT STEWARDSHIP PROGRAM}

\section{HENRY SEEGER}

\section{Pages}

This project is an examination of how strategies for innovation in fertilizer application are communicated to agricultural communities. Specifically, this project examines the $4 \mathrm{R}$ Nutrient Stewardship Program-a public communication campaign seeking to encourage the use of specific strategies, tools, and best practices in fertilizer application. The campaign is advanced by the Fertilizer Institute, an industry trade association, and targets local agricultural communities within the United States. To understand how this campaign functions to encourage adoption of innovative fertilizer application behaviors, this project draws on the principles of diffusion of innovations theory as well as established concepts within public relations, including issues management (Rogers, 2003).

KEYWORDS: Public Communication Campaigns, Issues Management, Diffusion of Innovations, Fertilizer Runoff, Water Contamination 
DIFFUSION OF INNOVATIONS AND PUBLIC COMMUNICATION CAMPAIGNS: AN EXAMINATION OF THE 4R NUTRIENT STEWARDSHIP PROGRAM

HENRY SEEGER

A Thesis Submitted in Partial
Fulfillment of the Requirements
for the Degree of
MASTER OF ARTS
School of Communication
ILLINOIS STATE UNIVERSITY

2018 
Copyright 2018 Henry Seeger 
DIFFUSION OF INNOVATIONS AND PUBLIC COMMUNICATION CAMPAIGNS: AN EXAMINATION OF THE 4R NUTRIENT STEWARDSHIP PROGRAM

HENRY SEEGER

COMMITTEE MEMBERS:

Caleb Carr, Chair

Rebecca Hayes

Pete Smudde 


\section{ACKNOWLEDGMENTS}

I wish to express my deep gratitude to my committee and the faculty in the School of Communication at Illinois State University. Dr. Caleb Carr has been patient and has modeled the highest standards for scholarship. Dr. Hayes' knowledge of public relations and issues management has been of critical importance in developing my grounding in the literature. I could not have accomplished this without Dr. Smudde's deep understanding of public campaigns, as well as his support and encouragement. I am grateful to Dr. Robyn Wilson from Ohio State University for sharing data from The Ohio State University's College of Agriculture, Food and Environmental Sciences. Above all, I am grateful for the enduring support of my family. This project has taught me a great deal not only about communication and public relations, but also about the rigors of scholarship, the importance of being open to new ideas, and the value of persistence.

H. S. 


\section{CONTENTS}

Page

ACKNOWLEDGMENTS

TABLES

FIGURES - vi

CHAPTER 1: INTRODUCTION

CHAPTER 2: LITERATURE REVIEW

The 4R Nutrient Stewardship Program $\quad 4$

$\begin{array}{ll}\text { Public Communication Campaigns } & 6\end{array}$

$\begin{array}{ll}\text { Public Relations } & 7\end{array}$

$\begin{array}{ll}\text { Campaign Design } & 9\end{array}$

$\begin{array}{ll}\text { Campaign Evaluation } & 12\end{array}$

Use of Campaigns in Strategic Issues Management 15

Diffusion of Innovations $\quad 24$

Elements of Diffusion of Innovations $\quad 25$

Innovation-Development Process $\quad 29$

Innovation-Decision Process $\quad 30$

Diffusion Within Social Systems $\quad 32$

Diffusion of Innovations and Public Communication Canpaigns 33

Diffusion of Innovations as a Framework for Campaign Design 35

Diffusion of Innovations as a Framework for Campaign Evaluation 36

Diffusion of Innovations and the 4R Nutrient Stewardship Program 39

Other Diffusion Research in Agricultural Communities 41 
$\begin{array}{ll}\text { Research Questions } & 42\end{array}$

$\begin{array}{ll}\text { Conclusion } & 44\end{array}$

CHAPTER 3: THE 4R NUTRIENT STEWARDSHIP PROGRAM 45

Water Contamination and Fertilizer Runoff 45

Fertilizer Runoff as a Contributor to Water Contamination 46

$\begin{array}{ll}\text { Obstacles to Policy Regulation } & 47\end{array}$

$\begin{array}{ll}\text { The 4R Nutrient Stewardship Program } & 48\end{array}$

The Fertilizer Institute $\quad 49$

International Plant Nutrient Institute $\quad 52$

The 4R Nutrient Stewardship Program in Ohio 52

Target Audiences $\quad 53$

Twitter Account $\quad 54$

$\begin{array}{ll}\text { The Brochure } & 57\end{array}$

Guidelines for Retailer $\quad 60$

$\begin{array}{ll}\text { The 4R Certification Program } & 61\end{array}$

$\begin{array}{ll}\text { Conclusion } & 63\end{array}$

$\begin{array}{ll}\text { CHAPTER 4: METHODS } & 64\end{array}$

$\begin{array}{ll}\text { Procedure } & 64\end{array}$

$\begin{array}{ll}\text { Respondents } & 65\end{array}$

$\begin{array}{ll}\text { Variables and Measurements } & 65\end{array}$

$\begin{array}{ll}\text { Knowledge } & 65\end{array}$

Sources of Information $\quad 66$

$\begin{array}{ll}\text { Extent of Diffusion } & 67\end{array}$ 
$\begin{array}{ll}\text { Demographics } & 68\end{array}$

$\begin{array}{ll}\text { Conclusion } & 68\end{array}$

CHAPTER 5: RESULTS $\quad 69$

$\begin{array}{ll}\text { Knowledge } & 69\end{array}$

Sources of Information $\quad 69$

$\begin{array}{ll}\text { Extent of Diffusion } & 70\end{array}$

$\begin{array}{ll}\text { Conclusion } & 71\end{array}$

CHAPTER 6: CONCLUSIONS AND IMPLICATIONS 72

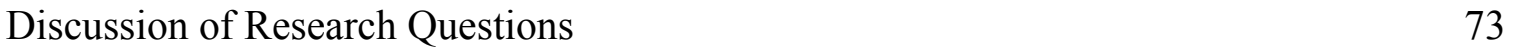

$\begin{array}{ll}\text { General Discussion } & 79\end{array}$

$\begin{array}{lr}\text { General Conclusions } & 80\end{array}$

Limitations and Future Research $\quad 87$

$\begin{array}{ll}\text { Conclusion } & 93\end{array}$

$\begin{array}{ll}\text { REFERENCES } & 94\end{array}$

APPENDIX A: SAMPLE TWITTER MESSAGES 111

APPENDIX B:THE BROCHURE 113

APPENDIX C: SELECTIONS FROM THE 4R POCKET GUIDE 114

APPENDIX D: OVERVIEW OF THE 4R CERTIFICATION PROGRAM 117

$\begin{array}{ll}\text { APPENDIX E: KNOWLEDGE } & 118\end{array}$

$\begin{array}{ll}\text { APPENDIX F: ADOPTION } & 119\end{array}$

$\begin{array}{ll}\text { APPENDIX G: SOURCES OF INFORMATION } & 120\end{array}$

$\begin{array}{ll}\text { APPENDIX H: DEMOGRAPHICS } & 121\end{array}$ 


\section{TABLES}

\section{Table}

Page

1. Comparison of Issues Management, Public Relations, and DOI 34

2. Sources of Information $\quad 67$

3. Comparison of Sources of Information $\quad 70$ 


\section{FIGURES}

\section{Figure}

Page

1. Diffusion of hybrid corn among farmers in two Iowa communities 28

2. Innovation-Decision Process Model 31 


\section{CHAPTER 1: INTRODUCTION}

Water is necessary for life, and fertilizer runoff from agricultural sites can result in the contamination of water systems. This contamination can be a significant health risk for any population depending on those systems. To protect the public, it is necessary to limit fertilizer runoff. This may be achieved in part by persuading farmers to adopt innovative fertilizer management practices.

This project examines the 4R Nutrient Stewardship Program, a public communication campaign seeking to encourage changes in fertilizer application behaviors with the goal of reducing runoff. The campaign was created and is operated by the Fertilizer Institute, a multistate trade association, in cooperation with the International Plant Nutrient Institute. This campaign is operated primarily to prevent the introduction of new policies regulating fertilizer use. Because this campaign constitutes an industry response to potential adverse policy creation, it is appropriate to regard the 4R Nutrient Stewardship Program as a strategic issues management campaign.

The focus of this investigation is the 4R Nutrient Stewardship Program's effort to persuade Ohio farmers living and working within the area of the Maumee River Watershed to adopt new practices. The Maumee River Watershed is a critical water system in Ohio that drains 5,024 square miles and flows through all or part of 18 Ohio counties (Ohio Environmental Protection Agency, 2018a). The 4R Nutrient Stewardship Program is approached as an issues management campaign targeted to farmers, fertilizer retailers, policymakers, and policy advocates. This examination is informed by diffusion of innovations theory (DOI), a framework describing the process whereby a community adopts a new innovation (Rogers, 2003). When a public communication campaign seeks to encourage behavioral change, the principles of DOI 
can directly inform campaign design and analysis. By illustrating the process of diffusion, DOI can answer questions about how strategic messaging decisions influence behavioral change across targeted populations. In some cases, the diffusion of an innovation may serve as strategy for managing issues faced by an organization or an industry.

The goal of this project is to demonstrate the utility of DOI in case studies of public communication campaigns seeking to encourage behavioral change within target audiences. Doing so will broaden the utility of this theory in a way that will inform both campaign scholarship and design. Findings from this research will be useful in design for future campaigns seeking to change fertilizer application behaviors to protect water systems.

To demonstrate the utility of DOI in these contexts, survey data collected from farmers within the Maumee River Watershed in Ohio are used to examine the $4 \mathrm{R}$ Nutrient Stewardship Program campaign. The survey data were collected by The Ohio State University's College of Agriculture, Food and Environmental Sciences and is used here with permission. The data are analyzed to determine rates of understanding about $4 \mathrm{R}$ innovations in the target public, the extent of diffusion of 4R innovations, and key sources of information among the target public. This information will be used to answer three research questions:

RQ1: Do agriculturalists within the Maumee River Watershed feel they have understanding of the $4 \mathrm{R}$ principles?

RQ2: How do specific sources of information relate to adoption of 4R practices within the Maumee River Watershed?

RQ3: What is the extent of the diffusion of the $4 \mathrm{R}$ frameworks' prescribed runoff reduction strategies through agricultural communities within the Maumee River Watershed? 
Taken together, the answers to these questions will provide a picture of the overall efficacy of the 4R Nutrient Stewardship Program at encouraging diffusion of innovative fertilizer application behaviors among farmers in the Maumee River Watershed. In addition, the results will help demonstrate that DOI is a useful framework for examining both public communication and issues management campaigns.

This thesis is organized into six chapters. Chapter 1 introduces the project and provides general context. Chapter 2 provides an overview of the 4R Nutrient Stewardship Program, reviews relevant scholarship relating to public communication campaigns and DOI, and proposes three research questions. Chapter 3 describes the 4R Nutrient Stewardship Program and identifies key channels used by the campaign. Chapter 4 presents the methods of data collection and analysis used in the study. Chapter 5 presents the results of the survey questionnaire used to collect data and interprets these results in terms of DOI. Chapter 6 concludes this thesis by answering the research questions and discussing implications, future research, and limitations. 


\section{CHAPTER 2: LITERATURE REVIEW}

This chapter briefly outlines the dimensions of the case and reviews relevant literature. This begins with a brief description of the 4R Nutrient Stewardship Program, including an overview of the campaign's primary goals and target publics. The chapter then explores relevant literature in the field of public communication campaigns, placing emphasis on research that examines issues management campaigns. This literature is then used to establish a need for new theoretical frames for campaign evaluation. Diffusion of innovations theory (DOI) is described and proposed as an approach for campaign scholarship. This chapter concludes by proposing three research questions.

\section{The 4R Nutrient Stewardship Program}

The 4R Nutrient Stewardship Program is a multi-state public communication campaign targeting agricultural communities within the United States. The program was created by the Fertilizer Institute and the International Plant Nutrient Institute in response to issues of fertilizer runoff (TFI, 2016a). The purpose of the 4R Nutrient Stewardship Program is to reduce fertilizer runoff as well as to prevent the formation of new government regulation regarding fertilizer use. Because of this design, the program can be understood as a strategic issues management campaign. Strategic issues management campaigns represent coordinated organizational responses to yet-unsettled issues, often public image crises or threats of adverse policy creation (Jaques, 2007).

An examination of the 4R Nutrient Stewardship Program suggests that the campaign's primary purpose is to prevent the introduction of new policies regulating fertilizer application. To achieve this, the campaign is structured around two objectives. The first objective of the campaign is to publically demonstrate both the fertilizer industry and the agricultural community 
are invested in reducing fertilizer runoff and are taking proactive measures. The secondary objective of this campaign is to encourage adoption of innovations in fertilizer application strategies among farmers.

The campaign is targeted to three different publics. Ostensibly, the primary publics for this campaign are farmers living and working in Ohio. The campaign seeks to encourage adoption of innovative fertilizer application practices among this population. A channel through which the campaign communicates with farmers is the secondary public of potential change agents in the target area. Fertilizer retailers, crop advisors, and nutrient service providers are important sources of information within agricultural communities and can drive adoption of fertilizer application strategies. They also have an interest in protecting their industry. Because of this, a number of the 4R Nutrient Stewardship Program's efforts are targeted to retailers, advisors, and providers.

Other publics targeted by the campaign include policymakers and policy advocates. As has been noted, the 4R Nutrient Stewardship Program is primarily concerned with avoiding or limiting potential policy regulation of fertilizer use. Encouraging adoption of innovative fertilizer application practices serves a duel purpose of reducing incidents of runoff (thus reducing the apparent need for regulation) and demonstrating to policymakers that the fertilizer industry is both able and willing to address issues of runoff without necessitating external regulatory action.

To achieve its goals, the campaign utilizes a variety of approaches. At the national level, the Fertilizer Institute funds several individual research programs in association with the United States Department of Agriculture (TFI, 2016b). The Fertilizer Institute engages with individual partners, stakeholders, and state-level associations to make this information available to farmers through efforts like the 4R Nutrient Stewardship Program. The Fertilizer Institute also places and 
promotes stories about reduction of nutrient runoff in media outlets. Together, these strategies and tactics constitute a cohesive public communication campaign.

\section{Public Communication Campaigns}

A public communication campaign can be understood as a series of strategic messages targeted at specific stakeholder groups with the goal of changing behaviors and/or attitudes (Moffitt, 2005). Campaigns are designed to help achieve a variety of strategic goals, including brand promotion, issue awareness, and behavioral change. These efforts are used in health communication, public relations, and political communication (Botan, 1997). Campaigns are also popular as a way to address social and environmental issues, such as water contamination and fertilizer runoff (Brulle, 2010). Morris (2003) referred to issue-driven campaigns of this form as "developmental communication," a term defined elsewhere as "the strategic application of communication technologies and processes to promote social change" (Wilkins, 2000, p. 197). At their core, all campaigns are designed to influence "individuals, groups, organizations, even whole societies" (Botan, 1997, p. 189). They are powerful methods for informing and persuading. Campaigns are defined by their use of particular channels, including brochures, public speakers, and advertisements, as well as new and traditional media sources (Rice \& Atkin, 1981).

Campaigns are systematic communication efforts aimed at achieving broad persuasive goals. The supervising organization, campaign design, and execution are all critical components of campaign communication. To gauge the effectiveness of campaigns, systematic approaches to campaign evaluation are also necessary. To understand how the 4R Nutrient Stewardship Program functions as a public communication issues management campaign, it is necessary to examine all the elements of campaign communication. 


\section{Public Relations}

The 4R Nutrient Stewardship Program is part of the public relations activity of the fertilizer industry. Campaigns are commonly used in the practice of public relations. According to the Public Relations Society of America, "Public relations is a strategic communication process that builds mutually beneficial relationships between organizations and their publics" (PRSA, 2017, para 1). Grunig and Hunt (1984) described four models of public relations. These models describe different views of how public relations is practiced and suggest different strategies and tactics for campaign design and evaluation. Although these models originated in the 1980 s, they continue to have relevance to contemporary campaign scholarship.

The press agent/publicity model uses persuasive tactics to influence the attitudes and behaviors of publics. According to this model, communication is a one-way process and accuracy is not necessarily important. Organizations may seek to generate publicity through the media, sometimes through use of deceptive practices. The second model proposed by Grunig and Hunt (1984) is the public information model. While the communication pattern is still understood as one-way, this model allows for ways to understand publics as guiding public relations strategies and tactics. In general, this approach is less manipulative of publics than the first model because it accounts for the publics' perspectives. The third model, the two-way asymmetrical model, prioritizes efforts made to improve the effectiveness of communication through a comprehensive understanding of key publics based on scientific research about planned communication. The approach is termed asymmetrical because the overall goal is to support the organization's key interests, after first ensuring audience concerns are suitably documented and addressed. The fourth and final model is the two-way symmetrical approach. This approach is based on research and especially dialogue to bring about "symbiotic changes in 
the ideas, attitudes and behaviors or both organizations and publics" (Grunig, 2001, p. 12). The model is termed symmetrical because the communication between the organization and its publics is designed to create a situation that is beneficial to all. Along with the public information model, this model has seen widespread use and serves as one of the key components of the excellence theory of public relations (Grunig \& Grunig, 2008).

Excellence theory is a normative approach describing generic principles for effective, efficient, and ethical public relations (Vercic, Grunig \& Grunig, 1996). A primary goal of these principles was to create a general theory, describe what constituted effective public relations practice, and make a case for the value of public relations (Tyma, 2008). A principle facet of the excellence theory holds that public relations should be a strategic management function that brings the voices of publics into the organization's decision-making process (Grunig, 2009). This emphasis on incorporating publics into the decision-making process is consistent with either twoway approach.

Public relations activities often draw on the organization's larger strategic plan, based on the organization's vision and mission, to develop communication strategies (Smudde, 2011). This supports the role of public relations as a strategic management function. The strategic planning process allows for organizations to connect the vision and mission to objectives, goals, strategies, and tactics across a variety of organizational levels. Tactics are the specific actions that are taken to support a series of strategies or choices. Strategies and tactics make up the substance and actions of a campaign. Both strategies and tactics support specific goals and objectives that flow from the larger vision and mission (Smudde, 2011).

The view of public relations as a strategic management function holds a number of implications for organizations. Embedding public relations practices into the core management 
infrastructure of organizations not only helps enhance the efficacy of public relations practice, but also encourages an organizational mindset regarding public messaging. This can be critical in avoiding image crises. Public relations, as a strategic management function, also encourages a long-term approach to public communication rather than a focus on short-term campaigns (Grunig \& Grunig, 2008). Drawing on the principles of the excellence theory, many contemporary campaigns are designed to achieve their persuasive goals through the use of coherent strategies implemented over time.

\section{Campaign Design}

Campaigns are a form of strategic communication practice often used in public relations and issues management (Moss, 2005). While campaigns may vary widely, they follow a similar structure regardless of context, due to the overall nature of strategic communication. They are precipitated from a situation, issue, need, crisis, or development requiring a communicative response from an organization (Moffitt, 1999). In initiating any campaign, it is necessary to first consider what elements of the situation are precipitating the campaign. Answers to these questions help form the campaign's goals and inform the campaign's strategies (Moffitt, 1999). Without first understanding the situation, campaign practitioners cannot effectively define their goals or perform necessary research or preparation (Smith, 2002).

Another important factor influencing campaign design is the organization creating the campaign. The vision, mission, goals, purpose, mechanisms, and structures of the organization will determine what the campaign is and is not able to do (Smudde, 2011). In addition, the history, values, and culture of the organization influence to a larger extent what kind of goals the campaign pursues and what kind of messages the campaign produces. The organization's external reputation may also help or hinder efforts to communicate with the public (Rice \& 
Atkin, 1981). Public communication will be most effective if the organization makes public communication campaigns a central component of their strategic management process. This ensures the values and goals of the campaign are wholly consistent with the values and goals of the organization and directs needed attention and resources toward the communication campaign.

Campaign design should also consider the target public or publics of the campaign. Understanding a campaign's audience, as suggested by two-way models, is critical for designing effective messages (Moffitt, 1999). One of the most common failings of public communication practitioners is inadequately understanding their publics (Gregory, 2010). At their core, campaigns are designed to influence public opinion. Opinions may be strongly or weakly held but are unlikely to be uniformly held across a given public. Therefore, it is necessary to devote effort in the campaign design process to understand the nuances and types of publics that are relevant to the campaign.

There are a number of potential populations that may make up the audience of a campaign. Among these are those external to the organization: consumers, clients or potential clients, or other relevant groups who may receive campaign messaging. Campaign messages may also be received by individuals internal to the organization, and understanding how the organization will respond to campaign communication is critical to campaign design. Stakeholders, those individuals and groups directly or indirectly impacted by the organization, including employees, should be considered as audiences (Ulmer, Seeger, \& Sellnow, 2005). Competing and neutral organizations may also receive campaign messages, and this may affect their relationship with and behavior toward the organization. In addition to stakeholders, stakeseekers are those groups seeking to influence the organization but may not have a direct stake in the organization's success and profitability (Holzer, 2008). These may be protest or 
activist groups, such as those associated with environmental movements. By declaring they have a stake in the organization, they work to have their concerns represented in organizational decisions.

Effectively understanding target publics may also require understanding a campaign's cultural context. Different publics may possess fundamentally different values, attitudes, and beliefs from organizations operating campaigns (Lim, Goh, \& Sriramesh, 2005). Other publics may not understand the role or purpose of public communication campaigns. Incorporating publics into the decision-making process, as advocated by the excellence theory, can go some way toward solving this problem (Sriramesh, 2010).

To engage with publics effectively, some campaigns may be designed to spark word-ofmouth communication through particular tactics. Word-of-mouth communication (WOM) can facilitate the dissemination of information through a social system. Nyilasky (2006) reviewed a number of definitions of WOM, and concludes that most emphasize communication that is between persons who do not necessarily have commercial motivation for the communication. The content of the communication is commercial, and concerns goods, products, services, and the nature of the organization (pp. 163-166). Nyilasky also distinguished between WOM communication that is "a naturally occurring phenomenon of consumer behaviour, and it may or may not be induced by the conscious efforts of marketers" and buzz marketing that is more intentional promotion of goods or services (p. 166). In addition, researchers have "found considerable support for the hypothesis that word-of-mouth is stronger than advertising or other marketing communication forms" (p. 170). It is important to note that WOM communication may be both positive and negative, and can take the form of social media (Mangold, \& Faulds, 2009). 
In the case of an issues management campaign, design choices should directly address the issues. Often, issues management campaigns are grounded in the response to a threat or a crisis and, thus, may employ image repair strategies (Benoit, 2006). Some scholars have suggested issues management and crisis communication are closely related (Seeger, Sellnow, \& Ulmer, 2003). A crisis may activate an issue if the issue is not managed successfully, and the issue may develop into a new crisis if not properly managed (Smudde, 2001). Issues also must be addressed in a more systematic, proactive, and strategic way than most crises (Hayes \& Smudde, 2015). The communicative response will follow a basic pattern of issue identification, monitoring and analysis, and response, with the response being dictated by the needs of the organization and the target publics (Seeger, Sellnow, \& Ulmer, 2003).

Most importantly, campaign design is not a linear process, nor does the design process end when the campaign is implemented. Rather, campaign design is "constant creation, recreation, evaluation, and re-evaluation of what has been thought of, written, understood, tested, thrown out, edited, and so on throughout the development process" (Smudde \& Courtright, 2015, p. 2). Public communication is a process, and a public communication campaign requires constant adjustments to account for the nuances of a particular public or context. Lessons learned from previous campaigns can be incorporated into future efforts, and campaigns may go through several iterations during their lifespan. Public communication campaigns are tied to an organization's strategic plan and should include an ongoing process of identification, refinement, and adjustment (Smudde, 2011).

\section{Campaign Evaluation}

Practitioners and scholars of public communication campaigns often struggle to evaluate the impact of specific campaigns. A number of strategies for evaluation exist; however, they all 
suffer from limitations. Many methods of evaluation are best suited to a particular kind of campaign or to a particular research goal. Because of this, practitioners and scholars must make informed choices when deciding on an evaluation method. What follows is a brief overview of some of the popular methods of evaluation.

Because campaigns are usually designed to achieve specific goals, their success is usually assessed via the achievement of those goals. Traditional methods of evaluation have focused on measuring short-term outputs and outcomes of campaigns (Grunig, 1999). This includes, for example, measuring the impact of a press release based on the amount of coverage a promotional event receives. These techniques can be effective at examining some of the outcomes of a specific campaign but cannot yield significant insights regarding the success or failure of the campaign or its place in long-term public communication strategies (Grunig, 1999).

Another method of evaluation proposed by the Institute for Public Relations in 1999 focused on evaluating the growth and development of long-term relationships between key publics and organizations (Grunig, 1999). The development of these relationships can then be compared with campaign goals to determine the overall value of the program in fostering positive relationships with publics. However, this method does not allow scholars to evaluate the persuasive nuance of specific strategies, nor does it allow for evaluating behavioral change following a public relations campaign. Understanding what behaviors have been impacted is important to the evaluation of a campaign when the campaign's goal is behavioral change.

Delegates attending the $2^{\text {nd }}$ European Summit on Measurement proposed a system of principles for evaluating the results of public relations efforts (Grupp, 2010). Termed the Barcelona Principles, these criteria provide a baseline of standard evaluation for public relations researchers. The principles are as follows: 
1. The importance of goal setting and measurement;

2. Media measurement requires quantity and quality;

3. Advertising Value Equivalents (AVEs) are not the value of public relations;

4. Social media can and should be measured;

5. Measuring outcomes is preferred to measuring media results;

6. Organizational results can and should be measured where possible; and

7. Transparency and replicability are paramount to sound measurement (Grupp, 2010). Although these principles do not constitute a coherent theoretical framework for evaluation, they draw needed attention to relevant factors in the practical evaluation of contemporary campaigns. Several of these may be useful in examining the $4 \mathrm{R}$ Nutrient Stewardship Program, including the use of quantifiable measures, examination of social media, and the assessment of results.

Moreo (2016) suggested that six questions should be answered in measuring the outcome of PR campaigns:

1. What is the strategic goal of the $\mathrm{PR} /$ marketing program?

2. Who are the key audiences?

3. What platforms will be affected?

4. What are the internal key performance indicators (KPIs) being used?

5. What is the internal reporting structure (for the campaign)?

6. What insights are we hoping for?

Answers to these questions are often difficult to generate with any single method, and some require access to internal organizational documents and discussion. Understanding the strategic goals of the 4R Nutrient Stewardship Program, the key audiences, and the desired outcomes is important to the overall evaluation. Key performance indicators (KPIs) are various kinds of 
performance measures that can be used to measure the success of a campaign. These may take many forms depending on the overall goals of the campaign and may include knowledge of a campaign and changes in behaviors among target audiences.

While the methods of campaign evaluation are well-established, these methods are most effective when applied in specific contexts. The dynamic and diverse nature of public communication practice necessitates a variety of different tools. Tyma (2008) doubted generalizable principles can be relevant to highly dynamic social, political, and corporate realities of public communication work, where change is a constant variable. Evaluation must be done in a way that is specific to the context of each campaign, and different methods of campaign evaluation are going to be more or less effective given the context. Because of this, there is a clear imperative to continue to test and refine new frames for campaign evaluation.

\section{Use of Campaigns in Strategic Issues Management}

Public communication campaigns are also popular tools in the larger process of strategic issues management. Through public communication campaigns, organizations participate in larger public policy debates about issues that may impact them (Coombs, 1992). Chase (1982) described strategic issues management as "the capacity to understand, mobilize, coordinate, and direct all strategic and policy planning functions, and all public affairs/public relations skills, toward achievement of one objective: meaningful participation in creation of public policy that affects personal and institutional destiny" (p. 1). Dougall (2008) described issues management as a process of anticipatory strategic management because it allows organizations to manage issues before they become settled policy. An issue is an "unsettled matter that is ready for a decision" (Chase, 1984, p. 38). Issues management is also a strategic and proactive process of "issue identification, monitoring, and analysis seeking to influence their resolution in a manner 
mutually beneficial to the organization and its stakeholders" (Seeger, Sellnow, \& Ulmer, 2003, p. 11). This area of scholarship "began as a corporate response to adverse public policy and the desire to move from reaction to participation, driven by a belief that identifying and managing issues early enhances corporate capacity to influence new regulations and guidelines rather than responding to them" (Jaques, 2009, p. 283). Issues management involves proactive efforts to influence policy decisions and settle matters of interest in ways that support the larger strategic interests of the organization. Issues management may involve changing organization activities, lobbying efforts, advertising, and public communication campaigns. Examples of issues management efforts include the American Coalition for Clean Coal Electricity campaign, the Panera Bread Clean Food campaign, and the Anheuser-Busch Global Smart Drinking campaign. As these campaigns show, strategic issues management is undertaken by both organizations and trade associations (Heath, 1988).

Heath and Palenchar (2009) pointed out that issues management involves crisis management, public relations, media relations, public affairs, and strategic planning in combination. Through proactive activities, such as issues advertising and public relations campaigns, developing interest groups, governmental relations activities, and direct lobbying efforts, organizations seek to influence public opinion about issues and the ways issues are resolved. The targets of issues management campaigns are influential publics, stakeholders, and decision makers. Campaigns may target both stakeholders and decision makers because the opinions of stakeholders are important to decision makers, and vice versa. Coombs (1992), for example, concluded that an issues management campaign around hunger targeted both the U.S. Congress and the general public, based on the belief public pressure would influence Congress and policy. Campaigns may make use of local opinion leaders, or individuals who are trusted by 
others in a community to evaluate and provide guidance about innovations, policies, and decisions (Valente \& Davis, 1999). Use of opinion leaders may also leverage WOM communication.

Issues may become more salient following a crisis event as publics become more aware of the issue. These crises may then serve as focusing events for the issue. Related to the agenda setting process, focusing events are events that cause a public to become aware of a policy failure or the potential risk of policy failure (Birkland, 1997). Focusing events cause issues to gain attention among policymakers and may contribute to eventual policy change (Kingdon, 1993). Sometimes, these are significant changes that would not or could not have been made without the crisis. In addition to serving as powerful symbols that define public discussion around issues, focusing events can inform the personal experiences and interests of key stakeholders and decision makers (Kingdon, 1993). Because of their rhetorical power to influence policy decisions, focusing events are often important tools for issues management campaigns (Birkland \& Warnement, 2013).

Issues develop over time based in part on how many people have an interest in the issue. Jaques (2007) suggested that lifecycle approaches to issues management follow two assumptions: "That some problems left unaddressed trend towards increasing seriousness and greater risk; and that the longer an issue survives, the choices available decrease and cost of intervention and resolution increases" (p. 150). Crable and Vibbert (1985) described the development of issues using five stages in their catalytic model. The potential stage is when some individuals or groups first recognize a problem exists. This recognition of an issue may be triggered by some event, such as a dramatic development or a crisis (Roper, 2005). One important component of this stage is the definition of the issue. The way the issue is defined can 
determine the available methods of resolution (Jaques, 2009). The imminent stage happens when others see the issue as legitimate and become interested in the issue. This may involve celebrity attention (Adams, 2014). The current stage is when the issue is known by a large number of stakeholders. Usually, the legacy media pay a role in making the issue known to larger groups but increasingly social media also play important roles (Reynolds, 1997). The critical stage occurs when the issue is moving toward a decision. At this point, the various positions and possible solutions have been established and there is some level of consensus. Last, the dormant stage, occurs after a decision about the issue has been reached. Even a dormant issue can return if people and groups again show interest and activate the issue (Crable \& Vibbert, 1985). Issues impact an organization because they often require the organization to change its practices, products, or how its products are used. For example, the tobacco industry was forced to change its advertising practices based on the issue of minors smoking. Jones and Chase (1979) described three approaches to the demands for change created by issues: reactive, adaptive, and dynamic strategies. A reactive approach involves limited change and minimal adjustments. The adaptive strategy involves accommodating the changes and making some adjustments. This could involve negotiation and compromise. Last, the dynamic strategy involves anticipating the changes and, in some cases, creating policy options that are in the organization's interests (Jones \& Chase, 1979). Crable and Vibbert (1985) later described a fourth strategy, the catalytic strategy. A catalytic strategy anticipates issues and tries to frame them in ways that are supportive of the organization's larger goals (Crable \& Vibbert, 1985). Issues management campaigns that employ a catalytic approach may engage in preemptive communication that seeks to frame issues in a proactive way. 
According to Heath and Palenchar (2009), issues management is a multi-stage and ongoing process involving five activities: issue monitoring, identification, analysis, evaluation, and action. In monitoring, an organization scans its larger environment for emerging issues that may affect it. This may involve ongoing scanning for the development of issues so the organization is not caught off guard (Dougall, 2008). Issue identification occurs when the organization actually observes an issue that is receiving attention from stakeholders. The organization may then determine if the issue is a priority. Organizations are also advised to conduct analysis of the issues, including examining stakeholder interests and connections to other issues. This can help clarify how the issues may be seen by influential publics, stakeholders, and decision makers. Evaluation involves determining the impact of the issue on the organization. Finally, action involves implementing issues management activities, such as lobbying efforts and advocacy through public communication campaigns (Heath, 2002). Heath (2002) also described four primary issues management functions:

1. Strategic business planning: Issues management can support the strategic planning process by informing organizations of threats and opportunities from key publics and markets.

2. Getting the house in order: Issues management can help organizations understand and meet stakeholder expectations of corporate responsibility.

3. Scouting the terrain: Issues management requires issue scanning, environment scanning, identification, monitoring, analysis and priority setting to function.

4. Strong defense and smart offense: Issues management provides direction and substance for organizational communication, including risk and crisis communication (p. 210). 
These four functions help link issues management activities to the larger vision, mission, and strategies of an organization. They also reduce the probability that issues management activities will be unethical by emphasizing corporate responsibility.

Because issues management aims to take into account the interests of stakeholders in issues, there must be some balance between stakeholder and organizational goals. According to Coombs (2012), "The goal of issues management is to lessen the negative impact or to create a positive effect from an issue. However, issues management is not the unbridled pursuit of selfinterest" (p. 54). This may involve not only efforts to influence the public but also to change and reach accommodations through reactive and dynamic approaches. Issues management campaigns may be grounded in two-way approaches to public relations. Two way-symmetrical approaches to public communication address some of the most significant ethical challenges of issue management. These include power inequities between organizations and stakeholder, exploitation and manipulation of stakeholder and issues, and deceptive communication practices. As Botan (1997) noted, public relations campaigns often focus on influence attempts and these raise serious ethical questions (p. 190). Through communication that includes a two-way mutual exchange and symmetrical power, public relations can move to a more dialogic model of ethical and practical approaches. This may help "build relationships that serve both organizational and public interests" (Kent \& Taylor, 2002, p. 21).

Visibility of issues can drive policy creation. Events such as water contamination due to fertilizer runoff can function as focusing events to draw public attention to an issue and may contribute to eventual policy change (Kingdon, 2003). Research has shown how focusing events influence the development of public policy discussion. One of the earliest and best known examinations of focusing events was Molotch and Lester's (1975) study, “Accidental News: The 
Great Oil Spill as Local Occurrence and National Event." The study involved an examination of public response to the 1969 Santa Barbara oil spill. Molotch and Lester argued the spill initiated broad public debate surrounding the failure of regulatory systems and ultimately led to significant reform. More recent work has examined events as diverse as the terrorist attacks of September 11, 2001; Hurricane Katrina in 2005; and the global financial crisis of 2008 (Birkland, 2013). These cases all included dramatic, highly public events that led to significant harm and demonstrated the inadequacy of existing policy. Each case was followed by intense public discussions of policy changes that would reduce the chances of similar cases happening again. In each case, significant changes in public policy occurred. These events functioned in different ways as focusing events because, as Birkland (1998) pointed out, different types of crises will have different dynamics, will function in different policy domains, and will have different stakeholder groups.

Crable and Vibbert (1985) noted "issue management is a fundamental way of influencing policies before they become policies" (p. 7). The 4R Nutrient Stewardship Program was created due to an industry concern that recent incidents of fertilizer runoff would lead to public demand for stricter policy regulation. The 4R Nutrient Stewardship Program seeks to influence public opinion regarding fertilizer use by encouraging voluntary efforts by farmers to reduce incidents of runoff. This can be accomplished through the diffusion of new innovative fertilizer application approaches throughout agricultural communities.

Issues management is not without controversy. Roper (2005) suggested that public relations activities, including issues management, will privilege the organization's position over the interests of stakeholders. In this way, issues management may be seen as a two-way asymmetrical approach to public relations as opposed to the two-way symmetrical approach 
favored by contemporary literature (Grunig, 2001). Rather than favoring an approach characterized by dialogue, and efforts and activities that are mutually beneficial to the organization and its publics, two-way asymmetrical approaches are characterized by thorough and formative audience research, ethical and appropriate communication, persuasion techniques, and communication tactics that present messages framed to influence publics to behave in ways are consistent with the organization's interests while also accounting for audiences' concerns. Bowen (2007) suggested issues management usually emphasizes one-sided persuasion and typically does not support contrary positions or contradictory evidence that may come from external publics.

Roper (2005) examined Shell Oil Company's issues management efforts in relation to questions of environmentalism and sustainability. She noted that Shell's position in relation to these issues was changed by two events. The first involved the public's response to disposal of an obsolete oil platform and the second involved the treatment of indigenous people in Nigeria. Following these crises, the company adopted a public position supporting sustainability. This included joining several sustainability advocacy groups and publically noting its acceptance of the science of carbon emissions and climate change. Roper's (2005) analysis demonstrated how organizations respond to crisis events with positions on issues and how these may translate into issues management activities.

Dearlove, Bialous, and Glanz (2002) explored the tobacco industry's efforts to manage a variety of issues related to smoking, including its social acceptability, especially with regard to the health effects of secondhand smoke. They concluded two approaches were used. First, the science showing that secondhand smoke was dangerous was attacked. Second, efforts were made to change perceptions of smoking in public. They noted a core message was both smokers and 
non-smokers should be accommodated. The tobacco industry targeted many of its messages to restaurants and casinos and provided data about the negative economic impact of smoking bans. Dearlove, Bialous, and Glantz (2002) stated that the 1989 Phillip Morris “Accommodation Program” public relations campaign included three major themes: “(1) harmony between smokers and non-smokers; (2) smoke-free policies are associated with businesses losses in the hospitality industry; and (3) ventilation removes second hand smoke, allowing smokers and nonsmokers to share the same environment" (pp. 95-96). The tobacco industry has used other efforts to protect the rights of smokers. This included organizing smokers' rights groups that argued their personal freedoms were being undermined by efforts to restrict smoking (Smith \& Malone, 2006).

The agriculture industry has faced a number of issues, including animal rights, use of pesticides, and sustainable practices. Issues management campaigns are commonly used to address agricultural issues. In one case, the beef industry was forced to respond to media portrayals of a meat product called Lean Finely Textured Beef as “pink slime.” Sellnow and Sellnow (2014) argued that managing this issue required reframing it to the public. In this case, pink slime had become an exemplar due to its vivid and repeated visual portrayal in the media. Pink slime was seen as a general exemplar of larger risks in the beef industry. Sellnow and Sellnow (2014) concluded reframing issues in these cases is especially challenging. This case also points to the importance of environmental scanning and early engagement in the issue lifecycle before the frame for an issue becomes entirely fixed. A similar case developed in 1989, when the National Resources Defense Council published a report regarding the dangers of an agricultural chemical called Alar used on apples. Advocacy groups working with public relations firms initially raised the issue of Alar's safety by promoting a non-peer reviewed report on the 
television show 60 Minutes. The question of Alar's safety quickly became an issue and, according to Bodensteiner (1995), progressed through all five stages of the crisis lifecycle. Bodensteiner noted the intense media attention may have been due to the symbolism of the poison apple and that fact apples were generally seen as a very healthy food.

\section{Diffusion of Innovations}

One theoretical frame that has seen limited application in campaign scholarship is DOI. DOI prescribes a number of elements that should be incorporated into campaigns seeking to facilitate diffusion. Most notably, DOI emphasizes the importance of local community members and opinion leaders as nodes of influence in communication networks. Campaigns should first seek to persuade those members of a target population who carry the most influence. DOI also describes a number of characteristics of an innovation that campaign messaging may emphasize to maximize an innovation's likelihood of being adopted. These include relative advantage, compatibility, complexity, trialability, and observability.

In addition to offering prescriptive, general principles that may inform campaign design, DOI provides clear procedures that may be used to examine the efficacy of campaign communications. The primary purpose of DOI is to retrospectively trace how an innovation diffuses throughout target populations. While functioning from an organizational perspective, this approach may have utility as a tool for evaluation in campaigns seeking to facilitate diffusion of innovation.

DOI's practical utility at identifying factors influencing adoption, as well as its wide applicability to a variety of contexts, make this theory very attractive to scholars seeking to understand how communities and individuals respond to innovations and make adoption decisions (Rogers, 2003). This theory has been used widely in marketing, organizational theory, 
international development, and social change to understand how communities come to adopt innovative new strategies, technologies, and ideas (Baumgart-Getz, Prokopy, \& Floress, 2012).

DOI theory explains how new ideas, technologies, and processes are spread (diffused) and adopted by communities as well as the role communication plays in this process. At its core, DOI posits four main elements that influence diffusion: the innovation itself, the channels through which it is communicated, time, and the social system the innovation is diffusing through (Rogers, 2003). Each of these main elements has been explored and operationalized by Rogers and other researchers studying diffusion. The theory in its current form is a product of decades of research in diffusion across a variety of academic disciplines, most notably within the fields of sociology, marketing, and, to a lesser degree, communication.

\section{Elements of Diffusion of Innovations}

Rogers (2003) identified four main elements of the diffusion process. These elements are the innovation itself, the channels the innovation is communicated through, the time period when the process takes place, and the social system the innovation is diffused through.

Innovation. Rogers (2003) defined innovations as "an idea, practice, or project that is perceived as new by an individual or other unit of adoption" (p. 12). The term innovation often carries connotations of newness, uniqueness, value, benefits, and change (Courtright \& Smudde, 2009). Five core characteristics of innovations contribute to their likelihood of it being adopted (Rogers, 2003): relative advantage, compatibility, complexity, trialability, and observability.

Relative advantage refers to the degree a potential adopter perceives the innovation as better than the idea or technology it replaces. Some perceived benefit to the innovation over existing ideas or technologies is necessary for it to be adopted. Compatibility refers to the degree that a potential adopter perceives the innovation as compatible with his or her values, norms, and 
needs. Complexity refers to the perceived difficulty of the innovation to be understood, used, or implemented. Innovations that are simple and easy to apply are more likely to be adopted. Trialability is a factor describing how much the innovation can be experimented with without commitment. A trial application can help the adopter explore the innovation, identifying what value it may add before fully adopting it. Finally, observability refers to the degree the value added by adopting an innovation is visible to other potential adopters (Rogers, 2003).

Communication channels. Rogers (2003) identified diffusion of innovations as occurring through both mass media and interpersonal channels. Innovations often move from mass media to interpersonal channels through opinion leaders. Opinion leaders are interpersonal sources who are trusted by others to evaluate innovations and provide guidance about whether or not to adopt (Valente \& Davis, 1999). Because what opinion leaders think about an innovation shapes the attitudes of others towards that innovation, opinion leaders provide an interpersonal channel for innovations to diffuse throughout a social system. Mass media channels are particularly important during the knowledge stage of the innovation-decision process, the process by which individuals decide whether or not to adopt an innovation. Interpersonal channels are more important during the persuasion stage of the innovation-decision process, when individuals are weighing the advantages and disadvantages of adoption.

Mass media and interpersonal communication channels can be further described as either cosmopolite or localite. Cosmopolite channels link potential adopters with sources outside of their social system. Localite channels link potential adopters with sources within their social system. Information about innovations almost always enter a system through mass media, cosmopolite channels; however, as the innovation diffuses through the system, localite channels become more widely used. It is important to note that all mass media channels are cosmopolite, 
however, not all interpersonal channels are localite. According to Rogers (2003), "interpersonal channels may be either local or cosmopolite while mass media channels are almost entirely cosmopolite" (p. 196). A potential adopter may communicate interpersonally with an individual outside of their social system.

Time. Time refers both to novelty of an innovation (as dependent upon the relative earliness/lateness of an adoption in the diffusion process) as well as to the rate of an innovation's diffusion through a social system. The rate of diffusion follows a $S$-shaped adoption curve, corresponding to a process where a few individuals (early adopters) adopt an innovation and then over time more members adopt the innovation. This process continues until a point of saturation is reached or when about half of the population has adopted the innovation (Rogers, 1995). After this point adoption rates slow, as there are fewer potential adopters left in the population and those that remain are resilient towards adopting. Figure 1 illustrates this $S$-shaped curve in the Ryan and Gross (1943) study of hybrid corn diffusion among farmers in two Iowa communities. 


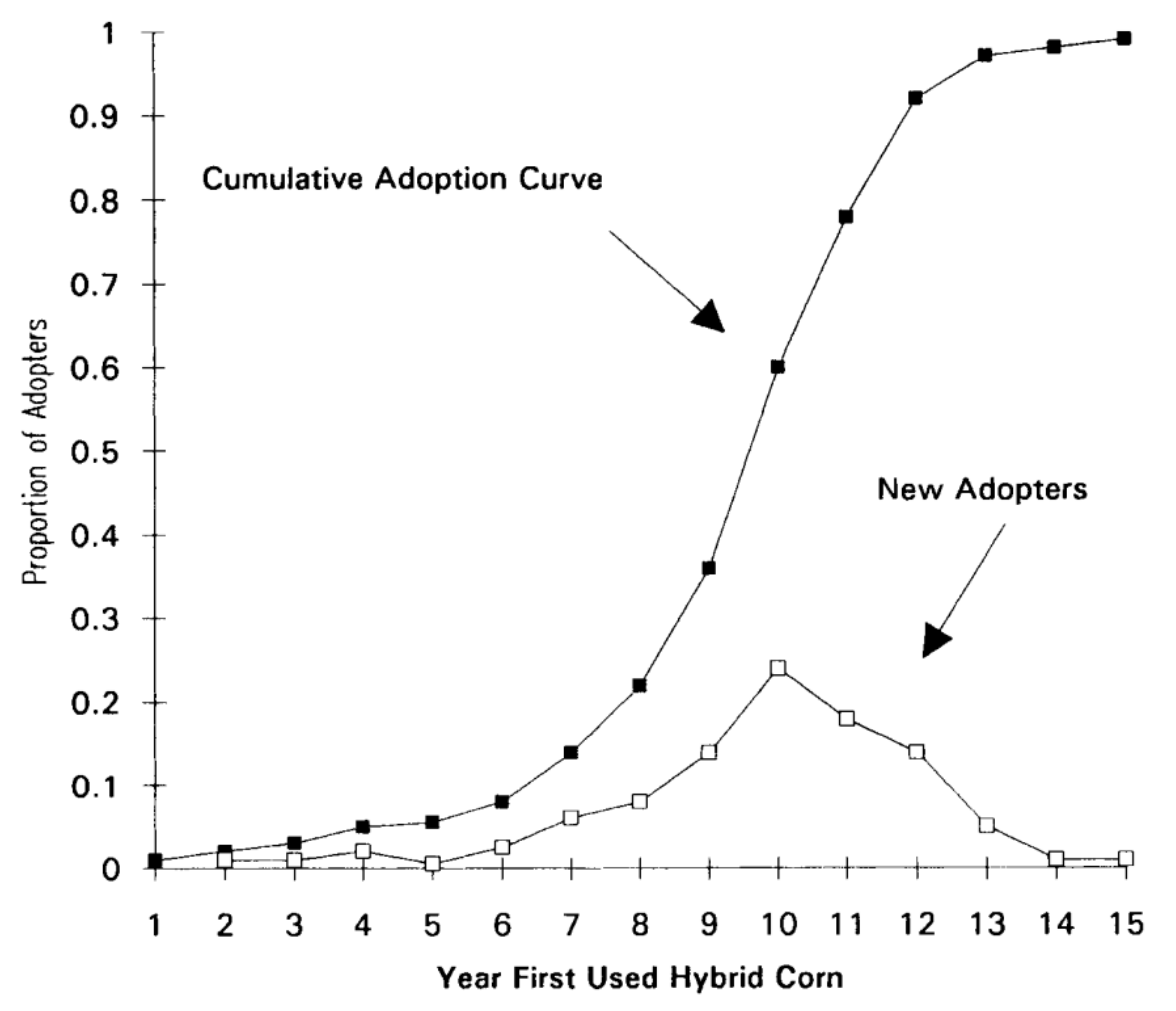

Figure 1. Diffusion of hybrid corn among farmers in two Iowa communities (Valente, 1993, p. $31)$.

As this figure indicates, the adoption rate of an innovation starts slowly, accelerates and then flattens out. This $S$-shape is universal to the diffusion of innovations, and this is due to the nature of an innovation as an external idea permeating a social system (Valente \& Rogers, 1995). The curve may be shorter for innovations that are valued highely and are therefore adopted quickly, or longer for innovations that take longer to catch on or fail to completely diffuse.

Social system. An individual's likelihood to adopt an innovation is dependent in part upon the innovation decisions of others within their network. Wide social contact with other potential adopters within a social network is positively related to innovativeness (Unay Gailhard et al., 2015). As more individuals in a network adopt, the observability and compatibility of the innovation increases, as do positive interpersonal messages about the value added by the 
innovation. Within social systems individuals seek to influence others to adopt similar behaviors and worldviews as themselves (Courtright \& Smudde, 2009). Early adopters can serve as opinion leaders driving adoption through trial and subsequent communication about an innovation (Valente \& Davis, 1999).

\section{Innovation-Development Process}

Innovations emerge through the "innovation-development process, "a process that precedes the innovation-decision process and consists of six stages" (Rogers, 2003, p. 137). The process begins in the knowledge stage, with the recognition of a problem or need that is not satisfied by existing ideas or technologies. Examples may include medical treatments, software packages, or a voting system in contexts where these technologies are lacking. Once a need has been identified, innovation enters into the research stage. Most innovations result from the interplay of scientific knowledge and applied research (Rogers, 2003). However, some innovations are the result of serendipity, or the accidental discovery of a new idea.

The development stage is often difficult to separate from the research stage. This stage constitutes the process of putting the new idea into a form that meets the needs of potential adopters. This may require extensive analysis and further research. After development comes the commercialization stage, when the idea or technology is produced, packaged, and marketed to the public.

The fifth stage is the diffusion stage, the primary focus of DOI theory. During the diffusion stage, information about an innovation is made available to an audience in a way that increases everyone's understanding, and individuals make decisions about whether or not they will adopt the innovation. A number of factors contribute to the success or failure of diffusion, and it is often difficult to determine what constitutes successful innovation and what factors may 
contribute to success or failure in a specific case (Morris, 2003). However, interpersonal contacts within and between communities are consistently recognized as one of the most important influencing factors on adoption behaviors (Rogers, 1995; Valente \& Davis, 1999). Reardon and Rogers (1988) wrote that "almost every diffusion study finds that peer networks play an especially crucial role in decisions to adopt a new idea" (p. 295). Given the demonstrable importance of interpersonal contacts in diffusion, one possible measure of diffusion is the saturation of communication messages within a target community.

The final stage of the innovation-development process is the consequence stage. This stage concerns the consequences of the innovation. These are the changes that occur to the adopter or the adopters' social system as a result of implementing the innovation. Changes may include the value added by the innovation, such as improvements in efficiency, safety, manageability, or profit. One observed consequence of some agricultural innovations may be that crop yields have increased significantly. Some innovations in the medical field, such as vaccines, have dramatically reduced premature deaths. The diffusion of an innovation is an important step in solving a number of significant social problems. This is particularly the case where a solution involves the application of a new method or technology.

\section{Innovation-Decision Process}

Individuals decide whether or not to adopt an innovation through the innovation-decision process (see Figure 2). Rogers (2004) described this process as consisting of five stages. Stage one is termed knowledge and consists of an individual's initial encounter with an innovation and their understanding of how the innovation functions (Crook et al., 2016). Individuals develop knowledge based on their perception of their own understanding of the innovation relative to the understanding displayed by others in their social system. Once an individual feels that they have 
a basic understanding of the innovation they enter into the second stage, persuasion, when that individual is exposed to persuasive messaging that seeks to influence the individual's attitude about the innovation. These messages generally emphasize the five core characteristics of the innovation: relative advantage, compatibility, complexity, trialability, and observability. In stage three, decision, the individual decides whether to adopt or reject the innovation. This decision is based on the individual's perceptions of the potential value added by the innovation, as identified in the persuasion stage. Stage four, implementation, consists of the individual's implementation of this decision. In stage five, confirmation, the individual seeks information about the innovations' value contribution that reinforces his or her decision, to avoid any remorse or cognitive dissonance about their adoption behaviors. This process is shown in figure 2 .

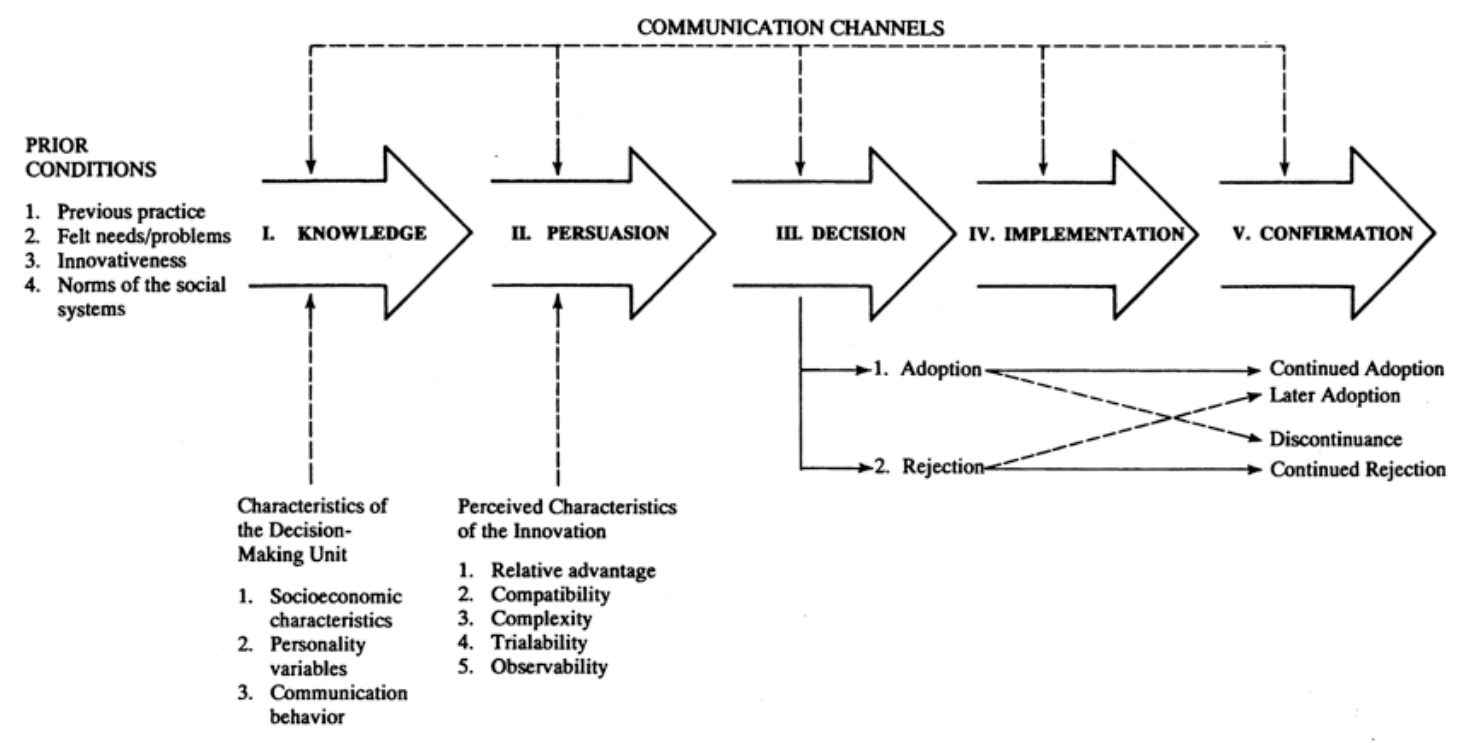

The innovation-decision process is the process through which an individual (or other decision-making unit) passes from first knowledge of an innovation, to forming an attitude toward the innovation, to a decision to adopt or reject, to implementation of the new idea, and to confirmation of this decision.

Figure 2. Innovation-Decision Process Model (Rogers 2003, p. 173).

The first and second stages of the innovation-decision process can be enhanced through use of public communication campaigns. Campaign messaging can help increase potential adopters' knowledge about innovations. Persuasive messaging through cosmopolite and localite channels 
can influence perceptions of the core characteristics of innovations, and may shape attitudes regarding the innovation.

Haider and Kreps (2010) described how the innovation-decision model has provided a guiding framework for the construction of public communication campaigns. They note "diffusion is a special type of communication, in which the messages are about a new idea" (p. 4). Public communication campaigns are often used to facilitate the diffusion of innovations throughout a community or other social system. Often, as in the case of the $4 \mathrm{R}$ framework, an external organization utilizes public communication to encourage adoption of certain practices or behaviors.

\section{Diffusion Within Social Systems}

To understand the process of diffusion, it is necessary to understand the ways that diffusion takes place within a social system. The individual units of adoption (people within the system) together constitute the community through which innovations diffuse. These individual responses to a potential innovation dictates how the innovation will diffuse.

Adopter categories. Over time, innovations are adopted in a pattern that follows a normal distribution. Rogers (2004) identified five adopter groups according to their readiness to adopt new innovations. These are: (1) innovators, (2) early adopters, (3) early majority, (4) late majority, and (5) laggards. He recognized innovators as the first 2.5\% to adopt an innovation. Early adopters are the next $13.5 \%$. The early majority are the next $34 \%$. Following are the late majority, for another 34\%. Last are laggards, the remaining 16\%. Some literature identifies a final category, skeptics, that adopt an innovation only at the very end of the diffusion process because few alternatives remain (Courtright \& Smudde, 2009). The distribution of adoption of an innovation over time is consistent with seeing diffusion of innovation as process. It also allows 
for the breadth of an innovation's diffusion to be tracked based on how many people in a social system report adopting the innovation. Rogers (2004) notes that diffusion does not happen overnight but takes time.

Critical mass. Eventually diffusion reaches critical mass, the point in the diffusion process where the increase in new adopters is perpetuated by communication within to the social system (Valente, 1993). This may be achieved when there is a perception that most everyone else in the system is adopting the innovation, because the value added by the innovation is significant (Mahler \& Rogers, 1999). Rogers (2004) suggested critical mass is the point where enough individuals have adopted an innovation that "further diffusion becomes self-sustaining" (p. 13). Prior to achieving critical mass, external organizations and policymakers must invest resources and energy toward driving adoption. This may include developing and disseminating messages through campaigns. Once a point of critical mass is reached, internal interpersonal pressures drive further adoption, and external attempts to encourage adoption become less effective. Public communication campaigns may be able to leverage WOM communication to drive further adoption.

\section{Diffusion of Innovations and Public Communication Campaigns}

Based on the previous discussion of public communication campaigns, issues management campaigns, and DOI, it may be helpful to describe how these ideas function in relation to each other. A proposed relationship among issues management, public relations campaigns, and the diffusion of innovations is presented in Table 1. 
Table 1

Comparison of Issues Management, Public Relations, and DOI

\begin{tabular}{|c|c|c|c|}
\hline & Issues management & $\begin{array}{l}\text { Public Relations } \\
\text { Campaigns }\end{array}$ & $\begin{array}{l}\text { Diffusions of } \\
\text { Innovations }\end{array}$ \\
\hline Purpose & $\begin{array}{l}\text { Manage and/or limit the } \\
\text { negative impact and } \\
\text { enhance the positive } \\
\text { impact of public policy } \\
\text { issues on an } \\
\text { organization }\end{array}$ & $\begin{array}{l}\text { Inform and or persuade } \\
\text { key publics }\end{array}$ & $\begin{array}{l}\text { To describe the process } \\
\text { of adoption of } \\
\text { innovations within and } \\
\text { throughout a social } \\
\text { system }\end{array}$ \\
\hline Inputs & $\begin{array}{l}\text { Monitoring and } \\
\text { identification of } \\
\text { environmental } \\
\text { conditions }\end{array}$ & $\begin{array}{l}\text { The organization's } \\
\text { vision and mission as } \\
\text { well as budget, } \\
\text { reputation, and } \\
\text { perceived need. }\end{array}$ & $\begin{array}{l}\text { Based on attributes of } \\
\text { the innovation as well as } \\
\text { the communication } \\
\text { associated with the } \\
\text { innovation }\end{array}$ \\
\hline Impetus & $\begin{array}{l}\text { Driven by broad public } \\
\text { policy issues that can } \\
\text { impact the organization }\end{array}$ & $\begin{array}{l}\text { Driven by organization's } \\
\text { strategic goals }\end{array}$ & $\begin{array}{l}\text { Driven by innovation } \\
\text { development and the } \\
\text { needs of potential } \\
\text { adopters }\end{array}$ \\
\hline Outputs & $\begin{array}{l}\text { Strategic response(s) to } \\
\text { public policy issues }\end{array}$ & $\begin{array}{l}\text { Planned messages } \\
\text { delivered through } \\
\text { specific channels } \\
\text { designed to reach target } \\
\text { audiences }\end{array}$ & $\begin{array}{l}\text { Messages emphasizing } \\
\text { aspects of the innovation } \\
\text { such as relative } \\
\text { advantage, } \\
\text { compatibility, } \\
\text { complexity, trialability, } \\
\text { and observability, as } \\
\text { well as aspects of the } \\
\text { social system. Delivered } \\
\text { through mass media } \\
\text { channels and } \\
\text { interpersonal channels }\end{array}$ \\
\hline Evaluation & $\begin{array}{l}\text { Various strategic } \\
\text { responses; lobbing, } \\
\text { adverting, lobbying, and } \\
\text { modification of } \\
\text { operations }\end{array}$ & $\begin{array}{l}\text { May be assessed using } \\
\text { various methods }\end{array}$ & $\begin{array}{l}\text { May be assessed based } \\
\text { on level of diffusion }\end{array}$ \\
\hline Future & $\begin{array}{l}\text { Ongoing process } \\
\text { matched to life cycle of } \\
\text { issues }\end{array}$ & $\begin{array}{l}\text { Typically, of a limited } \\
\text { duration }\end{array}$ & $\begin{array}{l}\text { Limited duration. } \\
\text { Matched to the life cycle } \\
\text { of the innovation }\end{array}$ \\
\hline
\end{tabular}

As this table indicates, issues management is a strategic function of organizations targeted

toward identifying public policy issues that may impact an organization. The purpose is to limit negative and enhance positive impacts on organizations. The general purpose of public relations campaigns is to inform and persuade key audiences in support of an organization's strategic 
goals. One form of a public relations campaign is an issue management campaign. This may include tactical implementation of one of several issues management strategies, such as reactive, adaptive, dynamic, or catalytic strategies. One approach to a managing a public policy issue may involve promoting an innovation among stakeholders. In these cases, public relations campaigns that are managing issues may be understood as efforts to promote the diffusion of innovations.

\section{Diffusion of Innovations as a Framework for Campaign Design}

DOI can be used as a framework for designing campaigns to promote innovation, even though it was not designed to be applied in the contexts of public communication campaigns. DOI specifies elements in a campaign that may facilitate the adoption of innovations. DOI also describes processes that may facilitate an innovation and the ways the innovation develops over time. Following the innovation-decision model, campaigns should first utilize mass media channels to maximize exposure to information about an innovation. This is a way to create awareness of the innovation and the value that it can add for a potential adopter. Then the campaign should engage in persuasive messaging relying more on interpersonal and communitylevel messaging to influence the formation of individual attitudes about an innovation. Interpersonal communication and mass media messages "routinely affect each other," and interpersonal talk can moderate or mediate campaigns (Southwell \& Yzer, 2007, p. 420).

The successful diffusion of an innovation is often facilitated by change agents, a term referring to individuals or groups seeking to encourage the adoption of an innovation by another group. Change agents are often opinion leaders, internal interpersonal sources trusted by community members to evaluate innovations because of their expertise. According to Rogers (2003), the behavior of change agents is strategic, as it is a "process of customizing the design and delivery of a communication program based on the characteristics of an intended audience" 
(p. 367). Haider and Kreps (2010) recommended campaigns "leverage the influential capacities of change agents" to more successfully influence attitudes of community members (p. 4). Once a potential adopter decides to adopt an innovation, campaign messaging should continue to engage with the community to ensure adopters provide positive feedback about their innovation decision to the rest of the community. Continued engagement with the community sparks more WOM communication around the innovation, and may reduce or eliminate the risk of adopters later rejecting the adoption and returning to earlier strategies.

Diffusion is reliant on peer-to-peer interpersonal networks to spread information about innovations. Campaigns designed to encourage diffusion should therefore be concerned with word-of-mouth communication. One of the explanations for the effectiveness of WOM communication is the fact that senders are often perceived to be more honest and credible because the have no commercial motivation for communicating. In addition, the relationship between the sender and receiver, such as family or friend, may enhance the credibility of the message (Nyilasky, 2006). This view is closely associated with concepts of opinion leaders and influencers, and localite change agents who leverage interpersonal relationships to distribute information through a social network (Sheth, 1971; Czepiel, 1974; Watts, \& Dodds, 2007).

\section{Diffusion of Innovations as a Framework for Campaign Evaluation}

The emphasis Rogers placed on communication suggests the diffusion of innovations among target publics can inform more traditional approaches of campaign analysis and evaluation. Because diffusion is a function of persuasion as well as sociological pressures, the reach and efficacy of persuasive messaging is a powerful determinate of adoption (Valente \& Rogers, 1995). DOI, therefore, can be used as a framework for evaluating public communication campaigns designed to promote innovation. 
Rogers suggested five characteristics of innovations (relative advantage, compatibility, complexity, trialability, and observability) determine the likelihood of the innovation being adopted. These characteristics can be features of the larger communication strategies seeking to promote diffusion. Campaigns may highlight the five elements of a potential innovation and in this way increase the likelihood an innovation will be adopted (Haider \& Kreps, 2010). This approach opens opportunities to determine the likelihood a campaign will succeed in facilitating diffusion.

A number of indicators suggest the progress of diffusion can be used to evaluate public communication campaigns seeking to facilitate diffusion. Key among these indicators are potential adopters' knowledge about innovations, the sources and channels through which information about innovations are communicated, and the extent of diffusion through a social system.

Potential adopters' knowledge. A key factor influencing adoption decisions is a potential adopter's understanding of the innovation. Initial understanding of an innovation is identified by Rogers in his model of the Innovation-Decision Process as the knowledge stage. The knowledge stage begins when a potential adopter is exposed to information about an innovation's existence and gains an understanding of how it functions. The knowledge stage ends when the potential adopter believes that they have an understanding of the innovation. This understanding may include initial perceptions of the innovation's expected value contribution, however, final value appraisal occurs later, in the decision stage of the Innovation-Decision Process. Knowledge is a function both of an individual's perceived understanding of the innovation and his or her understanding of the innovation relative to his or her perceptions of others understanding within a social system. 
Because the knowledge stage ends when the potential adopter becomes confident enough in his or her knowledge to form an opinion, the only requisite condition for proceeding from the knowledge stage is that individuals perceive themselves as having sufficient understanding about the innovation. This condition is conceptualized as perceived understanding.

Before forming attitudes on a particular subject, individuals will compare their levels of understanding to others within their social system (Festinger, 1954). To have confidence in attitude formation, an individual must feel his or her level of understanding about an innovation meets or exceeds the general levels of such understanding in his or her community. In the diffusion of agricultural innovations, other farmers' opinions are an important interpersonal source influencing al stages of the innovation-decision process (Unay Gailhard et al., 2015). Knowledge must be evaluated both as a function of an individual's perceived understanding as well as the individual's perceptions of general understanding in his or her community.

Sources and channels of information. Another marker that may indicate the success or failure of a campaign seeking to facilitate diffusion are potential adopters' primary sources of information about the innovation (Valente, 1993). According to Rogers (2003), information about innovations come either through cosmopolite channels or localite channels. Most innovation campaigns begin with cosmopolite channels in the form of mass media messages. Cosmopolite channels are most useful during the knowledge stage of the innovation-decision process, as these sources are effective at increasing basic literacy about innovations. Mass media, however, may be met with mistrust from potential adopters because these messages originate from individuals and organizations that are external to their community or social system. Localite channels may be used by more trusted sources of information such as opinion leaders, and are more likely to influence adoption behavior. Social contacts, social interaction, and 
interpersonal sources have been shown to be very influential in promoting innovation (Valente \& Rogers, 1995). Localite channels, particularly WOM communication through peer-to-peer channels, become increasingly more important in later stages of the diffusion process.

Rogers (2004) noted the majority of information about an innovation coming through peer-to-peer channels may be an indication diffusion has reached or is moving toward a point he termed critical mass. A point of critical mass is reached when enough individuals have adopted an innovation that "further diffusion becomes self-sustaining" (p. 13). At this point, external organizations can cease to invest resources toward driving adoption. Critical mass is the goal of any campaign seeking to facilitate diffusion of an innovation.

Extent of diffusion. Another potential avenue for evaluation is to track the rate of adoption within a social system. Rogers (2004) provided metrics backed by research showing how diffusion progresses throughout a social system. Diffusion follows patterns of adoption organized into a normal distribution. In diffusion research, adoption is understood in terms of stages of diffusion: (1) innovators, (2) early adopters, (3) early majority, (4) late majority, and (5) laggards. By determining at what stage an innovation is in this process, it is possible to assess the saturation of an innovation within a social system. It is then possible to determine how effective a campaign has been at facilitating innovation.

\section{Diffusion of Innovations and the 4R Nutrient Stewardship Program}

The 4R Nutrient Stewardship Program is a public communication campaign seeking to manage the issue of fertilizer runoff. One of the strategies employed by this campaign involves facilitating the diffusion of innovative fertilizer application strategies. There are a number of specific best-agricultural practices the 4R Nutrient Stewardship Program promotes, including the use of broadcast fertilizer, subsurface tilling, and nutrient use calculators. However, the core 
innovation being promoted is the idea of making efficiency a core part of fertilizer application decisions. Efficiency is understood in terms of the "4Rs" of the campaign; the right source of fertilizer should be applied, in the right place, at the right time, and at the right rate. This focus on an idea as an innovation is consistent with Rogers' (2003) definition of an innovation as "an idea, practice, or project that is perceived as new by an individual or other unit of adoption" ( $p$. 12). The campaign targets individual agricultural communities and seeks to persuade them to adopt efficiency as part of their calculus when they are making fertilizer application decisions. Once this idea is accepted, the goal is to change actual practice.

To facilitate adoption, the 4R Nutrient Stewardship Program utilizes a multi-level approach. The Fertilizer Institute designed and operates the campaign but does not provide explicit direction (TFI, 2016a). Instead, the Fertilizer Institute provides materials and resources to state-level organizers. Local-level retailers and fertilizer lobbyists serve as the primary agents of the campaign, communicating messages to agriculturalists in their areas. These messages are advanced chiefly through educational programs, brochures, guideline documents, posters, promotional events, certification programs, newsletters, and face-to-face interactions with retailers.

The campaign targets agricultural communities to encourage adoption of the recommended strategies. The changes in nutrient stewardship practices may be understood as an adaptive issues management strategy. The changes involve accommodations and adjustments in agricultural practices to address the negative impact and reduce the likelihood of regulation (Jones \& Chase, 1979). If fertilizer runoff can be substantially reduced through voluntary innovations by farmers, the issue may be sufficiently addressed and become dormant. These recommended strategies may also be understood as a method for the industry to get its house in 
order by enhancing the responsible use of fertilizers in ways that do not have a negative environmental impact (Heath, 2002). Achieving this goal requires the end users of fertilizer be persuaded to adopt innovative practices that they perceive will add some value. By reducing the chances of government regulation by demonstrating the industry is working to resolve the issue, the autonomy of organizations is maintained.

\section{Other Diffusion Research in Agricultural Communities}

An extensive body of research has already examined DOI in the context of agricultural communities. Ryan and Gross (1943) sought to understand the influence of sociological factors on the diffusion and adoption of hybrid seed corn in Iowa farming communities. Because hybrid seed corn increased production yields by close to $20 \%$, Ryan hypothesized the innovation would be adopted quickly. Surprisingly, the researchers discovered farmers took an average of seven years to transition from first planting hybrid seed to $100 \%$ adoption.

Riesenberg and Gor (1989) explored farmers' preferences for information and their assessment of credible and beneficial sources disseminating information about new farming innovations. The results indicated farmers generally preferred onsite interpersonal demonstrations of innovations. This supports Rogers' point that innovations that can be tried and demonstrated are more likely to be adopted.

Baumgart-Getz, Prokopy and Floress (2012) conducted an extensive meta analysis of studies examining the adoption of innovations by U.S. farmers. They sought to identify and assess the factors that influenced the adoption of agricultural best management practices. Their investigations examined 31 social factors assessed over 25 years of adoption research exploring best management practices. 
The variables with the most significant impact on adoption included access to high quality of information; the financial capacity of the farmer; and being connected to an agency, local communities, or groups of farmers. Financial capacity gives a farmer greater ability to experiment with new techniques and innovations. The impact of quality of information is consistent with Rogers' overall theory. Those farmers who have information about innovations are likely to have a better understanding of the proposed innovation and consequently have higher rates of adoption. Being part of a network may enhance social influence and create opportunities for trialability.

DOI's has utility as a frame for campaigns in agricultural contexts. Campaigns have been an important activity in agricultural communication (Boone, Meisenbach, \& Tucker, 2000; Tucker, 1996). They have been widely used to promote innovation in agricultural practices. This includes creating sustainable agricultural practices (Röling \& Jiggins, 1994), innovation in pest control practices (Heong, Escalada, Huan, \& Mai, 1998), and innovations in livestock vaccination (Heffernan, Thomson, \& Nielsen, 2008), among many others.

\section{Research Questions}

Because the 4R Nutrient Stewardship Program operates as several small campaigns within various states, it is possible to examine these campaigns individually in terms of their respective target communities. Within the state of Ohio, the majority of persuasive efforts target the Maumee River Watershed, an area that contains many farms as well as the primary water source for a number of high population communities. The Maumee River is a principal tributary of Lake Erie and is surrounded by farm land. The watershed has experienced several major contamination events as a result of fertilizer runoff, prompting efforts to regulate runoff. Communities in the Midwestern United States have been the target for many of these efforts 
given the presence of large numbers of agricultural operations in close proximity to the Great Lakes. For these reasons, the Maumee River Watershed is an appropriate community to evaluate the 4R Nutrient Stewardship Program.

To examine The 4R Nutrient Stewardship Program as an issues management campaign, as well as to demonstrate the utility of DOI in case studies of public communication campaigns, I propose the following general question:

How effective has the 4R Nutrient Stewardship Program been at promoting the diffusion of $4 \mathrm{R}$ practices among communities in the region of the Maumee River Watershed? As discussed earlier, promoting these changes is a key objective of the 4R Nutrient Stewardship Program that will help manage the issue of fertilizer runoff and reduce the risk that new regulatory policies will be put into place.

To answer this question, it is necessary to identify the reach of campaign messaging, the breadth of diffusion of the innovation, and the sources that are most effective in promoting the 4R principles. Therefore, I propose the following specific research questions for this study: RQ1: Do agriculturalists within the Maumee River Watershed feel they have knowledge of the $4 \mathrm{R}$ principles?

RQ2: How do specific sources of information relate to adoption of 4R practices within the Maumee River Watershed?

RQ3: What is the extent of the diffusion of the 4R frameworks' prescribed runoff reduction strategies through agricultural communities within the Maumee River Watershed?

The answer to the first question will provide an indication of the success of the campaign in introducing the principles to the key target audience. Knowledge of an innovation and its 
potential benefits is a key first step in the DOI process. The answer to the second question will identify the sources of information are associated with that knowledge and whether these sources make use of cosmopolite or localite channels of communication. Finally, the answer to the third question will provide an indication of the success of the 4R Nutrient Stewardship Program. Contextualized within the bigger picture of campaigns generally, the answer to these three questions will also provide insight into the larger process of innovation as promoted by public communication campaigns as well as the role that diffusion can play in managing issues of public policy.

\section{Conclusion}

This chapter provided a brief introduction to the content areas of this research study, paying particular attention to existing scholarship in public communication campaigns and DOI. This chapter also proposed three research questions that guide the study. Chapter 3 provides an overview of the 4R Nutrient Stewardship Program, its design, and the specific strategies used by the campaign within the state of Ohio. This includes identifying elements of relative advantage, compatibility, complexity, trialability, and observability present in the campaign. 


\section{CHAPTER 3: THE 4R NUTRIENT STEWARDSHIP PROGRAM}

The 4R Nutrient Stewardship Program addresses water contamination from fertilizer runoff, because such runoff and pollution are becoming more common both in the U.S. and internationally. However, regulations to reduce runoff are usually unpopular with farmers. Because of this, public communication campaigns seeking to change fertilizer application behaviors are promising approaches to reduce runoff and manage risk of water contamination.

This study examines the 4R Nutrient Stewardship Program as a public communication and issues management campaign seeking to encourage changes in fertilizer application behaviors to reduce runoff. This chapter provides a description of the key elements of the campaign, including the goals, the precipitating situation, the principal organizations involved, the messages and channels used, and the target audiences or the campaign. Considering these elements is important to understanding the design of a campaign. Smudde and Courtright (2015) noted "medium and message work together in rhetorical ways that organizations use to inspire cooperation with their stakeholders while also inviting them to celebrate their common ground" (p. 406). Strategies that are consistent with DOI framework are described. In addition, message content and organization are discussed (Ferguson, 1999). These factors are important to the overall evaluation of the campaign. The chapter begins with a discussion of fertilizer runoff and water contamination issues.

\section{Water Contamination and Fertilizer Runoff}

Water is a critical resource for life and is used in manufacturing, recreation, and agriculture. According to the International Conference on Water and the Environment, "Fresh water is a finite and vulnerable resource, essential to sustain life, development and the environment" (ICWE, 1992, para 1). The ICWE also emphasized the economic importance of 
water, saying "water has an economic value in all its competing uses and should be recognized as an economic good" (ICWE, 1992, para 1). Population growth, climate change, and commoditization has placed increasing pressure on fresh water resources. Water contamination is a significant threat to this resource.

\section{Fertilizer Runoff as a Contributor to Water Contamination}

The National Water Quality Assessment identified agricultural nonpoint source pollution as the leading cause of "water quality issues on surveyed rivers and streams, the third largest source for lakes, the second largest source of impairments to wetlands, and a major contributor to contamination of surveyed estuaries and ground water" (EPA, 2016, para 1). Increased nitrate runoff reduces a water system's ability to absorb and convert nitrate (Freeman, 2002). When this happens, water systems become supersaturated with nitrates, resulting in an accelerated growth of cyanobacteria, sometimes called blue green algae. These events of rapid growth are termed Harmful Algae Blooms, or HABs. Freshwater cyanobacteria produce microcystin, a form of dangerous toxin causing severe damage to the liver (Falconer, 1998). HABs may result in dangerous contamination of drinking water. Several cases of HABs affecting water systems have occurred, including several involving the Great Lakes. In addition, when microorganisms such as cyanobacteria die and decompose, they absorb oxygen from the surrounding environment, converting the water system into a hypoxic area known as a dead zone. Dead zones are hugely hostile toward most forms of aquatic life and can be challenging to repair or undo (Achenbach, 2008). Fertilizer runoff, therefore, is an environmental threat and a threat to public health.

Dramatic cases of water contamination often serve as focusing events that bring public attention to issues and drive policy creation (Birkland, 1997). The Toledo water crisis in 2014 was a dramatic event that raised public awareness about fertilizer runoff and increased political 
pressure for change, including a reduction in fertilizer runoff. In addition, this case called attention to the Maumee River Watershed as a source of runoff. On August 3, 2014, routine testing of Toledo, Ohio city water showed heightened levels of the toxin microcystin produced by cyanobacteria. The cyanobacteria had multiplied at a high level in Lake Erie due to fertilizer runoff. A citywide do not drink warning was issued. Within 48 hours, testing showed toxin levels were within safe parameters and the drinking ban was lifted (Seeger \& Seeger, 2017). Other HAB events have occurred in Lake Erie.

A similar event occurred in 2016 in Florida. This case demonstrated water contamination from fertilizer runoff is a national problem. In July 2016, a combination of synthetic fertilizer runoff from agricultural sites and heavy rainfall from the El Nino weather system triggered an HAB off the coast of Miami, Florida (Allen, 2016). This event prompted statements from the Southwest Florida Watershed Council saying the HAB demonstrated how "the duration and frequency and magnitude of cyanobacteria is changing" on an international level (Henry, 2016). These and similar events helped activate the issue of fertilizer runoff and prompted the Fertilizer Institute to take action to manage the issue by seeking to change the practices of farmers.

\section{Obstacles to Policy Regulation}

Few, if any, policy options are available to states seeking to impose limits on the amount of fertilizer used by farmers (Henry, 2015). The Clean Water Act of 1972 provided some governmental mechanisms to regulate the fertilizer industry; however, these mechanisms are strictly limited. Regulatory measures to reduce fertilizer at both state and federal levels are usually opposed by the Fertilizer Institute and associated lobbyist groups (Wines, 2014). The Fertilizer Institute has greatly increased its spending since the Toledo water crisis and 
contributed to several political campaigns in the 2015-2016 election cycle (Center for Responsible Politics, 2016).

Following the Toledo water crisis, the state of Ohio saw a surge in policy and regulatory efforts to limit runoff. In 2015, Ohio sought regional support from both the state of Michigan and the Canadian province Ontario. All parties agreed to drastically reduce runoff as a means of limiting algae growth in Lake Erie. The express goal of this initiative is to reduce fertilizer-based pollution in Lake Erie by more than $40 \%$ by the year 2025 (Seewer, 2015). In the same year, Ohio passed Senate Bill 1 and House Bill 150 to help curb water pollution. Ohio Senate Bill 1 banned the winter application of manure on farm fields while House Bill 150 set up a program to encourage certification of fertilizer applicators (Henry, 2015).

\section{The 4R Nutrient Stewardship Program}

The 4R Nutrient Stewardship Program seeks to persuade farmers and agriculturalists to voluntarily employ sustainability strategies in their fertilizer application by providing farmers with the information necessary for optimal fertilizer application. This information is presented in a way to promote innovation. The campaign consists of a series of messages and communication frameworks housed on its website and available for download and distribution. These messages seek to frame fertilizer in a positive way as a necessary and desirable component of a modern agricultural system. Runoff is framed as a problem that can be managed through appropriate agricultural practices. The $4 \mathrm{R}$ framework is proposed as a solution to this problem. This creates a very clear problem-solution structure for the campaign's larger persuasive efforts. The problemsolution pattern has been described as a classic approach to the design of persuasive messages that can both incite engagement and allay fears (Smudde \& Courtright, 2015). 
The 4R Nutrient Stewardship Program codifies nutrient runoff strategies in ways that are memorable and easily communicated. The Fertilizer Institute suggests that following the $4 \mathrm{R}$ strategies allows the producer to achieve desirable goals of "increased production, increased farmer profitability," while maintaining "enhanced environmental protection and improved sustainability" (TFI, 2016a, NP). The 4Rs refer to the right fertilizer source at the right rate, at the right time, and in the right place.

\section{The Fertilizer Institute}

The 4R Nutrient Stewardship Program was produced by the Fertilizer Institute, an international trade association for the fertilizer industry. Trade associations are affiliations or networks of organizations that have some shared interests. They seek to coordinate efforts, lobby government, influence policy, and address common threats. Trade association can also serve as structures to exchange and share important information thus helping reduce uncertainty for member organizations (Kirby, 1988). Barnett (2013) noted, "Trade associations are organizations through which a group of interdependent firms, typically in the same industry, pool their resources and coordinate their efforts so that they may speak with one voice on matters of shard interest" (p. 218). Speaking with one voice often means creating public communication campaigns that can address public policy issues. Barnett suggests that nearly every organization in the U.S. belongs to at least one trade association and these associations can increase the influence of organizations. Frandsen and Johansen (2015) described trade associations as intermediaries in strategic communication activities, providing additional resources and coordinating messages in a way that mediates the relationship between the organization and stakeholders. A trade association represents the member organization to further their interests (Frandsen \& Johansen, 2015). 
Commercial fertilizers are products used extensively in agriculture to enhance the crop yields. Some studies have shown that between $30 \%$ and $50 \%$ of the yield for any crop is associated with fertilizer (Stewart, Dibb, Johnston \& Smyth, 2005). Fertilizers are critical to modern, industrial, high-yield agriculture. The USDA noted U.S. rates of application peaked in 2004 at 24 million tons of fertilizer applied (USDA, 2017). Three types of nutrients are included in most commercial fertilizers: nitrogen, phosphate, and potash. Nitrogen is the most widely applied chemical component and, along with phosphorus, accounts for the majority of the negative impact from fertilizer runoff. The widespread use of commercially produced fertilizer is both praised for enhancing food production and feeding a growing world population, and criticized for significant environmental impacts, including those associated with climate change and water contamination (Charles, 2013).

To advance industry interests, the Fertilizer Institute lobbies politically for favorable regulation and legislation, collects and makes available important information and data, funds relevant research, and publicizes industry initiatives in safety and environmental stewardship. The Fertilizer Institute reported on its website that it represents over $90 \%$ of the fertilizer industry, a sprawling alliance of food producers, micronutrient manufacturers, fertilizer distributers, retailers, equipment suppliers, engineering firms, brokers and traders, transport firms, and other related businesses. Member organizations identified on their website include many large agricultural chemical companies, seed, feed, and agricultural technology, petrochemical, financial, and transportation companies (TFI, 2016a).

The Fertilizer Institute has existed in some form since the 1800s and has been a powerful voice in shaping U.S. and international agricultural policy. According to the Fertilizer Institute, their lobbying efforts successfully kept ammonia off the list of toxic air pollutants identified in 
the 1990 Clean Air Act. The Fertilizer Institute helped define sustainable agriculture in the U.S. as the "most efficient use of non-renewable resources" in the 1991 Farm Bill (TFI, 2016b). The Fertilizer Institute also ensured retail fertilizer dealers were made exempt from the Environmental Protection Agency's Stormwater Permit Program and was instrumental in organizing congressional opposition to the Kyoto Climate Treaty. The Fertilizer Institute described its mission on its website:

TFI is the voice of the fertilizer industry, representing the public policy, communication, stewardship and sustainability and market intelligence needs of fertilizer producers, wholesalers and retailers as well as the businesses that support them with goods and services (TFI, 2016a).

The Fertilizer Institute presents itself as advocating for its own versions of sustainability programs that better address the needs of its member companies. As more areas around the world experience issues with water quality, the Fertilizer Institute has identified a need for voluntary sustainability efforts across the industry. These efforts are encouraged as a way to prevent potential government regulation that may neglect the interests of its member organizations. More broadly, the Fertilizer Institute argues it is interested in protecting and improving water quality.

The Fertilizer Institute positions itself as an organization engaged in the management of public policy issues that may impact the industry or members. Several issues are described on the Fertilizer Institute website, including "security, international trade, energy, transportation, the environment, worker health and safety, farm bill and conservation programs to promote the use of enhanced efficiency fertilizer" (TFI, 2016a, NP). One of the most important issues facing the fertilizer industry is nutrient runoff, including both nitrogen and phosphorus. Runoff impacts 
water quality in very visible and sometimes dramatic ways and can place the agricultural community and fertilizer industry in conflict with other stakeholders who depend on water.

\section{International Plant Nutrient Institute}

Many of the Fertilizer Institute's efforts are in cooperation with the International Plant Nutrient Institute (IPNI). IPNI is an international non-profit organization devoted to conducting research in the responsible management of plant nutrition. While primarily a research organization, membership in the IPNI includes companies that are basic producers of plant nutrients for agricultural purposes. Member companies initiate, coordinate, and manage research projects; have unique access to research results; and represent the IPNI at government and public hearings when scientific input is deemed to be useful in supporting an industry position.

\section{The 4R Nutrient Stewardship Program in Ohio}

Campaigns are precipitated from a situation, issue, need, crisis, or development requiring a communicative response from an organization (Moffitt, 1999). In the case of the 4R Nutrient Stewardship program, the campaign was precipitated from developing water contamination issues in the Midwestern United States, most notably the Toledo water crisis. To understand a campaign, it is necessary to understand the organization behind the campaign, its vision, goals, and structure, as well as to understand the campaign's target publics.

The primary state-level association advancing the 4R Nutrient Stewardship Program in Ohio is the Ohio AgriBusiness Association (OABA), a state-level trade association representing 240 Ohio-based agricultural companies. The OABA primarily makes use of materials provided directly by the Fertilizer Institute. These materials consist of the campaign Twitter account, a brochure, and a document detailing guidelines for retailers (See Appendices A, B, C, and D). In addition to these materials, the OABA operates a state-level 4R certification program that 
provides training and recognition to farmers and agriculturalists who adopt the $4 \mathrm{R}$ recommended fertilizer application strategies (WTOL 11, 2016). The remainder of this chapter will identify the key audiences of the 4R Nutrient Stewardship Program and explore how these campaign materials are used to meet the the 4R Nutrient Stewardship Program's goals.

\section{Target Audiences}

To achieve its goals, the campaign targets three separate audiences: policy makers and political activists, fertilizer retailers, and farmers. Primary audiences of this campaign are the policymakers as well as political activists advocating for regulation on fertilizer use. The campaign seeks to demonstrate to these audiences that the agricultural community, working in tandem with the fertilizer industry, is able to address issues of fertilizer runoff on a voluntary basis using programs such as $4 \mathrm{R}$.

Additional audiences targeted by the 4R Nutrient Stewardship Program include the statelevel fertilizer retailers, crop advisors, and nutrient service providers. These roles may constitute opinion leaders who can be very important in persuading target audiences (Gregory, 2010). Retailers, advisors, and providers are gatekeepers for information within local agricultural communities and serve as important nodes in the 4R Nutrient Stewardship Program's persuasive network. Agriculturalists generally rely on retailers to provide information about correct or innovative fertilizer application strategies. If retailers, advisors, and providers can be persuaded to advise their customers and clients to follow $4 \mathrm{R}$ principles, then the $4 \mathrm{R}$ Nutrient Stewardship Program is much more likely to succeed in its secondary persuasive goal.

A third audience and the primary focus for the 4R Nutrient Stewardship Program are farmers. The campaign seeks to persuade this audience to adopt innovative new fertilizer application behaviors and strategies to reduce risk of fertilizer runoff. This is accomplished both 
through the use of retailers as opinion leaders as well as direct messaging. According to the USDA, in 2015 there were 74,400 farms in the state of Ohio (USDA, 2017). Agriculture is Ohio's largest industry, contributing over $\$ 93$ billion to the state economy annually. There are 75,462 principal farm operators in Ohio. Of these, 21,637 , or about $21 \%$ of the population, are older than 65 (Farmland Information Center, 2017). Farmers as publics may be described in a variety of different ways based on the level of engagement with the issue (Gregory, 2010). Some may be latent and not recognize the issue of runoff affects them. Some may simply be aware the issue exists and others may be active and ready to take action to solve the problem. Creating innovation requires moving members of the target audience to the active stage. Doing so may require they recognize the problem and that psychological constraints to taking action are removed (Gregory, 2010). This means convincing them they can take meaningful action without disrupting their income or lifestyle. The 4R framework provides farmers with concrete actions they can take to address the problem.

\section{Twitter Account}

Twitter is a global social media platform. Individuals and organizations can create Twitter accounts that allow them to communicate with each other. Messages are published in the form of tweets (short posts of 280 characters or less) viewable by anyone who subscribes to (or follows) the publishing Twitter account. Users also have the option to retweet messages-resend posts published by other accounts to a different network of followers. Because of its fast, shortform nature, messages produced on Twitter can easily reach a broad audience (Swasy, 2016). Twitter has become one of the most popular social media platforms in use today, with Twitter estimating more than 200 million users producing around 400 million messages per day (Tsukayama, 2013). 
Social media platforms, such as Twitter, are fertile environments for public communication campaigns. The fast-paced, interactive nature of social media is conducive to strategic, two-way communication between an organization and an audience (Grunig, 2009). Social media platforms provide opportunities for organizations to reach new publics and to engage in dialogic communication with existing publics (Kent \& Taylor, 1998). The 4R Nutrient Stewardship Program has made liberal use of social media platforms to communicate a variety of messages related to the $4 \mathrm{R}$ framework.

Tweets originating from the 4R Nutrient Stewardship Program's Twitter account focus on local environmental benefits. Stories presented include "Growers along the Chesapeake Manage Nutrients, Protect the Bay" and "Five Star Cooperative in Iowa... finds success in reducing nitrogen runoff." These kinds of appeals serve not only to encourage adoption but to demonstrate the credibility of the campaign. The 4R Nutrient Stewardship Program seeks to discourage regulatory policy by demonstrating farmers are taking action to address the issue of runoff. By framing appeals to relative advantage in terms of environmental benefits, the $4 R$ Nutrient Stewardship Program demonstrates to potential activists or policymakers that the Fertilizer Institute values environmental protection. This is particularly important for appeals made on Twitter, as anyone interested in investigating the campaign can easily find these messages. Appeals that address economic or policy goals are better communicated using channels that directly reach farmers.

A large number of the campaign tweets also emphasize the value of fertilizer and industrial farming, irrespective of the methods used for fertilizer application. Fertilizer application is presented as "feeding crops to feed the world" and problems of global hunger are seen as problems of "limited Ns" (limited nutrients). While not explicitly related to the $4 \mathrm{R}$ 
principles, these tweets appeal to one of the campaign's central goals of reducing regulatory pressures. Many tweets also criticize alternative methods of controlling fertilizer runoff, such as small-scale farming or policy regulation. Tweets claim that "organic does not equal sustainable" and that "industrial-scale farming is the sustainable path."

Finally, a number of tweets appeal to a sense of community belonging and responsibility. Examples include calls to "feed the world" or "save our water." These tweets may extend appeals to establish credibility by framing the $4 \mathrm{R}$ Nutrient Stewardship Program as a socially motivated project. These tweets often emphasize geographic areas in the Midwestern United States, such as the Iowa, Illinois, or Ohio, and by doing so appeal to the audience's sense of place. Because these tweets seek to persuade by appealing to community responsibility, it is helpful to remind the audience of their specific communities. By positioning the $4 \mathrm{R}$ Nutrient Stewardship Program as community based, it supports the idea that adopting these techniques is compatible with community values.

Many of the tweets address the complexity of the 4Rs by advancing specific fertilizer application strategies and techniques. These tweets frequently emphasis the ease of adoption, laying out simple steps and practices farmers can employ to implement $4 \mathrm{R}$ principles. In this way, the tweets are designed to reduce the perceived complexity of the $4 \mathrm{R}$ innovations. The Twitter account frequently highlights the observability of the $4 \mathrm{R}$ principles by spotlighting individual adopters across the U.S. In fact, these are among the most common messages included in the account. The presentation of these stories is simple and to the point, fitting the character limits of the channel (e.g., "Farmer Terry McClure says the \#4R effort really does provide a way to engage more growers in nutrient mgmt issues"). These spotlights help make adopters visible within agricultural communities and often emphasize the various ways adoption has helped the 
featured farmer achieve success. They serve as testimonials from members of the target audience (Gregory, 2010). These Twitter messages also create a sense of reference group membership by incorporating messages from farmers around the country. These reference group appeals can be very persuasive, especially when there may be strong identification with the group (Ferguson, 1999). Often these tweets will emphasize the relative advantage of adoption as well as the ease of adoption (Gregory, 2010).

\section{The Brochure}

A brochure is a "printed piece of collateral material used for public relations, advertising and marking purposes" (Daugherty, 2005, p. 140). Brochures can communicate a great deal of specific, targeted information. They generally have specific aims and are directed to a target audience. Brochures are usually produced in large quantities and distributed interpersonally, often through organizations. Daugherty (2005) suggests that a brochure should be created with a unifying design throughout the entire publication. This creates consistent tone and message. This unifying design should incorporate typeface, layout, pictures, and color schemes.

The Fertilizer Institute produces a 4R brochure to be distributed at retail and nutrient service provider sites. The brochure is made available to retailers through the nutrient stewardship website for them to print out and distribute on their own. The target audience of the brochure includes farmers and agriculturalists. Retailers would likely already have been persuaded to advocate for the $4 \mathrm{R}$ principles if they are willing to distribute brochures to their customers.

The 4R brochure consists of two images, printed back-to-back on a sheet of paper and folded to create eight separate pages. Blocks of text are juxtaposed with images of idyllic farm life. On the cover, two men walk away from the viewer through a sunlit field. Between them, 
holding onto each of the men's hands and swinging playfully, is a young boy. The image of the field continues into page two, creating a feeling of consistency. The brochure uses a soft color palette of light and dark greens set against a white background. These colors blend well with the large color photographs that take up the majority of visual space. The photographs themselves are primarily green, tinted slightly brown by a light sepia tone filter.

The visual presentation of the $4 \mathrm{R}$ brochure seems intent upon communicating a rural theme, with an underlying emphasis on family and farm values. The images all capture scenes of idealized rural life. The scene on the cover depicts men across generations engaged in agricultural work. The man on the left is gray haired; the man on the right has soft brown hair, and suspended between them is a young boy. The lack of any modern technology or fixtures of agriculture in any of the images evokes nostalgia and a sense of tradition.

The color scheme similarly invokes idealized rural life. The light green serves as the backdrop for most of the text and blends seamlessly into the sunlit, sepia-toned backdrop of each image, leading the eye effortlessly from the text to the visual presentations of rural life. The choice of a rust-toned red to highlight critical points evokes images of old tractors and other agricultural machinery. The softness of all the colors works together to create a calm feeling on the part of the viewer. This feeling is matched by an optimistic, informative tone of the text.

The visual layout is designed to lead the reader throughout the brochure. Ferguson (1999) notes visual elements in a message can be powerful persuasive devices. The powerful and vibrant photographs are the primary element of the brochure, and each of these images spans multiple pages. To experience the fullest effect of these images, it is necessary to turn on to the next page. As mentioned previously, the text is positioned so readers easily alternate between text, picture, and back to text as they progress through the brochure. The brochure ends with the 
back cover, where the words "4R NUTRIENT STEWARDSHIP" are connected back to the front with a thin white line. The line ends by encircling the trio walking through a field on the front cover, establishing a link between the values of family and rural tradition established throughout the brochure and the suggested practice of nutrient stewardship. Value appeals such as these focus on ideas of intrinsic worth, and can be very persuasive (Gregory, 2010).

The primary DOI characteristic emphasized by the brochure is compatibility. Attention is devoted to increasing social and political pressures for fertilizer regulation. These pressures are framed as a threat because of regulations' inability to predict the needs of individual farmers. Readers are warned that "pressure to limit the use of fertilizers is increasing" and "states throughout the country are being pressured by federal government and environmental groups to develop additional regulations.... These include reductions and... bans on nutrient application.” The brochure also presents social and environmental arguments for adoption. Statistics concerning global population growth and rates of food production are provided, as well as projected yield increases due to biotechnology. The brochure argues "increased food production will be achieved by intensified crop production" and to meet this goal "fertilizer inputs must be optimized to provide the greatest potential for success." This appeal targets farmers' sense of community responsibility, and the brochure urges agriculturalists to improve and refine fertilizer application as a form of social service. The text includes both positive and negative message elements (Ferguson, 1999). The threat of regulation is negative while the responsibility to feed a hungry world is a positive appeal. References to regulations may also be understood as a fear appeal.

The brochure also appeals to the relative advantage of adopting the $4 \mathrm{R}$ framework. The brochure describes $4 \mathrm{R}$ principles as "a framework to achieve [sic] increased production, 
increased farmer profitability, enhanced environmental protection and improved sustainability." Overall, these advantages are framed as "simply good business" that "provide economic, social, and environmental benefits." Emphasis is placed on improved agricultural productivity by improving fertilizer efficiency.

\section{Guidelines for Retailers}

The Fertilizer Institute produces a document, titled A Pocket Guide to 4R Nutrient Stewardship, that provides information on the 4R Principles and lays out strategies for retailers, advisors, and providers to encourage adoption. This document may help disseminate information about innovation through interpersonal and professional channels. Rogers (2004) emphasized that "almost every diffusion study finds that peer networks play an especially crucial role in decisions to adopt a new idea" (p. 295).

As might be expected, the primary audiences for this channel are the community-based fertilizer retailers, crop advisors, and nutrient service providers. As noted earlier, retailers, advisors, and providers are important gatekeepers and opinion leaders and involving them in promotion is an important tactic in the 4R Nutrient Stewardship Program. This document seeks to persuade retailers, advisors, and providers to encourage adoption of the $4 \mathrm{R}$ principles and prescribes strategies. Feder and Savastano (2006) observed that social links and structure of the community are important to diffusion. They concluded, "Communications and information relating to new knowledge were shown to be embedded within the more general fabric of social within the more general fabric of social interactions among individuals. The pattern of information flows received and transmitted by individuals is thus related to their social environment, the network of their contacts. .." (p. 1287). Ferguson (1999) emphasized that "communicators try and reach audiences in places and at times when they may be prepared to 
listen" (p. 172). Farmers go to retailers, advisors, and providers to receive information about fertilizer and they do so when they are prepared to make decisions.

According to web service Manta, there are at least 110 fertilizer companies operating in Ohio (Manta, 2017). Many of these are retail outlets for larger organizations, such as Crop Production Services, a subsidiary of a multinational fertilizer supplier with operations throughout the U.S. Individual retail outlets allow for direct contract with the consumers of fertilizer products. Because fertilizer is a complex product, farmers are likely to rely on opinion leaders who are part of the community and with whom they are familiar for technical information and advice (Feder \& Savastano, 2006). Thus, providing information to retailers, advisors, and providers so they can be informed when they speak to customers can be an important part of a diffusion of innovation campaign. Many of the appeals described in the Pocket Guide emphasize compatibility and relative advantage by emphasizing greater efficiency in fertilizer application and describing application decisions and processes. The $4 \mathrm{R}$ framework is also described as a critical approach for limiting potential regulation.

\section{The 4R Certification Program}

Certification is a process of ensuring individuals and groups have completed certain steps and acquired information so they are able meet specific standards and competently complete certain tasks. Certification is used extensively in professions, in organizations, and in certain industries, including the agricultural community (Auld, Gulbrandsen, \& McDermott, 2008). This

process can take many forms and serve several functions, including improving and standardizing practice, generating support, enhancing reputation, promoting ethical conduct, and disseminating a standard body of knowledge. 
The OABA operates a state-level certification program targeting fertilizer retailers and nutrient service providers throughout the Lake Erie Watershed. To be certified by this program, providers must meet three standards. First, $100 \%$ of agricultural customers of the provider must be educated and trained in the principles of $4 \mathrm{R}$ nutrient stewardship. Second, $100 \%$ of agricultural customers must have implemented $4 \mathrm{R}$ principles and practices, and this implementation must be recorded and monitored by the provider. Finally, $100 \%$ of agricultural customers must meet nutrient and fertilizer application recommendations for their crop as consistent with the 4R principles (OABA, 2016).

The primary purpose of the $4 \mathrm{R}$ certification program is observability. The program celebrates members of the Ohio agricultural community who have successfully adopted $4 R$ principles. In particular, community leaders are sought out and acknowledged for implementing 4R practices. These include Sunrise Cooperative and Crop Production Services, two particularly prominent retailers within Ohio's agricultural sphere. Emphasizing the most successful businesses that have become certified may also have characteristics of an appeal towards relative advantage. Potential adopters may see successful businesses becoming certified and associate their success with the certification process.

Making adopters within a community visible may also serve to demonstrate the compatibility of $4 \mathrm{R}$ practices with community values. Leaders may be gatekeepers of cultural norms associated with these values. When community leaders show a willingness to adopt new practices and engage with new ideas, they implicitly demonstrate that these practices and ideas are consistent with the values and ideas already in place within that community. The certification program can also be seen as appealing to complexity. The program produces a great deal of educational material to help local farmers comply with certification standards. This material 
presents $4 \mathrm{R}$ practices in a straightforward manner and lays out specific steps and strategies farmers can employ to meet the program's standards.

\section{Conclusion}

The 4R Nutrient Stewardship Program includes the DOI elements of relative advantage, compatibility, complexity, and observability. The only primary characteristic of an innovation not identified within the campaign was trialability. This is likely due to the fact that the $4 \mathrm{R}$ practices are not easily tried. By their nature, nutrient application strategies require a grower to commit to those behaviors for at least a single growing cycle. The campaign is designed around a broad problem-solution format and includes a number of specific persuasive strategies including testimonials, fear appeals, repetition, appeals to group membership and values. The $4 \mathrm{R}$ title is memorable and references the specific actions that are being advocated. Several methods are used to deliver the messages directly to farmers including twitter, brochures, and a certification program.

This chapter provided an overview of the 4R Nutrient Stewardship Program's regional public communication campaign in the state of Ohio. Through this discussion the key goals, publics, and channels of the 4R Nutrient Stewardship Program's in Ohio were identified. As this

chapter has shown, a variety of channels are employed at the local level to persuade Ohio-based agriculturalists to adopt new fertilizer application strategies. In addition, the campaign seeks to demonstrate to policymakers and activists that the industry is working hard to address the issue of runoff. Chapter 4 provides an overview of the research methodology used in this study to examine the 4R Nutrient Stewardship Program. 


\section{CHAPTER 4: METHODS}

This research utilizes Diffusion of Innovations theory (DOI) as a framework for understanding and evaluating public communication campaigns seeking to create social change. Through an examination of the 4R Nutrient Stewardship Program within the context of the Maumee River Watershed, it will be possible to draw conclusions about the nature of diffusion and public communication within these communities. These conclusions may then be useful in informing the design and implementation of future public communication campaigns.

The data used in this study were collected by The Ohio State University's College of Agriculture, Food and Environmental Sciences using a survey questionnaire (see Appendices E, F, G, and H). Funding for this data collection was made available through the International Plant Nutrient Institute. The data were made available by Professor Robyn Wilson, the principal investigator for the project, upon request. This chapter describes the survey methods used to collect data to answer the research questions proposed in chapter 2 . This includes a description of the survey, the sample, measurement, and the statistics used to examine the data.

\section{Procedure}

Data were collected from Ohio farmers between the end of December of 2015 and early March 2016 (Wilson \& McCormick, 2017). Several procedures were used to facilitate an adequate return rate of mail in surveys. A postcard indicating that a survey would be sent to the respondents was mailed to increase awareness of the study. This postcard included a web address for the online version of the survey. One week later a paper copy was mailed out to those who had not participated online. A second reminder postcard was send out two weeks later, followed by second copy of the survey (Wilson \& McCormick, 2017). 


\section{Respondents}

The initial contact information for the sample included 3,273 farmers living in the Maumee River Watershed. According to the Ohio Environmental Protection Agency, the Maumee River Watershed drains 5,024 square miles and flows through all or part of 18 Ohio counties. According to The Ohio Lake Erie Task force, nutrient run-off from within the Maumee River Watershed is the primary source contributing to harmful algal blooms in Lake Erie (Ohio Environmental Protection Agency (2018a). Once the sample frame was identified it was stratified according to farm size: farms 50 to 249 acres (15\%), 250 to 499 acres (13\%), 500 to 999 acres (22\%), 1000 to 1999 acres (31\%), and 2000 plus acres (19\%). This stratified sample closely matches the census data for Ohio farms operating with over 50 acres of land (Wilson \& McCormick, 2017).

Wilson and McCormick (2017) reported that of the 3,273 initial contacts, some surveys were unopened, some farmers asked to be removed, and others indicted they were no longer farming. This left a total sample of 2,574 respondents, of which 748 were returned usable, for a response rate of $29.1 \%$ and a total sample of 748 .

\section{Variables and Measurements}

Respondents completed a survey addressing perceived issues of nutrient runoff, nutrient application practices, and attitudes toward hiring Nutrient Service Providers. Demographic information was also collected. The present study examined only selected survey measures that directly tracked with the variables of knowledge, sources of information, and extent of diffusion.

\section{Knowledge}

Two items were used to evaluate knowledge of innovations. The first was a single Likerttype item designed to assess respondents' perceived understanding about an innovation. 
Respondents were asked to rank their agreement with the statement, "I feel that I have a pretty good understanding of the four nutrient management principles." This item made use of a fivepoint Likert-type measurement with anchors of -2 (strongly disagree) and 2 (strongly agree).

The second knowledge item evaluated relative understanding and asked respondents to rank their agreement with the statement, "I feel that I am better informed about nutrient stewardship than most farmers." This scale also made use of a 5-point Likert-type measurement with anchors of -2 (strongly disagree) and 2 (strongly agree). This was an important measurement for knowledge as it relates to diffusion because it contextualized understanding relative to the larger agricultural community.

The mean of these two items was used to operationalize each respondent's knowledge of the $4 \mathrm{R}$ principles. The items demonstrated adequate reliability, $\alpha=.74$. The mean value of these two items was thus used as a single metric for knowledge, $M=.71, S D=.72$.

\section{Sources of Information}

Respondents were also asked to report how often they receive information about nutrient stewardship from a variety of sources. Eleven potential information sources were provided with a five point Likert-type scale with anchors of 0 (never) and 4 (frequently). Responses included, "Your county Extension agent, University Extension generally, Farm bureau, Your county Soil and Water Conservation District, Your crop advisor/consultant, Your fertilizer applicator or retailer, USDA NRCS, Professional/industry magazines, Commodity Groups, A family member or farm partner," and "Other farmers in your community." These potential sources of information can be categorized into sources that make use of localite channels of communication and sources that make use of cosmopolite channels of communication. The sources of "crop advisor/consultant, your fertilizer applicator or retailer, a family member or farm partner," and 
"other farmers in your community" were sources that made use of localite channels. The sources of "the county extension agent, University Extension, the farm bureau, the county soil and water conservation district, the 4R Brochure, commodity groups" and "USDA NRCS" can be understood as sources that make use of cosmopolite channels. Descriptive statistics for these eleven potential information sources are provided in Table 2.

Table 2

Sources of Information

\begin{tabular}{|c|c|c|c|c|}
\hline Source & $\begin{array}{l}\text { Channel } \\
\text { Direction }\end{array}$ & Channel Type & Mean & SD \\
\hline $\begin{array}{l}\text { Your county } \\
\text { Extension agent }\end{array}$ & Cosmopolite & Mass media & 1.801 & 1.0315 \\
\hline $\begin{array}{l}\text { University } \\
\text { Extension generally }\end{array}$ & Cosmopolite & Mass media & 1.824 & .9113 \\
\hline Farm Bureau & Cosmopolite & Mass media & 1.679 & 1,0545 \\
\hline $\begin{array}{l}\text { Your county Soil } \\
\text { and Water } \\
\text { Conservation } \\
\text { District }\end{array}$ & Cosmopolite & Mass media & 2.167 & 1.0327 \\
\hline $\begin{array}{l}\text { Your crop } \\
\text { advisor/consultant }\end{array}$ & Localite & Interpersonal & 2.064 & 1.2268 \\
\hline $\begin{array}{l}\text { Your fertilizer } \\
\text { applicator or retailer }\end{array}$ & Cosmopolite & Interpersonal & 2.208 & 1.1415 \\
\hline USDA NRCS & Cosmopolite & Mass media & 1.796 & 1.0236 \\
\hline $\begin{array}{l}\text { Professional/industr } \\
\text { y magazines }\end{array}$ & Cosmopolite & Mass media & 2.425 & .9764 \\
\hline Commodity Groups & Cosmopolite & Mass media & 1.364 & 1.0177 \\
\hline $\begin{array}{l}\text { A family member or } \\
\text { farm partner }\end{array}$ & Localite & Interpersonal & 1.631 & 1.1398 \\
\hline $\begin{array}{l}\text { Other farmers in } \\
\text { your community }\end{array}$ & Localite & Interpersonal & 1.766 & .9784 \\
\hline
\end{tabular}

\section{Extent of Diffusion}

The extent of diffusion refers to the proportion of the agricultural population that has adopted the prescribed runoff reduction strategies. A binary measure asked respondents to report whether they had used 4R-related practices on their farm in the past three years (since the 
inception of the 4R Nutrient Stewardship Program). The proportion of individuals within a social system reporting adoption is the degree the innovation can be considered to have diffused through the social system.

\section{Demographics}

Demographic data was collected last. Respondents were asked basic demographic information. Gender was assessed with a single item in which respondents self-reported their gender as either male or female (male $=731$, female $=17$ ). Age was assessed with an openended item in which respondents indicated their age in years, $M=57.61, S D=11.78$, Mode $=60$. Education level was assessed as an ordinal-level measure using a single item in which respondents indicated their highest level of education ranging from some high school (1) to graduate or professional degree (6), $M=3.2, S D=1.31$, Mode $=2.0$. Experience farming was assessed with an open-ended item in which respondents indicated how many years they have been farming, $M=36.79, S D=13.46$, Mode $=40$. Annual net income was assessed as an ordinal-level measure using a single item in which respondents indicated their income, ranging from less than 50,000 (1) to 500,000 or greater (5), $M=2.60, S D=1.39$, Mode $=1$. Finally, respondents' total farm operation during the past growing season was assessed using an openended item in which respondents indicated total acres of both owned, $M=463,174, S D=501.60$, Mode $=400$, and rented land, $M=746.59, S D=1823.90$, Mode $=500$.

\section{Conclusion}

This chapter provided an overview of data collection procedures and measures used in this study. In chapter 5, the results of the data analysis will be presented. Results will then be used to answer the research questions for this study. 


\section{CHAPTER 5: RESULTS}

This chapter presents the results of the data analysis used to answer the three research questions proposed in chapter 1 . The survey data were analyzed using the IBM Statistical Package for the Social Sciences (SPSS v.24).

\section{Knowledge}

A one-sample $t$-test was used to determine whether agriculturalists within the Maumee River Watershed feel they have understanding of the 4R principles. The knowledge score was compared to a hypothesized population mean of 0 , which was chosen as a neutral midpoint denoting neither high nor low levels of knowledge. The knowledge score $(\mathrm{M}=.71, \mathrm{SD}=.72)$ was statistically significantly higher by 0.71 (95\% CI, 0.66 to 0.76$)$ than the knowledge comparison score of $0, t(739)=26.63, p=.0005, d=.98$. Respondents had a level of knowledge regarding the $4 \mathrm{R}$ principles statistically significantly above 0 according to this test.

\section{Sources of Information}

A binomial logistic regression was performed to ascertain the effects of the eleven information sources about nutrient stewardship from a variety of sources on the likelihood that farmers have changed their 4R-related practices on their farm in the past three years. The logistic regression model was statistically significant, $\chi^{2}(11)=108.89, p<.0005$. The model explained $19.7 \%$ (Nagelkerke $\mathrm{R}^{2}$ ) of the variance in $4 \mathrm{R}$ related farming practices and correctly classified $67.8 \%$ of cases. Sensitivity was $80.8 \%$, specificity was $49.7 \%$, positive predictive value was $69.1 \%$, and negative predictive value was $65.0 \%$. Of the eleven predictor variables, only crop adviser/consultant $(p<.001)$, professional/industry magazines $(p=.037)$, and the Farm Bureau $(p=.05)$ were statistically significant and had a positive relationship to changing farm practices. For every one unit increase in reported frequency of information from their crop 
adviser/consultant, professional/industry magazines, or the Farm Bureau, the odds of a farmer changing their practices on the farm increased by $1.43,1.24$, and 1.21 respectively. A comparison of the eleven predictor values is provided in Table 3.

Table 3

Comparison of Sources of Information

\begin{tabular}{|c|c|c|c|c|c|c|c|c|}
\hline & \multirow[t]{2}{*}{$B$} & \multirow[t]{2}{*}{ SE } & \multirow[t]{2}{*}{ Wald } & \multirow[t]{2}{*}{$D f$} & \multirow[t]{2}{*}{$P$} & \multirow[t]{2}{*}{$\begin{array}{l}\text { Odds } \\
\text { Ratio }\end{array}$} & \multicolumn{2}{|c|}{$\begin{array}{l}\text { 95\% CI for } \\
\text { Odds Ratio }\end{array}$} \\
\hline & & & & & & & Lower & Upper \\
\hline $\begin{array}{l}\text { Your County Extension } \\
\text { Agent }\end{array}$ & 0.115 & 0.111 & 1.068 & 1 & 0.301 & 1.121 & 0.902 & 1.394 \\
\hline University Extension & 0.168 & 0.133 & 1.613 & 1 & 0.204 & 1.183 & 0.913 & 1.535 \\
\hline Farm Bureau & 0.189 & 0.097 & 3.782 & 1 & 0.052 & 1.208 & 0.999 & 1.461 \\
\hline $\begin{array}{l}\text { Your County Soil and Water } \\
\text { Conservation District }\end{array}$ & 0.07 & 0.109 & 0.411 & 1 & 0.522 & 1.072 & 0.866 & 1.328 \\
\hline $\begin{array}{l}\text { Your Crop Advisor/ } \\
\text { Consultant }\end{array}$ & 0.355 & 0.097 & 13.431 & 1 & 0.000 & 1.426 & 1.179 & 1.724 \\
\hline $\begin{array}{l}\text { Your Fertilizer Applicator } \\
\text { or retailer }\end{array}$ & 0.101 & 0.104 & 0.95 & 1 & 0.330 & 107 & 0.903 & 1.357 \\
\hline USDA NRCS & $\begin{array}{c}- \\
0.034\end{array}$ & 0.107 & 0.103 & 1 & 0.748 & 0.966 & 0.783 & 1.192 \\
\hline $\begin{array}{l}\text { Professional/Industry } \\
\text { Magazines }\end{array}$ & 0.212 & 0.101 & 4.356 & 1 & 0.037 & 1.236 & 1.013 & 1.508 \\
\hline Commodity Groups & 0.113 & 0.104 & 1.177 & 1 & 0.278 & 0.893 & 0.728 & 1.096 \\
\hline $\begin{array}{l}\text { A family member or farm } \\
\text { partner }\end{array}$ & 0.148 & 0.095 & 2.415 & 1 & 0.120 & 1.16 & 0.962 & 1.398 \\
\hline $\begin{array}{l}\text { Other farmers in your } \\
\text { community }\end{array}$ & 0.068 & 0.113 & 0.363 & 1 & 0.547 & 1.071 & 0.857 & 1.337 \\
\hline
\end{tabular}

\section{Extent of Diffusion}

Some $56.4 \%(N=748)$ of respondents indicated they have changed 4R-related practices

on their farm in the past three years. Changes since the inception of the campaign are understood as adoption. DOI prescribes the following distribution of innovators: $2.5 \%$ early adopters, $13.5 \%$ early majority, 34\% late majority, and 16\% laggards (Valente, 1993). Taken together, innovators, early adopters, and early majority constitute $50 \%$ of the population distribution. This positions 
the diffusion of the 4R framework's prescribed runoff reduction strategies firmly in the late majority stage of the diffusion process.

\section{Conclusion}

This chapter presented the results of the statistical analysis used to answer the three research questions. Conclusions and implications that may be drawn from these analyses are discussed in chapter 6 . 


\section{CHAPTER 6: CONCLUSIONS AND IMPLICATIONS}

This chapter discusses the results of the analyses in relation to the goals of the study and the specific research questions presented earlier. The overall goal of this project was to demonstrate the utility of DOI as a framework for evaluation of and the planning for public communication campaigns seeking behavioral change. In addition to answering the three research questions, the implications of the study for understanding issues management, public communication campaigns, and the diffusion of the $4 \mathrm{R}$ innovations are explored. Limitations and directions for future research are also discussed.

This project examined the 4R Nutrient Stewardship Program as a public communication campaign. The first goal of the campaign was to encourage changes in fertilizer application behaviors among farmers with the outcome of reducing fertilizer runoff. A secondary but closely related goal was to demonstrate that both the fertilizer industry and the agricultural community are working toward reducing fertilizer runoff and are taking proactive measures to reduce water pollution. This was a response to public concerns about the issue of fertilizer runoff and water contamination, as well as an industry effort to reduce pressure for governmental regulation of the fertilizer industry. As described in chapter 3, fertilizer runoff is a significant pollutant of water and can have very adverse affects on water quality. Cases such as the Toledo water crisis were focusing events for the issue of fertilizer runoff and made the issue salient within the Maumee River Watershed. Fertilizer runoff has become an important public policy issue, and the 4R Nutrient Stewardship Program campaign was part of the Fertilizer Institute's effort to manage the issue. For this study, the 4R Nutrient Stewardship Program was approached as an issues management campaign targeting farmers, fertilizer retailers, policymakers, and policy advocates. 
This study also explored the relationship between issues management, public communication campaigns, and the diffusion of innovations. As described in chapter 2, issues management is a strategic function of organizations targeted toward identifying and addressing public policy issues that may impact an organization. Public communication campaigns are understood as efforts to inform and persuade key audiences in support of an organization's strategic goals. DOI is a framework that describes how an innovation is diffused through a social system and what factors may facilitate the adoption of an innovation. The 4R Nutrient Stewardship Program can be described as a public communication campaign, designed to manage a public issue by promoting innovations in agricultural practices.

This study was focused around three specific research questions. These questions were addressed using the data from the survey questionnaire presented in chapter 5 . These three focused questions are discussed first, followed by the more general discussion of the meaning and implications of these results.

\section{Discussion of Research Questions}

The first research question (RQ1) asked: Do agriculturalists within the Maumee River Watershed feel that they have an understanding of the $4 \mathrm{R}$ principles? As described in chapter 2, knowledge of an innovation is identified by Rogers (2003) as the first stage of the innovationdecision process, and is an important prerequisite to adoption. The results of the survey for RQ1 indicate respondents feel they do understand the $4 \mathrm{R}$ principles of nutrient stewardship. Perceived understanding was compared with the instrument midpoint of relative understanding, and was statistically significantly higher than the selected knowledge comparison score. Responses to the question, "I feel that I have a pretty good understanding of the four nutrient management principles," were significantly higher than the scale midpoint of knowledge. Because the four 
nutrient management principles are the basis of the $4 \mathrm{R}$ campaign, it is likely that the campaign has improved perceived understanding of the innovation, at least to some degree. BaumgartGetz, Prokopy, and Floress (2012) concluded knowledge was a significant predictors of adoption. Moreover, they note that efforts should go beyond a general knowledge of how agriculture can degrade water quality and focus on how the actions of individual farmer impact water quality $(\mathrm{p}, 23)$.

The second research question (RQ2) asked: How do specific sources of information relate to adoption of $4 \mathrm{R}$ practices within the Maumee River Watershed? The results for RQ2 indicated three specific sources of information were significantly associated with adoption of the 4R principles. The logistic regression analysis of information sources about nutrient stewardship accounted for roughly $20 \%$ of the likelihood of farmers reporting they had adopted $4 \mathrm{R}-$ related practices on their farms. The three sources of information associated with change, listed in order of significance, were the crop advisor/consultant, the professional/industry magazines, and finally, the Farm Bureau. Crop advisor/consultant and the professional/industry magazines were sources explicitly used by the 4R campaign, while the Farm Bureau is an organization that communicate information about agricultural innovations to agricultural communities, including information about the 4R principles (Snyder, 2018).

The crop advisor/consultant are change agents that fits the conventional profile of an opinion leader, a critical source of information identified by DOI as using localite channels of communication. Crop advisors are individuals who are "knowledgeable about plants and soil. They maintain a close relationship with their client and scout their fields for problems that may arise during the growing season" (AgCareers.com, 2018, NP). Crop advisors advise farmers about a range of issues, such as seed selection, pest and disease management, and fertilizer use. 
They typically have advanced education and may be certified in their state. Opinion leaders can be key sources of information in a program seeking to encourage the diffusion of an innovation (Valente \& Davis, 1999; Gregory, 2010). Crop advisors interact regularly with farmers and serve as key opinion leaders about issues of fertilizer use, and can therefore be considered to use localite interpersonal channels of communication (Schwartz, 1994).

Professional/industry magazines were made available to farmers in the form of brochures about the $4 \mathrm{R}$ principles distributed by fertilizer retailers, as well as $A$ Pocket Guide to $4 R$ Nutrient Stewardship. The brochure and Pocket Guide were key materials in the 4R Nutrient Stewardship Program and focus explicitly on the $4 \mathrm{R}$ principles. These materials were designed by the Fertilizer Institute and given to representatives within the community for local distribution. Although the Pocket Guide and brochure were cosmopolite, mass media channels of communication, they were designed to be distributed by retailers and may have functioned as collateral materials to support peer-to-peer communication within the farmers' social system. As discussed in Chapter 3, these materials were most effective at communicating the characteristics of compatibility and relative advantage. Using local change agents, such as fertilizer retailers, for distribution and emphasizing compatibility may increase farmers' feelings of connectedness with their local community, which has been shown to influence the adoption of agricultural innovations (Baumgart-Getz, Prokopy \& Floress 2012).

These results are consistent with previous research that has identified the Farm Bureau as an important part of agricultural diffusion networks (Lubell \& Fulton, 2007). The Farm Bureau is part of the agricultural extension services and serves to organize and educate farmers about new agricultural methods. The Farm Bureau describes itself as, "The unified voice of agriculture" (Farm Bureau, 2018, NP). While an external organization that primarily makes use of mass 
media channels of communication, the Bureau is organized down to the local county level with representatives working directly with farmers. In some cases, the Bureau may use mass media, cosmopolite channels and interpersonal, localite channels. However, the majority of the Bureau's communication would be categorized as using cosmopolite channels.

Baumgart-Getz, Prokopy, and Floress (2012) reached conclusions that provide additional insight into these results. Through an extensive meta analysis, they found that overall education and level of formal education were not related to the adoption of best management practices. Extension training did have a significant impact. The Farm Bureau provides training to agriculturalists through the county extension system, as well as through activation of crop advisor/consultants. In addition, Baumgart-Getz et al. found that participation in specific kinds of social networks were also associated with the adoption of new management practices. connectivity with local networks, neighboring farms, grass roots organizations, and agency networks were related to adoption. Agency networks would include organizations like the Farm Bureau. Baumgart-Getz, Prokopy and Floress (2012) suggest "using networks to implement extension efforts and disseminating information presents a logical way to combine and extend the reach of factors found to have a significant effect on BMP adoption” (p. 23).

Fertilizer retailers and nutrient service providers were not associated with adoption, despite the 4R Nutrient Stewardship Program prioritizing these groups as key change agents. Although fertilizer retailers and nutrient service providers utilize interpersonal communication to facilitate adoption, their connections to external organizations make retailers and providers cosmopolite channels of communication. As a result of the close professional relationships that exists between retailers and providers and the Fertilizer Institute's member organizations, potential adopters may believe that retailers and providers have more loyalty to the Fertilizer 
Institute than to farmers within the social system. The 4R certification program provided incentives to retailers and providers to encourage their customers to adopt the 4R principles, and may have created pressures that limited the influence of retailers and providers within the social system.

Some sources are more likely to reach the target audiences, and some sources will be more persuasive than others at different stages of the diffusion process (Baumgart-Getz, Prokopy, \& Floress, 2012). The results for RQ2 indicate that some of the channels emphasized by the 4R Nutrient Stewardship Program are associated with adoption. Localite channels, specifically the crop advisers, were associated with adoption. However, cosmopolite and mass media channels still appear to be the primary sources of information concerning the 4R principles. This conclusion regarding the second research questions is broadly consistent with the prescriptions of DOI and the results for the third research question (RQ3).

The third research question (RQ3) asked: What is the extent of the diffusion of the 4R frameworks' prescribed runoff reduction strategies through agricultural communities within the Maumee River Watershed? The results indicate a 56\% adoption rate for the $4 \mathrm{R}$ principles. At the late-majority stage of adoption, localite interpersonal channels should be more influential, but the influence of cosmopolite channels should still be felt. Opinion leaders seem to be particularly important in facilitating the adoption of innovative 4R practices. Other sources that used interpersonal channels, such as "other farmers in your community" and "a family member or farm partner," were not significant sources of information regarding 4R practices, indicating that diffusion of the 4R principles may not yet have reached the point where further diffusion is driven by peer-to-peer communication. Because cosmopolite channels were found to be 
associated with adoption more so than localite interpersonal channels, the 4R Nutrient

Stewardship Program appears to have not yet achieved the critical mass stage of diffusion.

Rogers (2004) noted that innovators are the first 2.5\% to adopt an innovation, followed by early adopters at $13.5 \%$, the early majority at $34 \%$, the late majority for another $34 \%$, and laggards as the remaining $16 \%$. These results indicate the $4 \mathrm{R}$ innovations have entered the late majority stage of adoption. This suggests the diffusion may be moving towards a state where the majority of information about an innovation comes from inside the social system and "further diffusion becomes self-sustaining” (Rogers, 2004, p. 13). Results for RQ2 indicated the diffusion of the $4 \mathrm{R}$ innovations may not yet be self-sustaining, as cosmopolite channels were associated with adoption more so than localite interpersonal channels. Peer-to-peer communication between community members is broadly consistent with diffusion entering a self-sustaining stage in the DOI framework. The primacy of sources of information that make use of localite interpersonal channels would be seen as one indication that the diffusion may have been successful and may be moving towards becoming self-sustaining (Rogers, 2003; Valente \& Davis, 1999).

Finally, as described in chapter 2, the over-arching question that guided this study asked: How effective has the $4 \mathrm{R}$ campaign been at promoting changes in nutrient management in the region of the Maumee River Watershed? The results suggest about half of farmers are knowledgeable about the principles, they have adopted some or all of the principles, and they have seen others adopt them. The conclusion that $56 \%$ of respondents indicate adoption suggests the campaign may have been partially successful in achieving the strategic goal of promoting innovation in fertilizer practices. These results indicate the $4 \mathrm{R}$ campaign may be achieving some success in promoting changes in nutrient management. However, it does not appear that 
campaign communication has yet achieved sufficient saturation of adoption for further diffusion to become self-sustaining.

\section{General Discussion}

The 4R Nutrient Stewardship Program has a number of objectives. The overall goal of the campaign to facilitate adoption of the 4R principles works to achieve a number of related goals. While farmers may adopt innovations because of the perceived value added by the innovation in terms of profit, crop yield, or environmental protection, the Fertilizer Institute works to drive adoption through the $4 \mathrm{R}$ Nutrient Stewardship Program in order to reduce the impact of runoff on water quality, avoid the introduction of new regulatory policies, and reduce pressures from environmental and activist groups.

The impact of the 4R Nutrient Stewardship Program on water quality in the Maumee River Watershed is not yet clear. However, some sources do indicate modest improvement (Felton, 2017). While harmful algal blooms have continued to occur in Lake Erie, none have been at a level to impact domestic water supplies since the Toledo water crisis. Chris Winslow, director of the Ohio Sea Grant program, noted that the 2017 harmful algal bloom was not as serious as it had been in years past. The 2017 bloom was rated at a severity of 7.5 , while the 2015 bloom was rated a 10.5 (Johnston, 2017). The Maumee River remained on the Ohio Environmental Protection Agency 2018 list of rivers with impaired water quality. The Agency noted, "most of the 31 waters placed on the nitrate watch list are in northwestern Ohio" (Ohio Environmental Protection Agency, 2018b, NP).

The 4R Nutrient Stewardship Program did not prevent new fertilizer regulation. In July 2015, the Ohio General Assembly passed Senate Bill 1, limiting the application of fertilizer and manure on frozen, snow-covered, or saturated fields (Ohio Legislature, 2018). This legislation 
was in direct response to the Toledo water crisis and was part of a larger plan for agricultural practices and water quality in Ohio, Michigan, and Ontario. In 2018, Michigan finalized details of a plan to cut phosphorus inputs to Lake Erie, identifying three main goals: 1) "minimize the extent of oxygen depleted zones in the waters of the central basin of Lake Erie; 2) maintain healthy animal and plant life in the western and central basins; and 3) maintain cyanobacteria (blue-green algae) levels that do not produce concentrations of toxins" (MDARD, 2018, para 2). Michigan's plan does not include regulation of fertilizer use, but instead calls for the implementation of agricultural best practices.

Some environmental and advocacy groups seem to regard the 4R Nutrient Stewardship Program favorably, indicating that some of the Fertilizer Institute's public image goals may have been achieved. The 4R Nutrient Stewardship Program was cited by the National Wildlife Federation as a positive step taken by the agricultural community because "nutrient management on participating farm fields minimize the potential for runoff and maximizes crop use of nutrients" (Hesse, 2018, para 3). In addition, the Fertilizer Institute has begun working with The Nature Conservancy to promote the 4R principles (Martin, 2016). Endorsements by environmental groups and the inclusion of 4R principles in the Ohio EPA plans for water quality improvement suggest that the campaign is visibly demonstrating efforts were being made to reduce runoff. This was one of the goals of the campaign. The $4 \mathrm{R}$ campaign appears to have reduced friction and increased harmony between fertilizer organizations and at least some of their key publics.

\section{General Conclusions}

Several conclusions can be drawn from this study about public communication campaigns, issues management, and DOI. First, public communication campaign efforts can help 
facilitate the diffusion of innovations. The primary goal of the 4R Nutrient Stewardship Program within the Maumee River Watershed was to facilitate the diffusion of the 4R principles to the local agricultural community and improve water quality. This goal supported the larger vision of The Fertilizer Institute to represent the policy and public communication needs of the fertilizer industry (TFI, 2016a). The adoption of these principles by farmers will limit fertilizer runoff and reduce the risk of harmful algal blooms. It is not possible to conclude at this point that the $4 \mathrm{R}$ Nutrient Stewardship Program has reduced fertilizer runoff or improved water quality. This study suggests the 4R Nutrient Stewardship Program is a factor in the adoption of nutrient stewardship principles within the target public. The specific information communicated by this campaign, as well as the channels through which they are communicated, can be understood and analyzed as tactics for facilitating the diffusion of innovations. This study suggests the characteristics of innovations identified by DOI (relative advantage, compatibility, complexity, trialability, and observability) could be useful in both developing and evaluating public communication campaigns seeking to facilitate a diffusion of any innovations. As discussed in chapter 2, several other studies, including those focusing on promoting innovation in health practices, have examined these principles in the context of developing campaigns (Haider \& Kreps, 2010; Rogers, 2003). These principles have seen limited application in the context of agricultural campaigns, issue management campaigns, and campaigns operated by trade associations.

Public communication practitioners with the objective of promoting innovation could design campaigns that are informed by Rogers' (2003) five characteristics of an innovation. Social media, for example, could be very useful in achieving observability for an innovation, provided that target publics value and make use of social media. Campaign communication can 
emphasize the relative advantage and compatibility of changes that are being advocated, as illustrated by the $4 \mathrm{R}$ campaign. Campaign communication can also emphasize the unique, unprecedented value added by innovations to audiences of potential adopters (Courtright \& Smudde, 2009). The complexity of a change can also be addressed in campaign messages and materials, such as $A$ Pocket Guide to $4 R$ Nutrient Stewardship. Trialability can be harder to achieve, and may be dependent on the characteristics of the innovation in question. Specific features of an innovation program can be used to enhance trialability, for example, materials could suggest implementing the $4 \mathrm{R}$ principles on one field to see how crop yields may be affected.

DOI is a theoretical frame that has the potential for broad applicability in the context of public communication campaigns. Many public communication campaigns have the diffusion of innovations as a primary objective, including health campaigns (Snyder, Hamilton, Mitchell, Kiwanuka-Tondo, Fleming-Milici, \& Proctor, 2004), campaigns designed to promote sustainability (Roper, 2005), and issues management campaigns. Promotion refers to campaign efforts to inform or persuade audiences about relative merits of a product, service, brand or issue (McCarthy, 1978). Project ChildSafe, for example, promotes the use of trigger locks on handguns (National Shooting Sports Foundation, 2018). The National Transportation Board and the Ad Council worked with the Leo Burnett firm to develop the Vince and Larry crash test dummies to promote the use of seat belts (America on the Move, 2018). The Health Promotion Branch of the Australian Board of Health used a campaign called Lifesaver to promote the use of condoms (U.S. National library of Medicine, 2016). Some health campaigns, such as efforts to encourage volunteer checkups and screenings, are designed to promote the adoption of a behavior to address health risks. Health-related behavioral changes promoted by campaigns have 
been described as behavioral innovations (Snyder, Hamilton, Mitchell, Kiwanuka-Tondo, Fleming-Milici, \& Proctor, 2004).

This study demonstrated DOI can be used as a framework for campaign evaluation, and may satisfy the need for new approaches for campaign evaluation (see Tyma, 2008). The principles of relative advantage, compatibility, complexity, trialability, and observability would be measureable factors for examining campaigns promoting innovation. Campaign messages can be examined to determine how well they are utilizing these factors. In addition, the level of adoption of the innovation can be used as a key performance indicator (KPI) of the campaign. In the case of the $4 \mathrm{R}$ campaign examined here, $56 \%$ of those surveyed reported adoption of the $4 R$ strategies, indicating the campaign had reached the beginning of the late majority phase, and may have achieved sustainability. Using the stages of adoption as a tool for evaluating campaigns directed toward promoting an innovation may help public relations professionals evaluate and refine strategies and tactics.

A second general conclusion of this study concerns its relationship to other research about DOI. This study adds to a very large and diverse body of research concerning communication and the diffusion of innovations. These results were generally consistent with previous work on diffusion of innovation in agricultural communities. These results demonstrated diffusion is supported by information sources, including opinion leaders and change agents such as crop advisors. Opinion leaders play an important role in influencing adoption and diffusion (Baumgart-Getz, Prokopy \& Floress 2012; Riesenberg \& Gor 1989; Rogers 2003; Ryan \& Gross, 1943). That the group promoting the innovation was an industry trade organization is a unique factor in this campaign. Much diffusion research has focused on diffusion efforts led by not-for-profit organizations or governmental agencies (Hanan, 2009; 
Mulgan et. al., 2007; Okaka, 2010; Valente \& Saba, 1998). Industry trade associations, such as the Fertilizer Institute, can leverage significant resources and can create opportunities for member organizations to speak with one voice. Trade associations' access to certain resources that others cannot access may allow trade associations to be more effective in promoting innovations than other organizations. In addition, the Fertilizer Institute, through its member organizations, had representatives near the communities targeted for innovation. The use of local change agents is an established tactic for facilitating diffusion, however, change agents may be most effective when they are opinion leaders. Opinion leaders such as crop advisors can access localite, peer-to-peer networks and make effective use of WOM communication. Rogers (2003) suggested activating peer networks can be effective as a method for accelerating diffusion. Baumgart-Getz, Prokopy, and Floress (2012) also emphasize that innovation in agricultural communities can be enhanced through the use of local networks to disseminate information, including information for extension services.

The results of this study do not necessarily support a rigid distinction between localite and cosmopolite channels as conceptualized in DOI. This study suggests external organizations, in this case a trade association, are able to activate and use localite channels in ways that blur the line between cosmopolite and localite communication. Such strategies may involve providing resources to opinion leaders, such as brochures or talking points, that can be used to support WOM communication. Carl (2006) noted that the power of WOM communication has been understood in campaign scholarship for some time. Efforts by organizations to create "buzz," which he defined as "contagious talk about a brand, service, product, or idea" is a more recent development (p. 601). Buzz involves the use of local change agents to drive peer-to-peer communication around a product, innovation, or idea. The ways that cosmopolite and localite 
channels interact and affect each other is an area where more research is needed, especially as new technologies of digital communication develop and as the channels blur and become harder to identify. Some diffusion scholarship challenged traditionally dichotomous perspectives of mass media and interpersonal channels (Valente \& Saba, 1998; Rogers, 1999). Contemporary scholarship has shown that emergent digital tools can function at the intersection of interpersonal communication and mass communication, creating a new conceptual space termed masspersonal communication (O’Sullivan \& Carr, 2017). There may be need for a revised diffusion frame that understands cosmopolite and localite channels as interactive and interwoven with each other in the contemporary media landscape that intertwines with interpersonal communication.

Finally, and perhaps most important, is the conclusion that DOI can function as a framework for strategic issues management. The issue of water contamination from fertilizer runoff resulted in the need to engage in issues management activities. As discussed earlier, the Toledo water crisis was a focusing event for the issue of fertilizer runoff and produced a great deal of support for legislation governing fertilizer application. It was to the advantage of the fertilizer industry and its trade association to resolve the issue through voluntary means rather than through legislation and regulation. The potential threat of regulation may serve as an additional persuasive factor, motivating farmers to adopt the $4 \mathrm{R}$ principles. Regulation through legislation would put limits on the industry and likely make it more difficult for farmers to operate. Threat of regulation may function as appeals to relative advantage and compatibility within campaigns seeking to encourage the voluntary adoption of innovations, such as in the $4 \mathrm{R}$ Nutrient Stewardship Program. The most direct way to address the issue of potential regulation was to reduce the level of fertilizer runoff, and the $4 \mathrm{R}$ campaign sought to do so by influencing fertilizer application behaviors of farmers. For the $4 \mathrm{R}$ campaign to be successful as an issues 
management program, it needed to visibly demonstrate efforts were being made and especially show success in reducing runoff. Based on the results of this study, it appears the campaign has impacted the practices of many farmers.

This study suggests the diffusion of an innovation may be used to inform the management of public policy issues. Public policy issues have the potential to significantly impact organizations, entire industries, and the people who depend on them. As discussed earlier, issues management is a way to limit and manage the resolution of an issue to mutually benefit the organization and stakeholders (Seeger, Sellnow, \& Ulmer, 2003). The demands for change created by issues can be approached using reactive, adaptive, and dynamic strategies (Jones \& Chase, 1979). The reactive strategy requires limited change and minimal adjustments, such a minor change in the chemical composition of fertilizer so as to reduce runoff. An adaptive strategy involves accommodating changes and making adjustments, such as reducing the amount of fertilizer sold. The dynamic strategy involves anticipating the changes and, in some cases, creating policy options that primarily favor the organization (Jones \& Chase, 1979). This approach might involve reducing or limiting regulation. A dynamic approach that anticipates issues and tries to frame issues in ways that are supportive of any organization's larger goals is referred to as a catalytic strategy (Crable \& Vibbert, 1985). The Fertilizer Institute influencing the definition of sustainable agriculture as "most efficient use of non-renewable resources" in the 1991 Farm Bill could be considered a catalytic strategy (TFI, 2016b, NP). As the 4R campaign shows, diffusing an innovation can be used in some cases as a catalytic strategy for issues management.

In the case of the $4 \mathrm{R}$ campaign, persuasive efforts were directed to changing how the products (fertilizer) of the Fertilizer Institute's member organizations were used by consumers. 
While this approach may be thought of as an example of a catalytic strategy, a more appropriate description may be the use of innovation as an issues management strategy. In the case of the $4 \mathrm{R}$ Nutrient Stewardship Program, a campaign is used both to change behaviors in innovative ways that address the issue and to demonstrate the issue is being resolved. The $4 \mathrm{R}$ campaign was not a case of an organization adapting its own behavior to address a public policy issue, it was a case of a trade association seeking to persuade the customers of its member organizations to change their behavior by adopting innovative practices to address the issue. Heath and Palenchar (2009) suggested issues management involves crisis management, public relations, media relations, public affairs, and strategic planning in combination. This study suggests issues management may also involve the diffusion of innovations tempered by principles of campaign design in ways that are specific to the issue. An innovation may reduce the saliency of the issue and therefore push the issue into dormancy. At the very least, an innovation may allow the organization to demonstrate it is working to manage the issue. Over time, the innovation may be shown to effectively resolve the issue. In addition, Jones and Chase's (1979) framework for issues management strategies only addresses the level of change. Understanding the specific kind and scope of change for which the organization undertakes or advocates in response to an issue could help expand issues management scholarship.

\section{Limitations and Future Research}

The conclusions of this study should be interpreted within the context of several important limitations. These limitations also suggest future areas of research. First, the data from the study were limited. Data were collected by researchers at Ohio State University, focusing within a limited geographic area and on one specific innovation campaign. Scholars should be careful to not quickly generalize from this study nor to expect these results to be consistent in 
other campaign contexts. The survey used to collect data on the 4R program in the Maumee River Watershed focused on a broad set of factors and did not collect detailed information about the communication practices of specific sources of information or the larger social structure of the community. Subsequent work could explore these questions in greater detail with a more targeted survey instrument. This survey instrument could more rigorously investigate respondents' perceptions of the campaign, as well as sources and channels, to explore how these relate to respondents' perceptions of the value added by innovations. This study also suggests other investigations of different issues and different regions may be helpful in creating a general understanding of how diffusion functions in issues management.

Second, it is important to examine how specifically innovations may affect the ways public policy issues develop and may be resolved. The 4R innovations do not eliminate fertilizer runoff; however, they may reduce some of the harm by limiting the risks associated with runoff. Further investigation should explore the use of DOI explicitly as an issues management strategy. This includes determining if the innovation actually resolved the issue. While public calls for government regulation appear to have been reduced, another event such as the Toledo water crisis could reactivate the issue and demonstrate the limits of the 4R Nutrient Stewardship Program.

Third, this study did not trace the diffusion of the $4 \mathrm{R}$ principles over time and only examined one small stage of the issues management lifecycle regarding water contamination from runoff. It may be that the successful diffusion of the $4 \mathrm{R}$ principles through this campaign will move the issue of fertilizer runoff to the dormant stage. It is also reasonable to suggest other major events, such as the Toledo water crisis, will reactivate the issue. Examining the issue at several points in the issue's lifecycle is important to creating a complete understanding of how 
this and other campaigns function in supporting innovations as issues management strategies. Longitudinal or series research is important to understanding how diffusion progresses and its connection to focusing events such as harmful algal blooms.

A fourth limitation concerns the lack of information about how the campaign was developed and what specific goals were pursued by the Fertilizer Institute. As with other investigations of public communication campaigns and issues management efforts, the goals must be inferred to a large degree. Organizations are usually unwilling to open their internal decision-making and strategy deliberations to researchers. In an August 2017 blog post, Lara Moody, the Fertilizer Institute's vice president of stewardship and sustainability programs, wrote:

All sectors of the fertilizer industry are on board with increasing 4R adoption. Fertilizer application practices are at the center of our industry. Say it's a nice slogan if you want, but applying the right source, at the right rate, the right time and in the right place provides a unifying and actionable message. It has brought significant resources and voices to addressing water quality challenges and preventing nutrient loss (Moody, 2017).

This post indicates the Fertilizer Institute has positioned the 4R campaign as a unifying and comprehensive solution to the fertilizer runoff problem in the Maumee River Watershed. The 4R campaign is the Fertilizer Institute's primary way of addressing the fertilizer runoff issue and supports one of its primary goals: "To effectively address issues impacting TFI member companies" (TFI, 2016a, NP).

An additional limitation concerns other persuasive tactics employed by the Fertilizer Institute that relate to other parts of the Institute's mission, target other audiences, or were not exclusive or significant components of the 4R Nutrient Stewardship Program in Ohio. The 
Fertilizer Institute employs a number of additional efforts to promote the $4 \mathrm{R}$ principles, including an annual conference, press releases, speakers, YouTube videos, and partnerships with other credible organizations, such as The Nature Conservancy. As these tactics did not directly pertain to the 4R Nutrient Stewardship Program or the Maumee Watershed, these tactics were not described as part of the campaign or considered as potential sources of information. An exhaustive analysis of all campaign materials related to the $4 \mathrm{R}$ principles in all geographic contexts was outside the scope of this research. The Fertilizer Institute also actively engages in direct lobbying efforts at the state and national level. These efforts were not systematically explored in the current study but should be examined as part of a comprehensive effort to understand trade association campaigns more broadly.

The role of social media in this and other DOI efforts may be especially important in future investigations. Social media, with its very immediate reach and ability to disseminate user-produced content, can blur the lines among localite and cosmopolite channels, mass media and interpersonal channels, and organizational and peer-to-peer communication. Social media will create new ways of effectively disseminating innovations. Digital opinion leaders and change agents can be especially important in the diffusion of innovations. In some cases, these leaders are recruited as a way to enhance the effectiveness of a campaign. Analysis of the patterns of Twitter use, for example, may help clarify the role social media can play (Nisbet \& Kotcher, 2009). Social media may increasingly be a key component to spark or fuel WOM communication. In addition, as the demographic characteristic of the farming community change and becomes younger, patterns of social media use may change.

In addition to the future research discussed, this investigation revealed some aspects of the role of industry trade associations in issues management. While others have suggested trade 
associations play an influential role in issues management, this area of research should be more broadly examined. Frandsen and Johansen (2015) suggested trade associations are intermediaries in strategic communication activities. They can leverage additional resources and coordinate messages in a way that mediates the relationship between the organization and stakeholders. A trade association represents the member organization to further its interests and can help member organizations speak with a unified voice (Frandsen \& Johansen, 2015). As representatives of entire industries, trade associations are also very powerful. The Fertilizer Institute notes that in 2016, the industry generated more than $\$ 139$ billion in economic benefit and provided more than 80,000 direct jobs (TFI, 2016a). The Fertilizer Institute's public communication and issues management outputs by most measures are very sophisticated. Other powerful trade associations, such as the National Tobacco Institute, the American Medical Association, the Business Roundtable, and the National Rifle Association, also exhibit significant influence over public policy issues. This study suggests trade associations can facilitate innovation to address issues that impact entire industries. Trade associations may command significant resources and influence, and their issues management and public communication efforts should be more fully investigated for how they are designed, executed, and measured.

The sources of information identified as important for innovation should also be explored. Specifically, the ways existing community members can function as change agents requires more study. In this case, opinion leaders were given both informational resources in the form of the $4 \mathrm{R}$ brochure and A Pocket Guide to $4 R$ Nutrient Stewardship, and incentives through the $4 \mathrm{R}$ certification program. Understanding how opinion leaders functioned as change agents for the 4R Nutrient Stewardship Program may clarify the underlying influence of these individuals in peer-to-peer interactions using word-of-mouth communication. Further exploring 
how these change agents communicate using cosmopolite and localite channels may reveal new aspects about the process of diffusion. Finally, it may be helpful to explore how these agents use resources and specific channels to promote innovation. Social media, for example, may have the potential to change DOI campaigns by allowing for some of the elements promoting innovation to be communicated more efficiently.

Finally, this study suggests the need to examine other public communication campaigns through the framework of innovation as an issues management strategy. There are a number of industries and fields, such as energy and health, where innovations are critical. Many of these have been understood as persuasive campaigns or issues management campaigns, but examining them as innovation campaigns may provide new insights into how they are designed and how they function. Many innovation campaigns may function as strategic issues management campaigns.

\section{Conclusion}

Water is necessary for life, and water systems are threatened by a number of factors, including population growth, commercialization of water resources, competition, climate change, and contamination. Educating people about innovative practices and technologies, encouraging support for these practices, and facilitating adoption and diffusion of these innovations, are necessary to protect water resources. Behavioral change is also necessary to manage many other public issues that impact both society and organizations. One effective way behavior is changed is through persuasive campaigns.

Scholarship regarding persuasive campaigns, including public communication campaigns, is one of the most vibrant fields of communication research (Botan, 1997, Han \& Zhang, 2009; Hanan, 2009). Researchers have been adept at responding to the changing face of 
public communication practice, and this research has, in turn, informed the methods and processes of public persuasion, yet more research is needed. As described earlier, theories of design and evaluation are often crafted to examine specific campaigns in specific contexts. Most often these frames examine campaigns retrospectively. Principles and theories with broader applicability that allow scholars to examine campaigns in new contexts are needed (Tyma, 2008). Developing new frames for campaign research is important to both enhance the effectiveness of campaigns and to understand how organizations, including powerful trade associations, influences issues, public policies, and behaviors. These new frames can also inform communication practice by enhancing campaign design. Scholars should thus continue to test and evaluate theories, especially DOI, in specific case contexts, such as the 4R Nutrient Stewardship Program, to continue to expand and refine this area of scholarship. 


\section{REFERENCES}

Achenbach, J. (2008, July 9). 'Dead Zones' appear in waters worldwide. Washington Post. Retrieved from http://www.washingtonpost.com/wpdyn/content/article/2008/08/14/AR2008081401910.html

Adams, R. J. (2014). Consumer deception or unwarranted product disparagement? The case of lean, finely textured beef. Business and Society Review, 119, 221-246. doi:

10.1111/basr.12031

AgCareer.com (2018). Crop Advisor. Retrieved from https://www.agcareers.com/careerprofiles/crop-advisor.cfm

Allen, G. (2016, July 9). 'A Government-sponsored disaster': Florida asks for federal help with toxic algae. Weekend Edition Sunday. Retrieved from http://www.npr.org/2016/07/09/485367388/a-government-sponsored-disaster-floridaasks-for-federal-help-with-toxic-algae

America on the Move, (2018). Seat Belt Campaigns. National Museum of American History. Retrieved from https://amhistory.si.edu/onthemove/themes/story_86_20.html

Auld, G., Gulbrandsen, L. H., \& McDermott, L. C. (2008). Certification schemes and the impacts on forest and forestry. Annual Review of Environment and Resources, 33, 187211. doi: 10.1146/annurev.environ.33.013007.103754

Barnett, M. (2013). One voice, but whose voice? Exploring what drives trade association activity. Business \& Society, 52, 213-244. doi: 10.1177/0007650309350211

Baumgart-Getz, A., Prokopy, L., \& Floress, K. (2012). Why farmers adopt best management practice in the United States: A meta-analysis of the adoption literature. Journal of Environmental Management, 96, 17-25. doi: 10.1016/j.jenvman.2011.10.006 
Benoit, W. L. (2006). President Bush's image repair effort on Meet the Press: The complexities of defeasibility. Journal of Applied Communication Research, 34, 285-306. doi: $10.1080 / 00909880600771635$

Birkland, T. A. (1997). After disaster: Agenda setting, public policy, and focusing events. Washington, D.C.: Georgetown University Press.

Birkland, T. A. (1998). Focusing events, mobilization, and agenda setting. Journal of Public Policy, 18, 53-74. doi: 10.1017/s0143814x98000038

Birkland, T. A., \& Warnement, M. K. (2013). Focusing events, risk, and regulation. North Carolina State University. Department of Public Administration, School of Public and International Affairs. Retrieved from http://kenan.ethics.duke.edu/wpcontent/blogs.dir/2/files/2013/10/Birkland-Warnement_final_1_22.pdf

Bodensteiner, C. A. (1995). Predicting public and media attention span for social issues. Public Relations Quarterly, 40(2), 14-19. doi: 10.1002/9781444361506.wbiems 133

Boone, K., Meisenbach, T., \& Tucker, M.A. (2000). Agricultural communications: Changes and challenges. Ames, IA: Iowa State University Press.

Botan, C. (1997). Ethics in strategic communication campaigns: The case for a new approach to public relations. Journal of Business Communication, 34, 188-202. doi: $10.1177 / 002194369703400205$

Bowen, S. A. (2007). Ethics and public relations. Gainesville, FL: Institute for Public Relations. Brulle, R. (2010). From environmental campaigns to advancing the public dialogue: Environmental communication for civic engagement. Environmental Communication: A Journal of Nature and Culture, 4, 82-98. doi: 10.1080/17524030903522397 
Carl, W. J. (2006). What's all the buzz about? Everyday communication and the relational basis of word-of-mouth and buzz marketing practices. Management Communication Quarterly, 19, 601-634. doi: 10.1177/0893318905284763

Center for Responsible Politics (2016). Annual Lobbying by Fertilizer Institute. Center for Responsible Politics. Retrieved from https://www.opensecrets.org/lobby/clientsum.php?id=D000025789

Charles, D. (2013, May). A Fertilized World. National Geographic. Retrieved from http://ngm.nationalgeographic.com/2013/05/fertilized-world/charles-text

Chase, W. H. (1982). 'Issues management Conference - A Special Report', Corporate Public Issues and Their Management, 7: 1-2.

Chase, W. H. (1984). Issues management-Origins of the future., Stanford, CT: Issue Action Publications.

Coombs, W. T. (1992). The failure of the task force on food assistance: A case study of the role of legitimacy in issues management. Journal of Public Relations Research, 4, 101-122. doi: 10.1207/s1532754xjprr0402_03

Coombs, W. T. (2012). Parameters for crisis communication. In Coombs, W. T., \& Holladay, J. S. (Eds.), The handbook of crisis communication (pp. 17-53). Malden, MA: WileyBlackwell.

Courtright, J. L., \& Smudde, P. M. (2009). Leveraging organizational innovation for strategic reputation management. Corporate Reputation Review, 12(3), 245-269. doi: 10.1057/crr.2009.18

Crable, R. E., \& Vibbert, S. L. (1985). Managing issues and influencing public policy. Public Relations Review, 11(2), 3-16. doi: 10.1016/S0363-8111(82)80114-8 
Crook, B., Stephens, K. K., Pastorek, A. E., Mackert, M., \& Donovan, E. E. (2016). Sharing health information and influencing behavioral intentions: The role of health literacy, information overload, and the Internet in the diffusion of healthy heart information. Health Communication, 31(1), 60-71. doi:10.1080/10410236.2014.936336

Czepiel, J. A. (1974). Word-of-mouth processes in the diffusion of a major technological innovation. Journal of Marketing Research, 11, 172-180. doi: 10.2307/3150555

Daugherty, E. (2005). Collateral. In R. L. Heath (Ed.), Encyclopedia of public relations. (Vol. 1, pp. 140-141). Thousand Oaks, CA: Sage.

Dearlove, J. V., Bialous, S. A., \& Glantz, S. A. (2002). Tobacco industry manipulation of the hospitality industry to maintain smoking in public places. Tobacco Control, 11(2), 94104. doi: 10.1136/tc.11.2.94

Dougall, E. (2008, December 12). Issues Management. Institute for Public Relations. http://www.instituteforpr.org/issues-management/

EPA (2016). Nonpoint source: Agriculture. US Environmental Protection Agency. Retrieved from https://www.epa.gov/polluted-runoff-nonpoint-source-pollution/nonpoint-sourceagriculture

Farmland Information Center (2017). Farmland Information Center. Retrieved from www.farmlandinfo.org/

Falconer, I. R. (1998). Algal toxins and human health. In Hrubec, J. (Ed.) Quality and treatment of drinking water II. (pp. 53-82). Berlin, Heidelberg: Springer.

Feder, G., \& Savastano, S. (2006). The role of opinion leaders in the diffusion of new knowledge: The case of integrated pest management. World Development, 34. 12871300. doi: $10.1596 / 1813-9450-3916$ 
Felton, C. (2017, August 15). Lake Erie water quality has improved, but much more can be done, experts say. The News-Herald. Retrieved from http://www.newsherald.com/article/HR/20170715/NEWS/170719571

Ferguson, S. D. (1999). Communication planning: An integrated approach. Thousand Oaks, CA: Sage.

Festinger, L. (1954). A theory of social comparison processes. Human Relations, 7, 117-140. doi: $10.1177 / 001872675400700202$

Frandson, F., \& Johansen, W. (2015). Organizations, stakeholders, and intermediaries: towards a general theory. International Journal of Strategic Communication, 9(4), 253-271. doi: 10.1080/1553118X.2015.1064125

Freeman, S. (2002). Biological science. Upper Saddle River, NJ: Prentice Hall.

Gregory, A. (2010). Planning and managing public relations campaigns. London: Kogan Page Publishers.

Grunig, J. E. (1999). Measuring the value of public relations by measuring the qualities of relationships between organizations and publics. In T. Achelis (Ed.), PR baut Brucken (pp. 175-190). Munich, Germany: DPRG (German Public Relations Association).

Grunig, J. E. (2001). Two-way symmetrical public relations: Past, present, and future. In R. L, Heath (Ed) Handbook of public relations. (pp. 11-30). Thousand Oaks, CA: Sage.

Grunig, J. E. (2009). Paradigms of public relations in an age of digitalization. Prism 6(2). 1-16. doi: $10.4135 / 9781452220727 . n 5$ 
Grunig, J. E., \& Grunig, L. A. (2008). Excellence theory in public relations: Past, present, and future. In A. Zerfass, B. van Ruler, \& K. Sriramesh (Eds.). Public relations research: European and international perspectives and innovations (pp. 327-347). Wiesbaden, German: VS Verlag.

Grunig, J. E., \& Hunt, T. T. (1984). Managing public relations. Boston, MA: Holt, Rinehart and Winston.

Grupp, R. (2010). The Barcelona Declaration of Research Principles. Institute for Public Relations. Retrieved from http://www.instituteforpr.org/the-barcelona-declaration-ofresearch-principles/

Haider, M., \& Kreps, G. (2010). Forty years of diffusion of innovations: Utility and value in public health. Journal of Health Communication, 9, 3-11. doi:

$10.1080 / 10810730490271430$

Han, G., \& Zhang, A. (2009). Starbucks is forbidden in the Forbidden City: Blog, circuit of culture and informal public relations campaign in China. Public Relations Review, 35, 395-401. doi: 10.1016/j.pubrev.2009.07.004

Hanan, M. A. (2009). HIV/AIDS prevention campaigns: A critical analysis. Canadian Journal of Media Studies, 5, 129-158. http://cjms.fims.uwo.ca/issues/05-01/hanan.pdf

Hayes, R. A., \& Smudde, P. M. (2015). The incident: Not just another organizational disruption. Journal of Public Relations Research, 27(5), 416-430. doi:

10.1080/1062726X.2015.1086652

Heath, R. L. (1988). The rhetoric of issue advertising: A rationale, a case study, a critical perspective - and more. Communication Studies, 39, 99-109. doi:

$10.1080 / 10510978809363241$ 
Heath, R. L. (2002). Issues management: Its past, present and future. Journal of Public Affairs, 2, 209-214. doi: 10.1002/pa.114

Heath, R. L. (2005). Issues Management. In R. L. Heath (Ed). Encyclopedia of public relations. (pp. 460-463). Thousand Oaks, CA: Sage.

Heath, R. L., \& Palenchar, M. J. (2009). Strategic issues management: Organizations and public policy challenges. Los Angeles, CA: Sage.

Heffernan, C., Thomson, K., \& Nielsen, L. (2008). Livestock vaccine adoption among poor farmers in Bolivia: Remembering innovation diffusion theory. Vaccine, 26, 2433-2442. doi: 10.1016/j.vaccine.2008.02.045

Henry, T. (2015, August 23). Explaining Toledo's water treatment process. The Toledo Blade. Retrieved from http://www.toledoblade.com/A-E/2015/08/23/Explaining-Toledo-s-watertreatment-process.html

Henry, T. (2016, July 24). Lake Erie, S. Florida algae crisis share common toxins and causes. The Toledo Blade. Retrieved from http://www.toledoblade.com/local/2016/07/24/LakeErie-S-Florida-algae-crises-share-common-toxins-and-causes.html

Heong, K. L., Escalada, M. M., Huan, N. H., \& Mai, V. (1998). Use of communication media in changing rice farmers' pest management in the Mekong Delta, Vietnam. Crop Protection, 17, 413-425. doi: 10.1016/s0261-2194(98)00036-2

Hesse, G. (2017, August 2). Three Years Since the Toledo Drinking Water Crisis. [Blog post]. National Wildlife Federation. Retrieved from http://blog.nwf.org/2017/08/three-yearssince-the-toledo-drinking-water-crisis 
Holzer, B. (2008). Turning stakeseekers into stakeholders: A political coalition perspective on the politics of stakeholder influence. Business \& Society, 47, 50-67. doi:

$10.1177 / 0007650307306341$

ICWE (1992). The Dublin statement. World Meteorological Organization. Retrieved from http://www.wmo.int/pages/prog/hwrp/documents/english/icwedece.html

Jaques, T. (2007). Issues management and crisis management: An integrated, non-linear, relational construct. Public Relations Review, 33, 147-157. doi:

10.1016/j.pubrev.2007.02.001

Jaques, T. (2009). Issue and crisis management: Quicksand in the definitional landscape. Public Relations Review, 35, 280-286. doi: 10.1016/j.pubrev.2009.03.003

Johnston, L. (2017, September 27). 2017 harmful algal bloom blossoms across Lake Erie, as Toledo mayor wants water designated 'impaired'. Cleveland.com. Retrieved from http://www.cleveland.com/metro/index.ssf/2017/09/2017_harmful_algal_bloom_bloss.ht $\mathrm{ml}$

Jones, B. L., \& Chase, W. H. (1979). Managing public policy issues. Public Relations Review, 5(2), 3-23. doi: 10.1177/1558689806298224

Kent, M., \& Taylor, M. (1998). Building dialogic relationships through the world wide web. Public Relations Review, 24, 321-334. doi: 10.1016/s0363-8111(99)80143-x

Kent, M. L., \& Taylor, M. (2002). Toward a dialogic theory of public relations. Public Relations Review, 28, 21-37.

Kingdon, J. W. (1993). How do issues get on public policy agendas. In W.J. Wilson (Ed.). Sociology and the public agenda, pp.40-50. London, England: Sage. 
Kingdon, J. (2003). Agendas, alternatives, and public policies. (2nd ed.) Longman Classics in Political Science. New York, NY: Longman.

Kirby, A. (1988). Trade associations as information exchange mechanisms. The RAND Journal of Economics, 19(1). 138-146. doi: 10.2307/2555403

Lim, S., Goh, J., \& Sriramesh, K. (2005). Applicability of the generic principles of excellent public relations in a different cultural context: The case study of Singapore. Journal of Public Relations Research, 17, 315-340. doi: 10.1207/s1532754xjprr1704_1

Mahler, A., \& Rogers, E. M. (1999). The diffusion of interactive communication innovations and the critical mass: the adoption of telecommunications services by German banks. Telecommunications policy, 23, 719-740. doi: 10.1016/S0308-5961(99)00052-X

Mangold, W. G., \& Faulds, D. J. (2009). Social media: The new hybrid element of the promotion mix. Business Horizons, 52, 357-365. doi: 10.1016/j.bushor.2009.03.002

MDARD. (2018, March 7). Michigan releases final plan to improve Lake Erie water quality. Retrieved from https://www.michigan.gov/mdard/0,4610,7-125-1660-462931--,00.html

Manta. (2017). Fertilizers in Ohio. Retrieved from https://www.manta.com/mb_45_B610505L_36/fertilizer/ohio

Martin, J. (2016, June 15). The Nature Conservancy and The Fertilizer Institute Join Forces in Nutrient Stewardship Partnership. The Fertilizer Institute. Retrieved from https://www.tfi.org/the-feed/nature-conservancy-and-fertilizer-institute-join-forcesnutrient-stewards

McCarthy, E. J. (1978). Basic marketing: a managerial approach. Toronto: RD Irwin. Moffitt, M. A. (1999). Campaign strategies and message design. Westport, CT: Praegar 
Moffitt, M. A. (2005). Campaign. In R. Heath (Ed). Encyclopedia of public relations. (pp. 109111). Thousand Oaks, CA: Sage.

Molotch, H., \& Lester, M. (1975). Accidental news: The great oil spill as local occurrence and national event. The American Journal of Sociology, 81, 235-260. doi: 10.1086/226073

Moody, L. (2017, August 10). It Begins with the 4Rs. [Blog post]. Retrieved from https://www.tfi.org/the-feed/it-begins-with-the-4Rs

Moreo, N. (2016). Why is Measurement Usually an Afterthought? Institute for Public Relations. Retrieved from http://www.instituteforpr.org/measurement-usually-afterthought/

Morris, N. (2003). A comparative analysis of the diffusion and participatory models in development communication. Communication Theory, 13, 225-248. doi: $10.1093 / \mathrm{ct} / 13.2 .225$

Moss, D. A. (2005). Strategies. In R. L. Heath (Ed.), Encyclopedia of public relations. (pp. 823826). Thousand Oaks, CA: Sage.

Mulgan, G., Tucker, S., Ali, R., \& Sanders, B. (2007). Social innovation: what it is, why it matters and how it can be accelerated. Skoll Centre for Social Entrepreneurship, Oxford.

National Shooting Sports Foundation. (2018). Project ChildSafe. Retrieved from https://www.nssf.org/safety/project-childsafe/

Nisbet, M. C., \& Kotcher, J. E. (2009). A two-step flow of influence? Opinion-leader campaigns on climate change. Science Communication, 30, 328-354.

Nyilasy, G. (2006). Word of mouth: What we really know - and what we don't. In J. Kirby \& P. Marsden (Eds.), Connected marketing: the viral, buzz and word of mouth revolution (pp. 161-184). New York, NY: Elsevier.

OABA. (2016). Ohio AgriBusiness Association. Retrieved from www.oaba.net 
Ohio Legislature (2018). Senate Bill 1. Retrieved from https://www.legislature.ohio.gov/legislation/legislation-summary?id=GA131-SB-1

Ohio Environmental Protection Agency (2018a). Maumee River Watershed. Retrieved from http://www.epa.state.oh.us/dsw/tmdl/maumeeriver.aspx

Ohio Environmental Protection Agency (2018b). Ohio Integrated Water Quality Monitoring and Assessment Report 2018. Retrieved from http://www.epa.ohio.gov/dsw/tmdl/OhioIntegratedReport.aspx\#1798510166-summaryof-2018-report)

Okaka, W. (2010). Developing regional communications campaigns strategy for environment and natural resources management policy awareness for the East African community. Res Journal of Environmental Earth Sciences, 2, 106-111.

O'Sullivan, P. B., \& Carr, C. T. (2018). Masspersonal communication: A model bridging the mass-interpersonal divide. New Media \& Society, 20, 1161-1180. doi:

\section{$10.1177 / 1461444816686104$}

PRSA (2017). About Public relations. Retrieved from http://apps.prsa.org/AboutPRSA/publicrelationsdefined/

Reardon, K., \& Rogers, E. M. (1988). Interpersonal versus mass media communication: A false dichotomy. Human Communication Research, 15, 284-303. doi: 10.1111/j.14682958.1988.tb00185.x

Reynolds, C. (1997). Issues management and the Australian gun debate. Public Relations Review, 23, 343-360. doi: 10.1016/s0363-8111(97)90050-3

Rice, R., \& Atkin, C. (1981). Public communication campaigns. Thousand Oaks, CA: Sage. 
Riesenberg, L. E., \& Gor, C. O. (1989). Farmers' preferences for methods of receiving information on new or innovative farming practices. Journal of Agricultural Education, 30(3), 7-13. doi: 10.5032/jae.1989.03007

Rogers, E. M. (1999). Anatomy of the two subdisciplines of communication study. Human Communication Research, 25, 618-631. doi: 10.1111/j.1468-2958.1999.tb00465.x

Rogers, E. M. (2003). Diffusion of innovations. New York, NY: Simon \& Schuster.

Rogers, E. M. (2004). A prospective and retrospective look at the diffusion model Journal of Health Communication, 9, 13-19. doi: 10.1080/10810730490271449

Röling, N. G., \& Jiggins, J. L. S. (1994). Policy paradigm for sustainable farming. European Journal of Agricultural Education and Extension, 1, 23-43. doi: $10.1080 / 13892249485300041$

Roper, J. (2005). Symmetrical communication: Excellent public relations or a strategy for hegemony?. Journal of Public Relations Research, 17, 69-86. doi: 10.1207/s1532754xjprr1701_6

Ryan, B., \& Gross, N. C. (1943). The diffusion of hybrid seed corn in two Iowa communities. Rural Sociology, 8, 15-24. doi: 10.3386/w14141

Schwartz, L. A. (1994). The role of the private sector in agricultural extension: Economic analysis and case studies (pp. 54-54). London, England: ODI.

Seeger, M. W., Sellnow, T. \& Ulmer, R. (2003). Communication and organizational crisis. Westport, CT: Praeger.

Seeger, M. W, \& Seeger, H. (2017). “Don’t Drink the water: Warning Communication in a Northern Ohio Water Emergency.” In Casing risk and crisis communication, In C. Leiberman, T. Avtgis \& D. Rodriguez (Eds.), Dubuque, IA: Kendall Hunt. 
Seewer, J. (2015, June 13). Ohio, Michigan, Ontario to curb phosphorus runoff feeding Lake Erie algae. The Columbus Dispatch. Retrieved from http://www.dispatch.com/content/stories/local/2015/06/13/ohio-michigan-ontario-tocurb-phosphorus-runoff-feeding-lake-erie-algae.html

Seewer, J. (2017, February 14). Ohio moves forward with strategy to combat Lake Erie's algae. The Morning Journal News. Retrieved from http://www.morningjournal.com/generalnews/20170214/ohio-moves-forward-with-strategy-to-combat-lake-eries-algae

Sellnow, D. D., \& Sellnow, T. L. (2014). The challenge of exemplification in crisis communication. Journal of Applied Communications, 98(2), 5. doi: 10.4148/10510834.1077

Sheth, J. N. (1971). Word-of-Mouth in low risk innovations. Journal of Advertising Research, 11(3), 15-18. https://www.researchgate.net/publication/235361640_Word-ofMouth_in_Low-Risk_Innovations

Smith, R. (2002). Strategic Planning for Public Relations. Mahwah, NJ: Lawrence Erlbaum Associates.

Smith, E. A., \& Malone, R. E. (2006). 'We will speak as the smoker': the tobacco industry's smokers' rights groups. The European Journal of Public Health, 17(3), 306-313. doi: 10.1093/eurpub/ck1244

Smudde, P. (2001). Issue or crisis: A rose by any other name... Public Relations Quarterly, 46(4), 34-36. doi: 10.1099/00221287-147-1-1

Smudde, P. M. (2011). Public Relations as Dramatistic Organizing: A Case Study Bridging Theory and Practice. Cresskill, NJ: Hampton. 
Smudde, P. M., \& Courtright, J. L. (2015). In C. E. Caroll (Ed.). Form Following Function: Message Design for Managing Corporate Reputations. The Handbook of Communication and Corporate Reputation, 404-417. New York, NY: Wiley-Blackwell.

Snyder, L. B., Hamilton, M. A., Mitchell, E. W., Kiwanuka-Tondo, J., Fleming-Milici, F., \& Proctor, D. (2004). A meta-analysis of the effect of mediated health communication campaigns on behavior change in the United States. Journal of Health Communication, 9(S1), 71-96. doi: 0.1080/10810730490271548

Snyder. (2018). 4R Nutrient Stewardship Program celebrates four year anniversary. Ohio Farm Bureau. Retrieved from https://ofbf.org/2018/03/29/4r-nutrient-stewardship-certificationprogram-celebrates-four-year-anniversary/

Southwell, B. G., \& Yzer, M. C. (2007). The roles of interpersonal communication in mass media campaigns. Annals of the International Communication Association, 31(1), 420462. doi: $10.1080 / 23808985.2007 .11679072$

Sriramesh, K. (2010). Globalization and Public Relations: Opportunities for growth and reformulation. In R. Heath (Ed.), The handbook of public relations $\left(2^{\text {nd }}\right.$ ed.), Thousand Oaks, CA: Sage. 691-707.

Stewart, W. M., Dibb, D. W., Johnston, A. E., \& Smyth, T. J. (2005). The contribution of commercial fertilizer nutrients to food production. Agronomy Journal, 97(1), 1-6. doi:10.2134/agronj2005.0001

Swasy, A. (2016). A little birdie told me: factors that influence diffusion of twitter in newsrooms. Journal of Broadcasting \& Electronic Media, 60(4), 643-656. doi: $10.1080 / 08838151.2016 .1234480$

TFI (2016a). The Fertilizer Institute. Retrieved from www.tfi.org 
TFI (2016b). State of the Fertilizer Industry Report. The Fertilizer Institute. Retrieved from www.tfi.org/sites/default/files/tfi_soi_report.pdf

Tucker, M. (1996). Ferment in our field: Viewing agricultural communication research from a social science perspective. Journal of Applied Communications, 80(4), 4. doi: $10.4148 / 1051-0834.1332$

Tsukayama, H. (2013, March 21). Twitter turns 7: Users send over 400 million Tweets per day. The Washington Post. Retrieved from articles.washingtonpost.com/2013-03-21/business/ 37889387_1_tweets-jack-dorsey-twitter

Tyma, A. W. (2008). Public relations through a new lens-critical praxis via the excellence theory. International Journal of Communication, 2, 193-205. https://digitalcommons.unomaha.edu/cgi/viewcontent.cgi?article=1028\&context=commf acpub

Ulmer, R. R., Seeger, M. W., \& Sellnow, T. L. (2005). Stakeholder theory. In R. L. Heath (Ed.), Encyclopedia of public relations, (Vol. 2, pp. 808-811). Thousand Oaks, CA: Sage.

Unay Gailhard, İ., Bavorová, M., \& Pirscher, F. (2015). Adoption of agri-environmental measures by organic farmers: the role of interpersonal communication. The Journal of Agricultural Education and Extension, 21(2), 127-148. doi:

$10.1080 / 1389224 x .2014 .913985$

USDA (2017). Fertilizer Use \& Markets. Retrieved from https://www.ers.usda.gov/topics/farmpractices-management/chemical-inputs/fertilizer-use-markets/

U.S. National library of Medicine. (2016). Visual Culture and Health Posters. Profiles in Science. Retrieved from https://profiles.nlm.nih.gov/ps/retrieve/ResourceMetadata/VCBBGV 
Valente, T. (1993). Diffusion of innovations and policy decision-making. Journal of Communication, 43, 30-45. doi: 10.1111/j.1460-2466.1993.tb01247.x

Valente, T., \& Davis, R. (1999). Accelerating the diffusion of innovations using opinion leaders. Annals of the American Academy of Political and Social Science, 566, 55-67. doi: $10.1177 / 000271629956600105$

Valente, T., \& Rogers, E. M. (1995). The origins and development of the diffusion of innovations paradigm as an example of scientific growth. Science Communication, 16, 242-273. doi: 10.1177/1075547095016003002

Valente, T. W., \& Saba, W. P. (1998). Mass media and interpersonal influence in a reproductive health communication campaign in Bolivia. Communication Research, 25, 96-124. doi: $10.1177 / 009365098025001004$

Vercic, D., Grunig, L. A., \& Grunig, J. E. (1996). Global and specific principles of public relations: Evidence from Slovenia. In Hugh M. Culbertson, Ni Chen (eds) International Public Relations: A Comparative Analysis, 31-65. Mahwah, NJ: Lawrence Erlbaum Associates,

Watts, D. J., \& Dodds, P. S. (2007). Influentials, networks, and public opinion formation. Journal of Consumer Research, 34, 441-458. doi: 10.1086/518527

Wilkins, K. (2000). Accounting for power in development communication. In K.G. Wilkins (Ed.) Redeveloping communication for social change: Theory, practice, and power (pp. 197-210). Lanham, MD: Rowman \& Littlefield.

Wilson, R. S., \& McCormick, B. R. (2017). Retrieved from http://4Rcertified.org/wpcontent/uploads/2017/05/Prokup.etal_.2017.4R-Nutrient-Stewardship-in-the-westernLake-Erie-basin.pdf 
Wines, M. (2014, August 5). Behind Toledo's water crisis, a long-troubled Lake Erie. The New York Times. Retrieved from http://www.nytimes.com/2014/08/05/us/lifting-ban-toledosays-its-water-is-safe-to-drink-again.html?_r=0

WTOL 11. (2016). Fertilizer certification training offered in northwest Ohio. Retrieved from http://www.wtol.com/story/31142593/fertilizer-certification-training-offered-innorthwest-ohio. 


\section{APPENDIX A: SAMPLE TWITTER MESSAGES}

〔】 4R Nutrients Retweeted

Morgan @MorganSmallman·26 Jul 2017

Replying to @4Rnutrients @Fertilizer_Inst @CCASoundAdvice

It took our \#Farm a couple of years worth of trials. But we adapted our whole \#crop to \#4R \#Sustainable \#Practice
Q 1
七】 1
O 2
9

4R Nutrients @4Rnutrients · 7 Aug 2017

Congratulations Melinda Sposari of @Fertilizer_Inst for winning the first ever Honorable Mention capstone project award @PurdueAgBiz on \#4R

4R Nutrients @4Rnutrients · 23 Aug 2017

New \#4R practice- Variable rate $\mathrm{N}$ and modeling as confidence in data improves \#farmerpanel \#4Rfieldday
Q
〔】
○ 5

4R Nutrients @4Rnutrients · 23 Aug 2017

New \#4R practice - satellite images - less time than drones, to get idea of where the crop is going. \#farmerpanel \#4Rfieldday

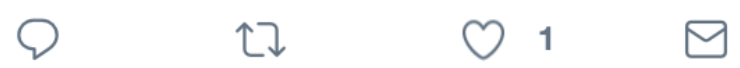

4R Nutrients @4Rnutrients·23 Aug 2017

New \#4R practice - grid soil sampling with yield and variable rate nutrients to monitor changes in the soil \#farmerpanel \#4Rfieldday
Q
个2
O 2

〔】 4R Nutrients Retweeted

4R Certified @4RCertified·31 Aug 2017

A new video by @nature_org shows how \#agretailers are working with cities like Toledo to improve \#waterquality 
4R Nutrients @4Rnutrients · 6 Sep 2017

Best of Indiana Ag continues to inspire us on the \#CTICTour. @ISDAgov

@IndianaNRCS@INCornFarmers

4R Nutrients @4Rnutrients.13 Oct 2017

Enjoying breakfast \& tea at my desk \& appreciating access to tasty \& nutritious food. \#FertilizerDay @Fertilizer_Inst

4R Nutrients @4Rnutrients.13 Oct 2017

"2 out of Every 5 People on Earth Today Owe Their Lives to Fertilizer" @BillGates Happy Global \#FertilizerDay
Q
^】
O 2
9

4R Nutrients @4Rnutrients · 15 Oct 2017

Fear can never feed the world.....

4R Nutrients @4Rnutrients · 15 Nov 2017

California fruit \& vegetable growers find success with \#4R

westernfarmpress.com/sustainability... @Fertilizer_Inst

4R Nutrients @4Rnutrients · 13 Dec 2017

\#4R practices in the field are the start to reducing nutrient losses that can also help the farmers bottom line @ISUAgWaterMgmt

4R Nutrients@4Rnutrients·Feb 13

The \#4Rs are an economic system not just a conservation system. The efficient producers understand the value of \#4Rs to giving them added value over their peers. @StromGrant @Fertilizer_Inst \#tfiannual @agripulse
Q
† 6
○ 9 
APPENDIX B: THE BROCHURE

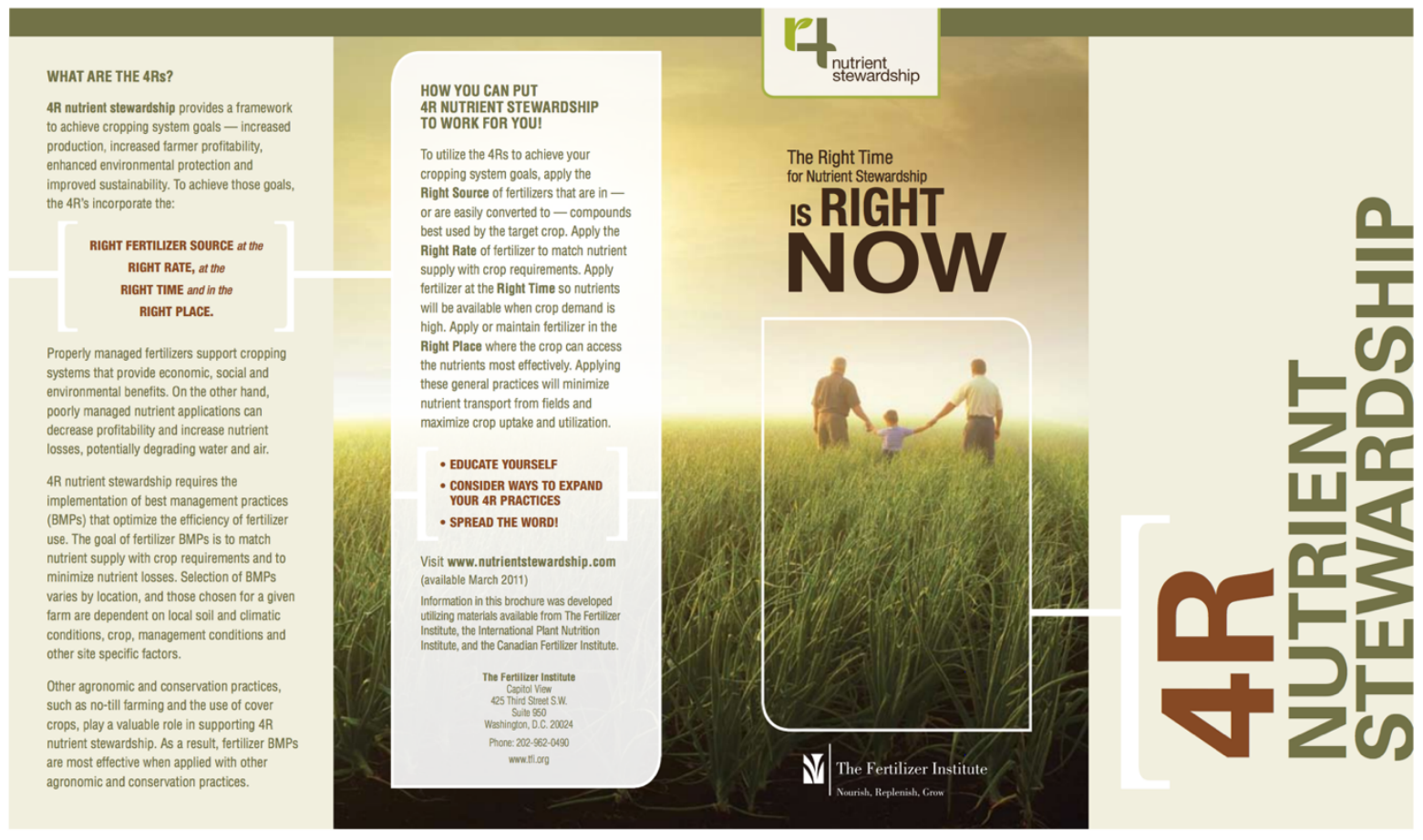

\section{WHY USE THE 4RS RIGHT NOW?}

\section{AGRICULTURE IS FACING CHALLENGES}

\section{POPULATION PRESSURES}

Actording to the United Nations, the gobo: popolation will insrease by more than two billion people in the next 40 years, and many reports have indicated that food production needs so double by 2050 industry experts ayes that increased toos production will be achiemod ty intetssified crop production and not by an expandes arabie land base. Genatic and bioteces Setd industries have predictad niell incteases
of three to tour percant per yere, Howeres to optimice the yields of advanced sonds, tartilieg inguts must be optimizgd to provoste the greatest poitental for suxcess.
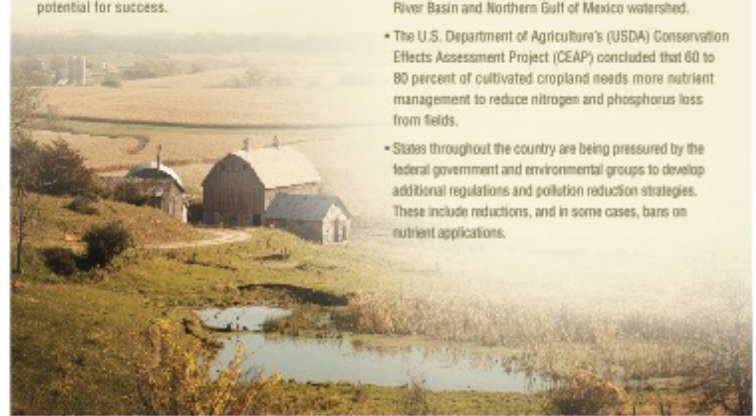

\section{REGULATORY PRESSURES}

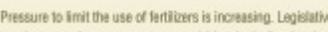

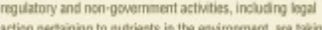

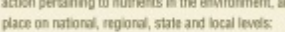

- Assesssments by he Emrionmental Probostion Apency have assigned ayriculture responsititity for 44 percest Chasepedak Bay.

-The National Academry of Sciences eth nitrogen-based

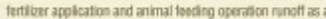

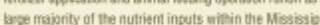

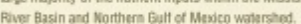
The U.S. Dipartoment of Agricuhares (USDA) Consenvation

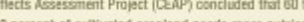

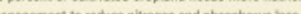
a of the nitroger and phosphorus being detivered to the

\section{ANSWERING THE CHALLENGE WITH AR NUTRIENT STEWARDSHIP}

AR nutriant stewardship can help $\quad$ 4R nutrient stewardship can help

IMPROVE AGRICULTURAL PRODUCTIVITY: MENIMIZE IMPACT TO THE ENVIRONMENT:

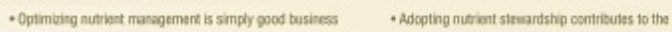

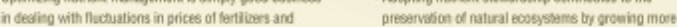

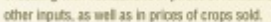

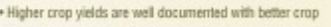
and soil managament. onless bend

- Improved bertlibar ettidengy increases the quartity

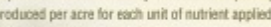
wetheyt sacrithing yian potemal.

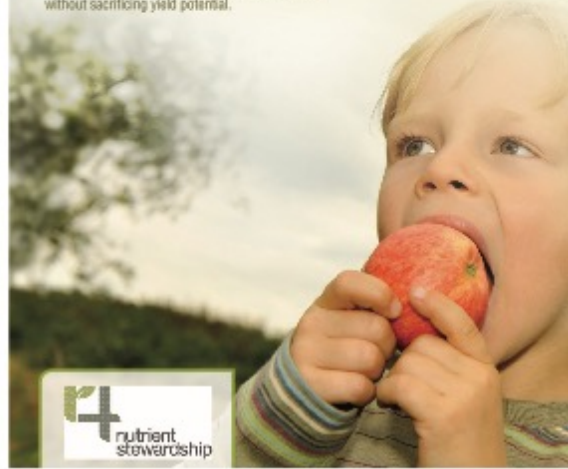




\section{APPENDIX C: SELECTIONS FROM THE 4R POCKET GUIDE}

CONCEPT

\section{The $4 \mathrm{R}$ Nutrient Stewardship Concept}

Fertilizer management, to be considered "right," must support stakeholder-centric goals for performance. However, the farmer, the manager of the land, is the final decision-maker in selecting the practicessuited to local site-specific soil, weather, and crop production conditions, and local regulations-that have the highest probability of meeting the goals.

Because these local conditions can influence the decision on the practice selected, right up to and including the day of implementation, local decision-making with the right decision support information would perform better than a centralized regulatory approach. Specific scientific principles guide the development of practices determining right source, rate, time and place. Farmers and crop advisers make sure the practices they select and apply locally are in accord with these principles.
CONCEPT

\section{THE 4R NUTRIENT STEWARDSHIP CONCEPT}

The principles are the same globally, but how they are put into practice locally varies depending on specific characteristics:

\begin{tabular}{|l|l|}
\hline Soil & Weather \\
\hline Crop & Economic \\
\hline Climate & Social Conditions \\
\hline
\end{tabular}

The four "rights" provide a simple checklist to assess whether a given crop has been fertilized properly. To help farmers and advisers identify opportunities for improvement in fertilizing each specific crop in each specific field, they can ask:

"Was the crop given the right source of nutrients at the right rate, time and place?"

The sciences of physics, chemistry and biology provide fundamental principles for the mineral nutrition of plants growing in soils. The application of these sciences to practical management of plant nutrition has led to the development of the scientific disciplines of soil fertility and plant nutrition. 


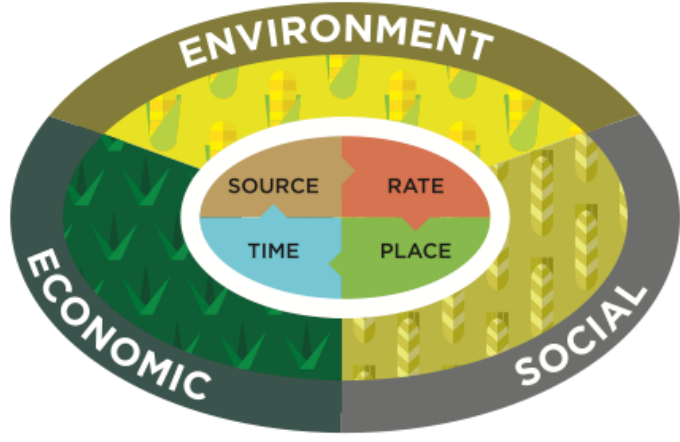

CONCEPT

\section{THE 4R NUTRIENT STEWARDSHIP CONCEPT}

Source, time and place are more frequently overlooked and may hold more opportunity for improving performance. Plant nutrition practices interact with the surrounding plant-soil-climate system (Figure 2). For fertilizer use to be sustainable, it must enhance the performance of the plant system.

The performance of the system is influenced not only by the $4 \mathrm{Rs}$, but also by how they interact with other management practices such as tillage, drainage, cultivar selection, plant protection, weed control, etc.

The plant-soil-climate system interacts with the

A balance of effort among the four "rights" is appropriate. It helps avoid too much emphasis on one at the expense of overlooking the others. Rate may sometimes be overemphasized, owing to its simplicity and direct relation to cost.

FIGURE 1 The 4R Nutrient Stewardship concept defines the right source, rate, time and place for fertilizer application as those producing the economic, social and environmental outcomes desired by all stakeholders to the plant ecosystem. management of plant nutrition and includes factors such as:

\begin{tabular}{|l|l|}
\hline Genetic yield potential & Drainage \\
\hline Weeds & Compaction \\
\hline Insects & Salinity \\
\hline Diseases & Temperature \\
\hline Mycorrhizae & Precipitation \\
\hline Soil texture and structure & Solar radiation \\
\hline
\end{tabular}




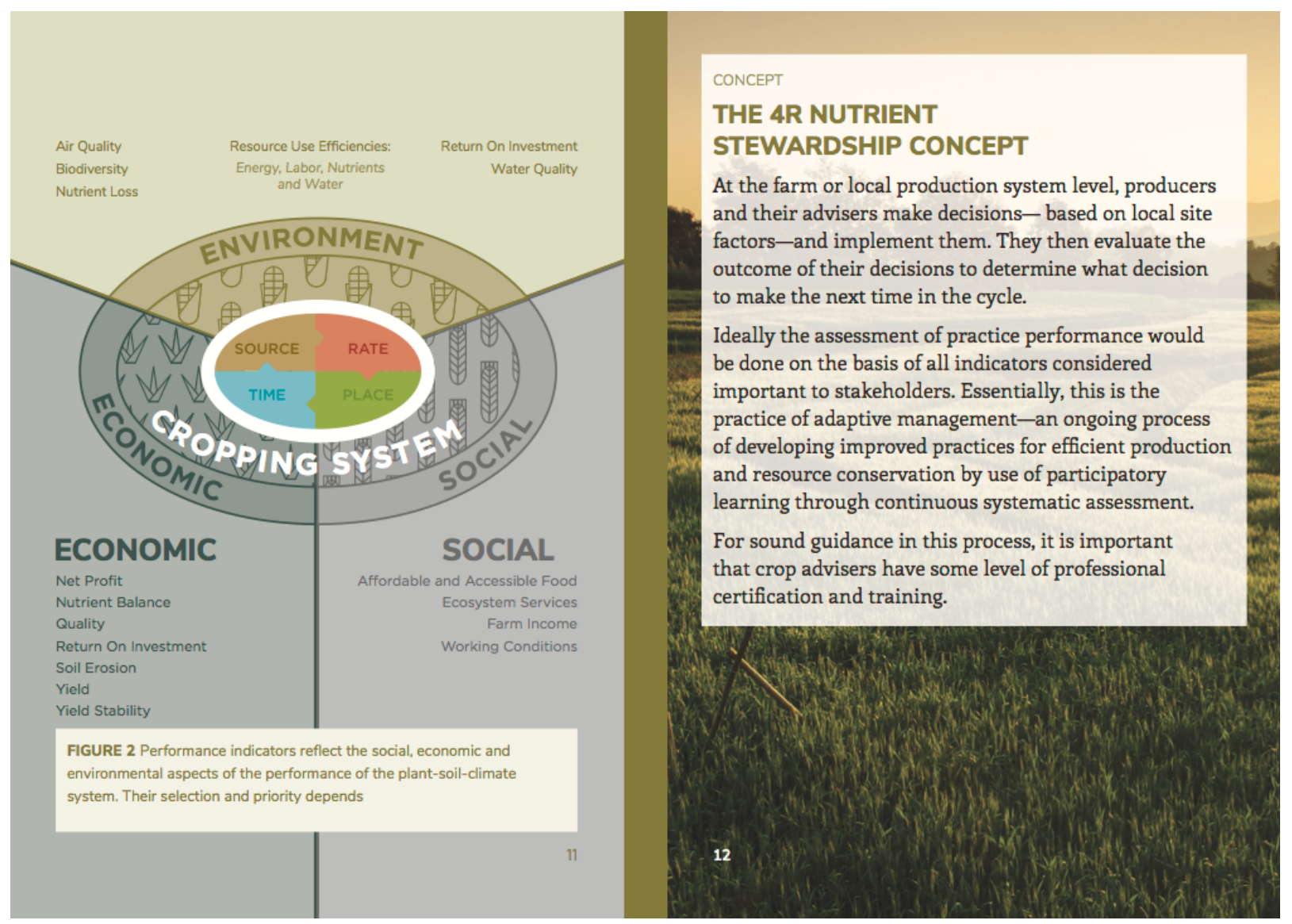




\section{APPENDIX D: OVERVIEW OF THE 4R CERTIFICATION PROGRAM}

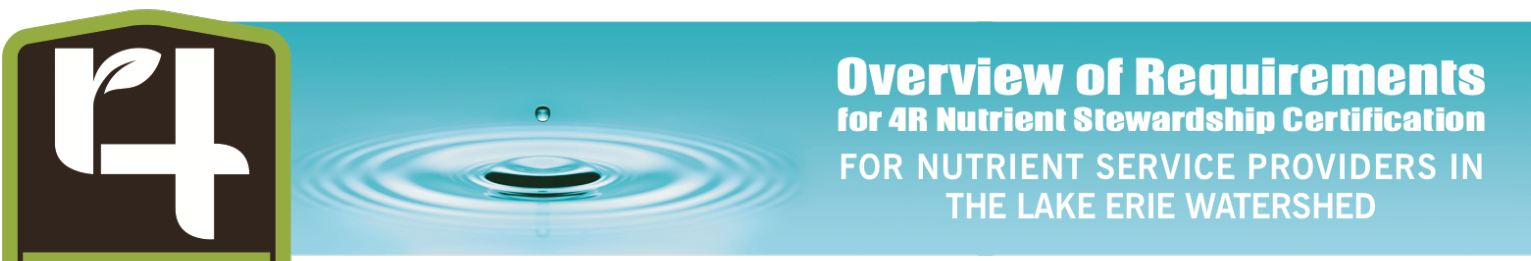

NOHHillint

SH

The 4R Nutrient Stewardship Certification Program outlines an initial three-year plan for Nutrient Service Providers. A brief summary of standard requirements during the first three years is provided below.

\section{YEAR 1}

Nutrient Service Providers and their grower customers shall be educated and trained on the principles of $4 R$ Nutrient Stewardship, and support the adoption of new research and technologies for nutrient management.

- Education of staff on 4R Nutrient Stewardship

- Maintain records with soil test at least every four years, recommendations based on university recommendations and actual applications reviewed with client

- Account for all sources of nutrient applied

- Identify sensitive areas of nutrient applied

\section{YEAR 2}

The implementation of $4 \mathrm{R}$ principles and practices are recorded and monitored. Records of implementation are checked by the Nutrient Service Provider to evaluate progress of the implementation of $4 R$ principles and practices over time.

- Continued education on 4R Nutrient Stewardship internally to staff and to growers through meetings or materials

- Maintain records of conditions at time of application and consider pre-application weather conditions

- Have digital field boundary maps and identify sensitive features with soil tests and yield maps

- Soil test no larger than 25 acres

\section{Y VEAR 3}

Nutrient recommendations and application are made with the goal of maximizing crop uptake (with goals for crop yields calculated and included) and minimizing nutrient losses to the environment. Records are maintained for customers and their nutrient recommendations. Soil testing must be based on appropriate sampling frequency and intensity. Recommendations and application must be consistent with the Tri-State Fertilizer Recommendations or other reato must be consistent with the supported by a land-grant university, allowing for adaptive management based on ed crop yield without increased risk of harm to water quality.

Nutrient recommendations and application must observe setbacks to water bodies and other features. Nitrogen and phosphorous must not be applied on frozen ground All sources of nutrients must be accounted for in the recommendation and must be reviewed by a certified professional. Variable Rate Application is used when justified. Nutrients are not applied at more than a two-year application rate.

- Field records include watershed information for fields

- Customer signature on 4R Nutrient Stewardship support

- Geo-referred soil testing

- Include weather criteria as part of application planning

- Use of variable rate planning

- Use of variable rate technology

Download complete requirements and details at 4 Rcertified.org/how.

\#Rcertified.org

@4Rcertified

s. $/ 4$ 


\section{APPENDIX E: KNOWLEDGE}

1. Below is a list of statements addressing how informed you feel you are about nutrient stewardship.

Please circle the number indicating to what extent you agree or disagree with each

statement.

\begin{tabular}{lccccc} 
& $\begin{array}{c}\text { Strongly } \\
\text { disagree }\end{array}$ & $\begin{array}{c}\text { Neither } \\
\text { agree nor } \\
\text { disagree }\end{array}$ & $\begin{array}{c}\text { Agree } \\
\text { Disagree }\end{array}$ & $\begin{array}{c}\text { Strongly } \\
\text { agree }\end{array}$ \\
\hline $\begin{array}{c}\text { a. I think I am better informed about nutrient } \\
\text { stewardship than most farmers. }\end{array}$ & -2 & -1 & 0 & 1 & 2 \\
$\begin{array}{l}\text { b. I feel that I have a pretty good understanding } \\
\text { of the four nutrient management principles. }\end{array}$ & -2 & -1 & 0 & 1 & 2 \\
\hline $\begin{array}{c}\text { c. I often think about nutrient stewardship as it } \\
\text { relates to my farm's profitability. }\end{array}$ & -2 & -1 & 0 & 1 & 2 \\
$\begin{array}{l}\text { d. I often think about nutrient stewardship as it } \\
\text { relates to water quality. }\end{array}$ & -2 & -1 & 0 & 1 & 2 \\
\hline
\end{tabular}




\section{APPENDIX F: ADOPTION}

1. For the following statements, please place a check in the box for all that apply to you.

a. I am aware of the Ohio law requiring fertilizer applicators to be certified.

ㅁ b. I have already participated in the private fertilizer applicator certification training.

$\square$ c. I am aware of the Ohio law restricting application on saturated/frozen ground, and before storms.

$\square$ d. I work with a consultant to make my nutrient management decisions.

$\square$ e. I have noticed changes in 4R related practices in the past three years among farmers in my community.

$\square$ f. I have changed $4 \mathrm{R}$ related practices on my farm in the past three years.

g. I use manure as a source of fertilizer on my farm. 


\section{APPENDIX G: SOURCES OF INFORMATION}

Farmers get information about nutrient stewardship from a variety of sources. During a typical year, how often do you receive information (e.g., via mail, email, workshops, one-onone, etc.) about nutrient stewardship from the following sources? Please circle the number indicating your answer.

\begin{tabular}{|c|c|c|c|c|c|}
\hline & Never & Rarely & Sometimes & Frequently & $\begin{array}{c}\text { Very } \\
\text { frequently }\end{array}$ \\
\hline a. Your county Extension agent & 0 & 1 & 2 & 3 & 4 \\
\hline b. University Extension generally & 0 & 1 & 2 & 3 & 4 \\
\hline c. Farm bureau & 0 & 1 & 2 & 3 & 4 \\
\hline d. Your county Soil and Water & 0 & 1 & 2 & 3 & 4 \\
\hline e. Your crop adviser/consultant & 0 & 1 & 2 & 3 & 4 \\
\hline f. Your fertilizer applicator or & 0 & 1 & 2 & 3 & 4 \\
\hline g. USDA NRCS & 0 & 1 & 2 & 3 & 4 \\
\hline h. Professional/industry & 0 & 1 & 2 & 3 & 4 \\
\hline i. Commodity groups & 0 & 1 & 2 & 3 & 4 \\
\hline j. A family member or farm & 0 & 1 & 2 & 3 & 4 \\
\hline k. Other farmers in your community & 0 & 1 & 2 & 3 & 4 \\
\hline
\end{tabular}




\section{APPENDIX H: DEMOGRAPHICS}

The Final section asks for basic demographic information. Why do we ask this? We like to understand if certain types of farms or farmers take different approaches or have different views about nutrient management. All information provided will be anonymous and never reported other than as averages across many other respondents. Thank you for your candid responses

1. Are you: Male Female

2. What is your age? years

3. How much formal education have you completed?

$\square$ Some high school

$\square$ High school degree or equivalent

$\square$ Some college, no degree

$\square$ Associate's degree

$\square$ Bachelor's degree

$\square$ Graduate or Professional degree

4. How many years have you been farming? years

5. This past year, what was your total farm operation's annual net income?

ㅁ Less than $\$ 50,000$

ㅁ $\$ 50,000-\$ 99,999$

ㅁ $\$ 100,000$ - $\$ 249,999$

ㅁ $\$ 250,000-\$ 499,999$

ㅁ $\$ 500,000$ or greater

6. Do you or your spouse receive offfarm income?
- Yes No (continue to \#8)

7. If you or your spouse receives offfarm income, what was your annual gross household income from offfarm sources this past year?

$$
\begin{aligned}
& \square \text { Less than } \$ 10,000 \\
& \square \$ 10,000-\$ 49,999 \\
& \square \$ 50,000-\$ 99,999 \\
& \square \$ 100,000 \text { or more }
\end{aligned}
$$

8. Are you retired from an occupation other than farming?

$$
\square \text { Yes No }
$$

9. Is your farm registered as a Concentrated Animal Feeding Operation (CAFO)?

$$
\square \text { Yes No }
$$

10. How large was your total farm operation this past growing season? For total acres, include cropland, woodland, pasture, wasteland, land in farmsteads, and land in government programs.
a. Owned
b. Rented 